\title{
THE IMPACT OF
}

THE MALE PRIMARY HEALTH CARE PROGRAMME ON THE HEALTH KNOWLEDGE AND PRACTICES OF THE POPULATION

8 IN AFGHAN REFUGEE VILLAGES

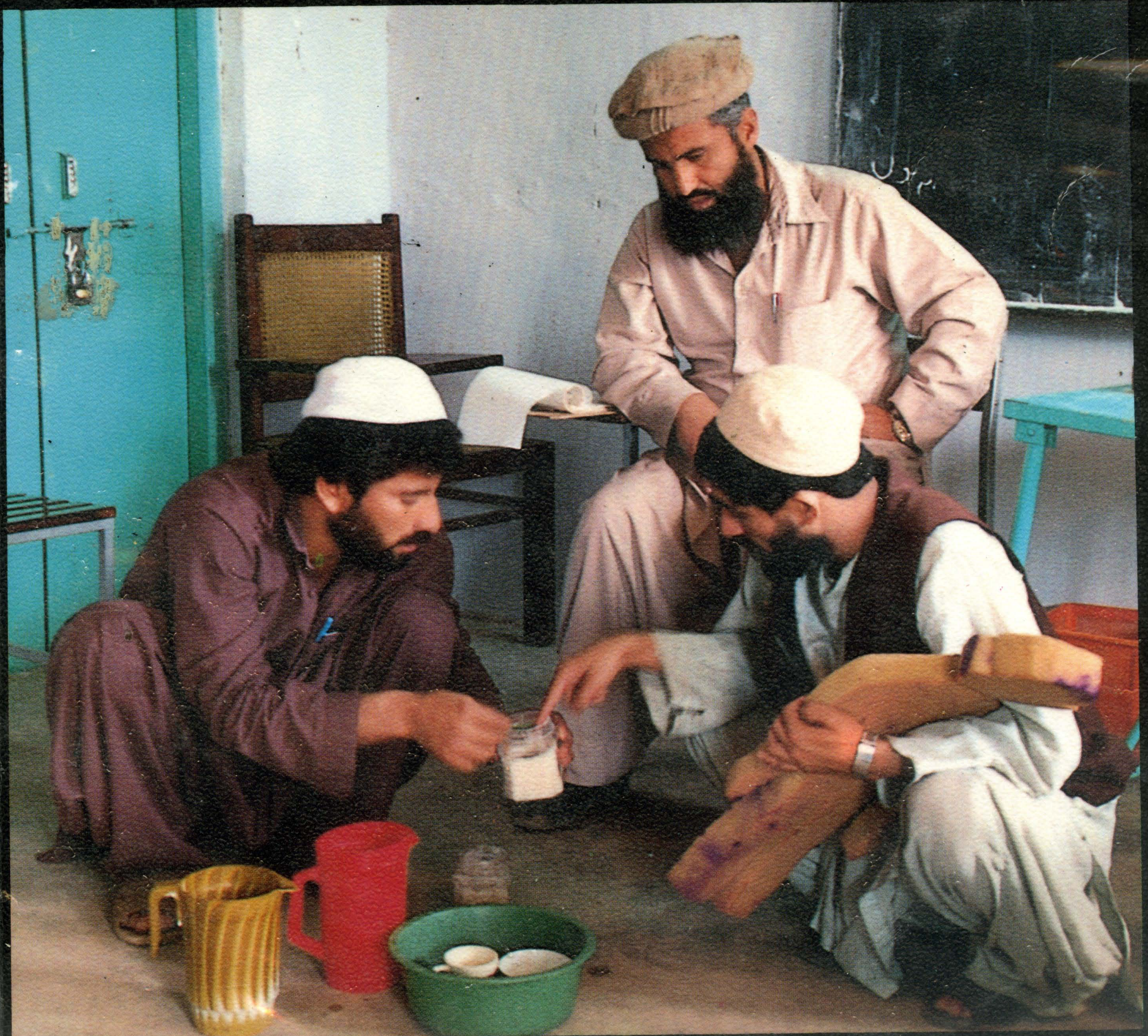




\section{Cover Photo:}

One of Save the Children Fund's Primary Health Care teachers observes Community Health Supervisors preparing oral rehydration salts in a class at Badabare Training Centre near Peshawar, Pakistan. 
SAVE THE CHILDREN FUND

\section{THE IMPACT OF THE MALE PRIMARY HEALTH CARE PROGRAMME ON THE HEALTH KNOWLEDGE AND PRACTICES OF THE POPULATION IN AFGHAN REFUGEE VILLAGES}

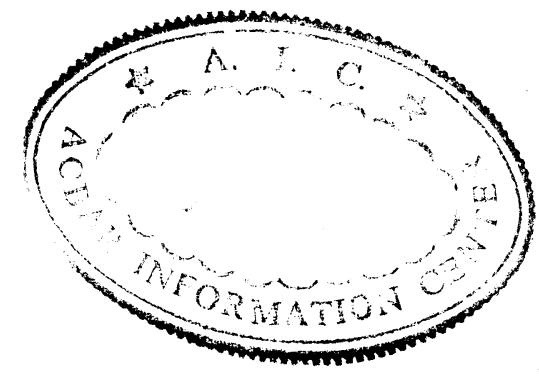


THE IMPACT OF THE MALE PRIMARY HEALTH CARE PROGRAMME ON THE HEALTH KNOWLEDGE AND PRACTICES OF THE POPULATION IN AFGHAN REFUGEE VILLAGES

Peshawar, November 1988 by: Desiree M. Jongsma 
CONTENTS

Acknowledgments

Surmary $\quad$ ii

Plan of action iv

1. Introduction 1

2. Evaluation issues 3

3. Demographic characteristics 6

4. Acquaintance with the Community Health Workers 7

4.1 Contacts with Community Health Workers 7

4.2 Utilization of health services 10

5. Knowledge of topics important to health promotion 13

5. 1 Prevention of diseases; 13

5.2 Immunization 16

5.3 Sanitation and water supply 18

5.4 Oral Rebydration Therapy 20

6. Child's health indicators - 27

6. 1 Prevalence of diarrhoea and the use of Oral
Rehydration Therapy

$\begin{array}{ll}6.2 \text { Immunization coverage } & 29\end{array}$

7. Tuberculosis defaulting rates 31

8. Recommendations : 33

Appendices

Appendix 1 Description of the sampling procedure 35

Appendix 2 Calculations 38

Appendix 3 Curriculum vitae evaluator 39

Appendix 4 Questionnaire. 41

Appendix 5 Aids to assist in determining dates of birth and death 51

Appendix 6 Statistics for 1987 based on SCF's Disease

Appendix 7 An anthology of remarks about the Cormunity. Health Worker Programe 55

Appendix 8 Judgments of Oral Rehydration Therapy descriptions

Appendix 9 An anthology of incorrect Salt--Sugar-

Solution descriptions 59

Appendix $10 \begin{aligned} & \text { Mortality rates and possible causes of } \\ & \text { death }\end{aligned}$

Glossary $\quad 64$

References 65 


\section{Acknowledgments}

The writing of these acknowledgments is a pleasure since it calls to mind many people whose advice, hard work and kindness have helped to rnake this study possible.

First, we would like to thank the survey field team, comprising four Pakistani women and four Afghan men. Of invaluable assistance during all the different translation activities were Mr. Akhtar Mohanmad, Mr. Baz Mohammad and Mr. Zalmai.

Among those who have given their advice and time, we wish to mention the entire staff of Save the Children Fund (U.K), dr. A. Forro (UNHCR), dr. M. Sertoli (ICD) and dr. H.A. Saeed (DPD-PHC).

We are grateful to the Italian Corporation for Development (ICD) for providing data on $\mathrm{TB}$-defaulting rates of the refugee villages under study.

Sincere thanks are due particularly to Mr. Asif Sarwar for his: assistance during the processing of the data.

Last, but certainly not least, warm thanks go also to the many interviewed Afghan refugees without whom this study would not have been possible. 


\section{SUMAARY}

The objective of Save the Children Fund's Male Primary Health Care Project is to establish a viable community based Primary Health Care Programme that can become an extension of, and integrated into, the existing health infrastructure in Afghan refugee villages. Community Health Workers are trained to provide health education and treatment of simple diseases to their extended family group, under supervision of Community Health Supervisors.

In order to evaluate the programme's impact on the health status of the refugee population in NWFP, a quasi-experimental research design was used. A refugee village where the programme had been running for a relatively long period was compared with a village where the programme had been running for a relatively short period and with one where the programme had not started yet.

Given the resources available for an evaluation a broad coverage of the programme was not feasible. Therefore, the assessment of the impact of the programme focused on:

- The refugees' acquaintance with the Community Health Workers;

- The knowledge about, and practices with regard to, several topics of importance to health promotion; and

- Some indicators of the health status of the population, especially of children.

It appeared that men are more acquainted with the Community Health Workers than women. Men have also more often noticed a change. in their village or family since the programme started than women. Most Community Health Workers have regular health related contacts with approximately 90 per cent of the male and 70 per cent of the female members of their extended family group, no matter whether the programme has been running for a short period or a long period. This implies that the programme has a big potential to affect the health of many Afghan refugees.

The outcomes indicate that due to the programme there may be:

- a reduction of the work load and the over-utilization of the Basic Health Units in the refugee villages

- a decline in the use of alternative services, such as traditional healers, private practioners and medical shopkeepers

- an increased awareness of the possibilities to prevent diseases and to improve health

- a rise in the number of vaccines, known by the refugees

- an increase in the number of children who get vaccinated against tuberculosis

- a decrease in the number of TB patients defaulting their treatment

- a rise in the familiarity with and the use of Oral Rehydration Therapy (ORT)

- an increase in the number of persons who know how to prepare Oral-Rehydration-Salt (ORS) and Salt-Sugar-Solution (SSS) properly. 
The programme has some shortcomings as well. Firstly, the number of women reached by the Community Health Workers is not as large as it could be. As the role of the women is crucial with regard to the treatment of children, one of our main recommendations is that more attention should be paid to measures to stimulate the access to women.

Secondly, our analysis indicates that the programme's positive impact is impaired after some years. This may be prevented by more support and follow up of the Community Health Workers and Community Health Supervisors. The information system to monitor the performances of both health workers requires strenghtening as well.

Thirdly, despite the increase of the number of people who believe that diseases can be prevented, the entrenched cultural ideas among refugees about the miracles of curative medicine remain strong. In future it may be useful to pay more attention to changing this attitude and to increasing the community's involvement and self-reliance in their own health.

Finally, the efficiency of the ORT method taught by the CHWs, for . preventing dehydration from diarrhoea, may be enhanced by the use of a simpler method. Many people have heard of ORS and SS.S, but less people know how to prepare it correctly. In view of the possible return of the refugees to Afghanistan it makes sense to promote the use of SSS, prepared e.g. with the pinch and scoop method, at the expense of the use of ORS-packages.

It can not be concluded whether the programme affects mortality rates, the prevalence of diarrhoea, and the refugees' knowledge about the importance of a safe water supply and sanitation.

It is felt that the programme would substantially benefit .. from surmounting the above mentioned shortcomings. To utilize the full potential of the programme, especially in view of the repatriation to and resettlement of the refugees in Afghanistan, it is advisable to reconsider and prioritize the most essential tasks of the Primary Health Care workers. In this respect, there appears to be a need for coordinated health guidelines and targets, agreed: upon by the Government of Pakistan, the United Nations High Commisioner of Refugees and voluntary agencies working in the same area.

Based on the recommendations of this study SCF has formulated a plan of action. 


\section{PLAN QF ACTION}

by C.M. Lidwill

Primary Health Care Adviser,

Save the Children Fund UK,

Peshawar, Pakistan.

As a result of previous experience and the recommendations made

in this report, the following Plan of Action has been formulated:

1. Jirgas (meetings with community leaders) will emphasise that male CHWs should have access to the female members of the families for which they are responsible.

2. The need for CHWs to ensure that health messages taught on home visits reach female family members, (directly or indirectly) will be stressed during training.

3. More emphasis will be given during the training of CHSs and CHWs, to how health education topics are taught on home visits.

4. The number of CHWs will be increased when agreement has been reached with the Project Directorate of Health (PDH), and funding made available from UNHCR. It would be necessary to train extra CHSs in order to provide adequate supervision for the CHWs.

5. The expansion of the Female Programme will be continued in 1989. Due to cultural constraints, this expansion has to proceed cautiously to ensure an effective programme.

6. Trainers from other Voluntary Agencies, will be trained by Save the Children Fund (UK) in 1989, to increase the coverage of both Male and Female Programmes.

7. Following the change in management structure, the Primary Health Care Adviser will be responsible for the coordination of both the Male and Female Programmes.

8. CHWs will continue to be involved in assisting the identification of women for training in their area.

9. Refresher courses "for the CHSs lasting a minimum of one week will be held every 6 months. The CHSs will subsequently hold, refresher training sessions for the CHWs. The, content of these courses will be determined by means. of a 'survey which will identify the training needs of the CHWs.

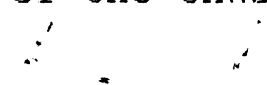


10. Prior to the handover of responsibility for the PHC Programme (excluding training) to the $\mathrm{PDH}$, the information system will be simplified. This will enable the information to be utilised at Basic Health Unit (BHU) level to provide feedback and motivation for the CHSs and CHWs.

11. Increased emphasis will be placed on sensitising the BHU staff to the role of the CHSs and CHWs in the health services, through workshops and meetings. The follow up of defaulters of Tuberculosis and Immunisation will be stressed in these.

12. Discussions will be held between SCF, PDH and UNHCR in order to facilitate the handover of responsibility for the PHC Programme (excluding training) to the PDH.

13. Curricula will be reviewed and revised as necessary to meet the needs of the Afghan community. These curricula will be standardised for use in Pakistan for the Afghan refugees, and hopefully in a future Afghanistan.

14. The importance of extra fluid of any sort, at the onset of diarrhoea will continue to be emphasised strongly. Discussions will be held with the CHSs regarding the simplest method of preparing salt sugar solution, within their cultural context. Discussions will also be held with other agencies to ensure standardisation. Following the result of these discussions, and other considerations, a decision will be made as to which method will be taught in future. 
Save the Children Fund (SCF) runs a Primary Health Care Project for Afghan refugees in the North West Frontier Province (NWFP) of Pakistan. The project is funded by UNHCR and, UNICEF, and it operates in close cooperation with the Government of Pakistan's (GOP's) health services for Afghan refugees. The objective of the project is to establish a viable community based Primary Health Care programme that can become an extension of, and integrated into, the existing health infrastructure in Afghan refugee villages. Primary Health Care (PHC) constitutes an approach to medical care which encourages communities to become involved in the prevention and treatment of simple diseases. The Afghan Refugee Health Programme (ARHP) has emphasized this approach since 1983. It is expected to lead toward greater self-reliance of the refugees. Active health education. may" help to avoid overcrowding and over-utilizing of the Basic Health Units (BHUs), which are established in the refugee villages, mostly by GOP/UNHCR. In. this context, SCF started a Male PHC programe in 1984.. A Female PHC programe, operating on a much smaller scale, followed in 1985.

The Male PHC programme consists of two tiers, namely Community Health Supervisors (CHSs) and Community Health Workers (CHWs). These persons are supposed to be acting as a kind of intermediary between the refugee population and the BHUs. The CHS's are selected from amongst, and in consultation with, the refugee community and are trained as teachers of Primary Health Care at a training centre near Feshawar. When the CHSs have returned to their villages, the communities select about 30 men to be trained by each CHS as CHWs. The CHSs work in the BHUs of the refugee villages under supervision of a medical officer. The activities of the CHWs are co-ordinated by the CHSs. These CHWs provide health education and treatment of simple diseases for their extended family clusters comprising up to 30 families. It is not required that the CHWs are literate, but it is a prerequisite that they must have access to the women within their family group, in order to increase the scope of the prograrme. The CHSs are employed by the GOP, while the CHWs are volunteers.

In 1988 approximately 1,000,000 Afghans living in refugee villages in Peshawar, Bajaur, Manshera, Mohmand, Dir, Haripur, Kohat and Kurram are covered by SCF's Male PHC Programme. Yet, such a quantification does not indicate who benefits, neither to which extent nor when they benefit from the programme. The outcomes of the disease report forms, which are regularly filled in by all the CHWs do not lend themselves to a deeper understanding of the programme, although they give an indication of the type of disease problems the CHW are faced with. Therefore, in 1988 the present study started in order to assess the impact of SCF's Male PHC programme on the health status of the population in Afghan Refugee Villages. However, within the limits of the resources available for an evaluation, a broad coverage of the programme was not feasible. Hence, it was decided that the assessment of the impact of the programme would 
focus on:

- The refugee's acquaintance with SCF's Male PHC programme;

- The knowledge about, and practices with regard to, several topics of importance to health promotion; and

- Some indicators of the health status of the population, especially of children.

Since a baseline survey has never been conducted, a before-after comparison of the situation was not possible. Therefore a quasi-experimental research design was considered most appropriate. An Afghan Refugee Village where SCF's Male PHC Programme had been running for a relatively long period (three years) was compared with a village where the programme had been running for a relatively short period ( 1.5 year) and with one where the programme had not yet started. In the latter village SCF intended to start her programme in mid 1988. Since SCF works district-wise, this approach implied a choice for certain regions (namely: Dir District, Bajaur Agency and Kurram Agency). The location of the selected refugee villages is depicted in the map on this: page.

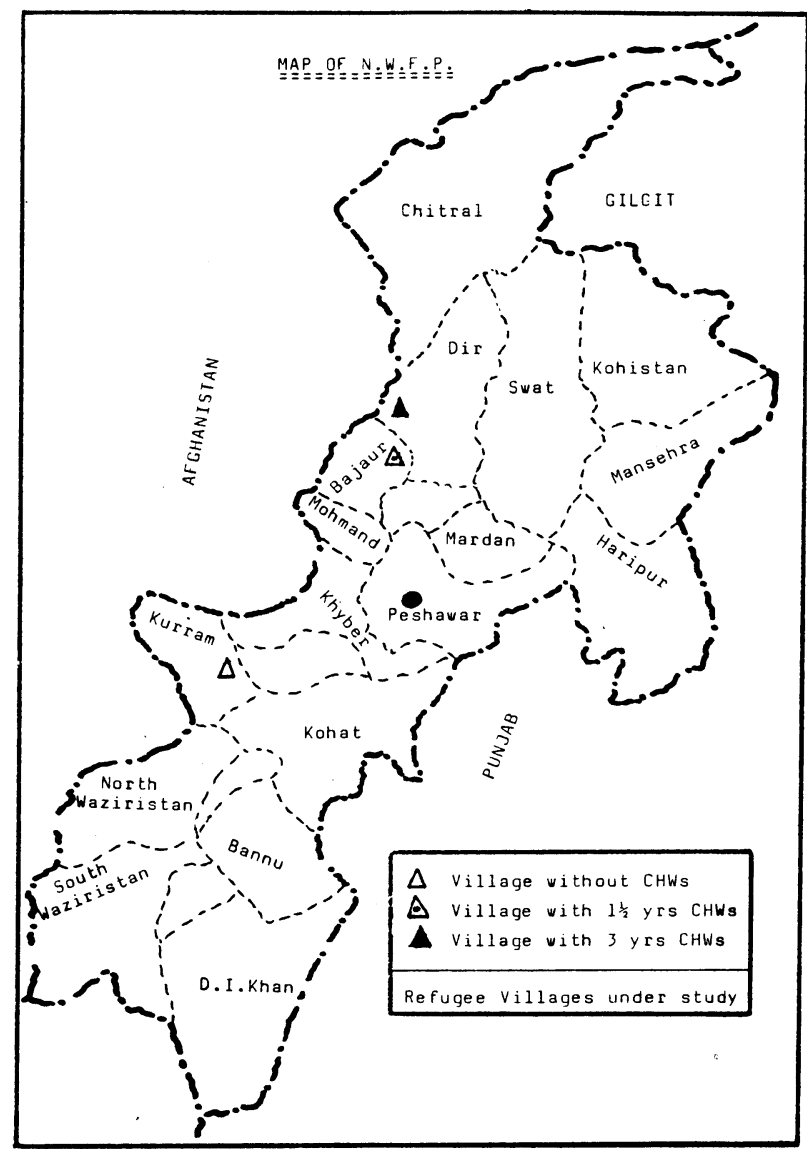

Assessing the impact of a programme by and large boils down to determining to what extent differences between variables with and withiout the programme can be attributed to that programme. This comprises two steps.

Firstly, one has to determine whether or not the differences found are statistically significant. For this purpose a number of procedures exist for different kind of data. We intend not to bother the reader too much with detailed statistical analysis. Yet no remarks at all about the procedures used makes a report almost inscrutable for readers with a statistical background and interest. Therefore, some remarks about our computations of confidence limits have to be made. In most cases the data in this report may be regarded as "proportions of successes". For instan$c e$, if a respondent is familiar with the Community Health Worker, this is , called in statistical terms a "success" as long as we distinguish only two possibilities (familiar and not-familiar). The 'formula used for determining the 95 per cent confidence 
limits for proportions of successes is included in Appendix 2. Sometimes the data required other computations and in these cases the procedure used will be mentioned in the text. In order to increase the readability of this report we will discuss only those differences which are statistically significant, without emphasizing each time that they are. Consequently non-significant differences will either be neglected in the text or we will say that the values concerned do not differ.

Secondly, one has to examine to what extent differences can be explained by the programme to be evaluated. A quasi-experimental design, as used in this study, involves more problems than a before-after comparison. With the latter method the same population is compared at different points of time, whereas the former compares different populations at different places, but at the same point of time. Of course these populations do not necessarily have to be fully comparable.

In order to enhance the comparability of the villages, the villages in the sample frame were beforehand ratched on a number of essential variables. Yet this procedure does not imply that an inference of the resultis is allowed to villages with other characteristics than the ones included in the sampling frame. So it is still not possible to generalize the results of this study to refugee villages in the neighbourhood of urban centres, as these villages were excluded from the sample frame. The exact methodology used is discussed in Appendix 1 to this report.

The data collection in the villages took place in the period from February to April 1988. All the fieldwork was completed before the month of Ramazan. The survey field team was supervised by a Dutch evaluator, whose biodata are included in Appendix 3. The team comprised four male Afghan and four female Pakistani interviewers. All eight had experience in conducting interviews in the Afghar refugee villages in NWFP. Before the pilot test of the questionnaires as well as before the fieldwork started they received additional training in interview-techniques. Most interviews took place in Pashtu.

2.

EVALUATION ISSUES

In each village one man and woman per sampled compound, were interviewed about their health knowledge and practices and their familiarity with SCF's Male PHC programme (from now on briefly called the CHW Programme). To assess mortality- and morbidity rates and immunization coverage among children less than 5 years old, all the women living in the selected compounds were questioned about their children. The various issues covered by the evaluation and the procedures used for the collection of these data are presented in table 2.1 . 
Table 2.1. Procedures used for the collection of data on the evaluation issues

$\begin{array}{cll}\text { interviews check } & \text { SCF } \\ \text { with } & \text { scar/ Disease } \\ \text { men women } & \text { card } & \text { Reports }\end{array}$

Aoquaintanoe with CHW programme

* Utilization health services

* Contacts with CHW

$x \quad x$

Knowledge about health topics

* Prevention of diseases

* Irmunization

* Sanitation and water supply

* Oral Rehydration Therapy(ORT)

Child's health indicators

* Prevalence of diarrhoea and the use of ORT

* Immunization coverage

* Infant mortality rate

* Under 5 mortality rate

$\mathbf{x} \quad \mathbf{x}$

TB defaulting rates

$\mathbf{x}$

The questionnaires used for the interviews with men and women overlapped to a large extent. The main difference between the two consisted of, questions related to children, which were posed only to women. Because of the similarities of the two types of questionnaires only the female questionnaire is attached to this report (see Appendix 4).

Men and women were only interviewed if they had at least one child younger than 5 years old, who lived the whole or part of the year preceding the interview. Succeeding the collection of some background-information of the respondents, data were gathered on the availability and the perceived advantage of having improved water sources and latrines. To determine respondents' opinions about the possibilities of disease prevention, they were asked whether people themselves can do something to take care that they do not fall ill, and if so what. All respondents were also invited to mention which way they believed was the best to improve the health situation in their village. In order to examine the knowledge about vaccines they were asked to name all the immunizations they could recall Responses related to the six immunizations included by the Afghan Refugees Expanded Programme on Immunizations (EPI) were especially taken into consideration.

With regard to Oral Rehydration Therapy (ORT) for the treatment of dehydration from diarrhoeda, CHWs are taught to promote the use of oral rehydration salts (ORS), or of home made salt-sugarsolution. (SSS) among their families. Therefore, all respondents were asked:

1) which action was firstly undertaken at their home in case one of their children was suffering from diarrhoea; 
2) whether the existence of ORS and SSS was known to them;

3 ) to describe how to prepare these solutions; and

4 ) by whom they were taught in these solutions.

The female respondents were also asked who in their household normally prepared these solutions.

Following these questions about topics of importance to health promotion, questions were asked about the acquaintance with the CHW programme. To investigate the utilization of health facilities a distinction was made between "minor illnesses" (e.g. a bad throat), "major illnesses" (e.g. high fever) and cases of sudden distress (e.g. a burn). In the villages where the CHW programme is operating, respondents were also asked if they knew the name of their CHW, whether they had ever asked the CHW for advice and when was the last time they were visited by the CHW. Furthermore these respondents were asked whether they had noticed any change in their family and in their village since the CHW programme had started.

To determine some indicators of the health status of children in the villages, this study followed to a large extent the design of a survey carried out by the Centers for Disease Control (CDC) and UNHCR, which focused on the entire Afghan refugee population in Pakistar. In each household visited all women available were interrogated about their children less than 5 years of age, who lived the whole or part of the year preceding the interview. The forms used for the collection of information dealing with children who died in the last year and with children alive at the time of the interview were included in the female questionnaire (see Appendix 4). An updated form of the Western and Islamic calendar was used to obtain accurate information on the children's dates of birth (see Appendix 5). Another aid to determine the date of birth is also included in Appendix 5. For children less than 5 years old who had died during the 12 months preceding the interview, the collected data included the date of the child's death and the possible cause of death.

In each household, the mothers present were also asked about the occurrence of diarrhoea among children alive during the week prior to the interview and the treatment given. To ascertain whether children were participating in any immunization activities both arms of each child were examined for a scar of a BCG (Tuberculosis) vaccine. The presence of a vaccination certificate handed out by a Basic Health Unit or an outreach programme was checked as well. Since the recommended date of this inoculation is at birth, all children could in principle be exposed to this examination.

The Italian Cooperation for Development (ICD), which runs a TB Control Programme among Afghan Refugees in NWFP provided data on the number of tuberculosis patients in the three villages under study who failed to collect their drugs. 
In this chapter some brief information about the background of the respondents is presented. In each village we planned to gather data on at least 400 children and to interview 175 men and 175 women, who were having one or more children below the age of 5 years. None of the approached persons refused the interview. More children were present in the compounds visited in the village without CHWs than in the two other villages. In the village with three years CHWs even a few additional compounds had to be surveyed to reach the target of at least 400 children per village. The main characteristics of the respondents and children are presented in table 3.1 .

Table 3.1 Some background information about the respondents and children, by village

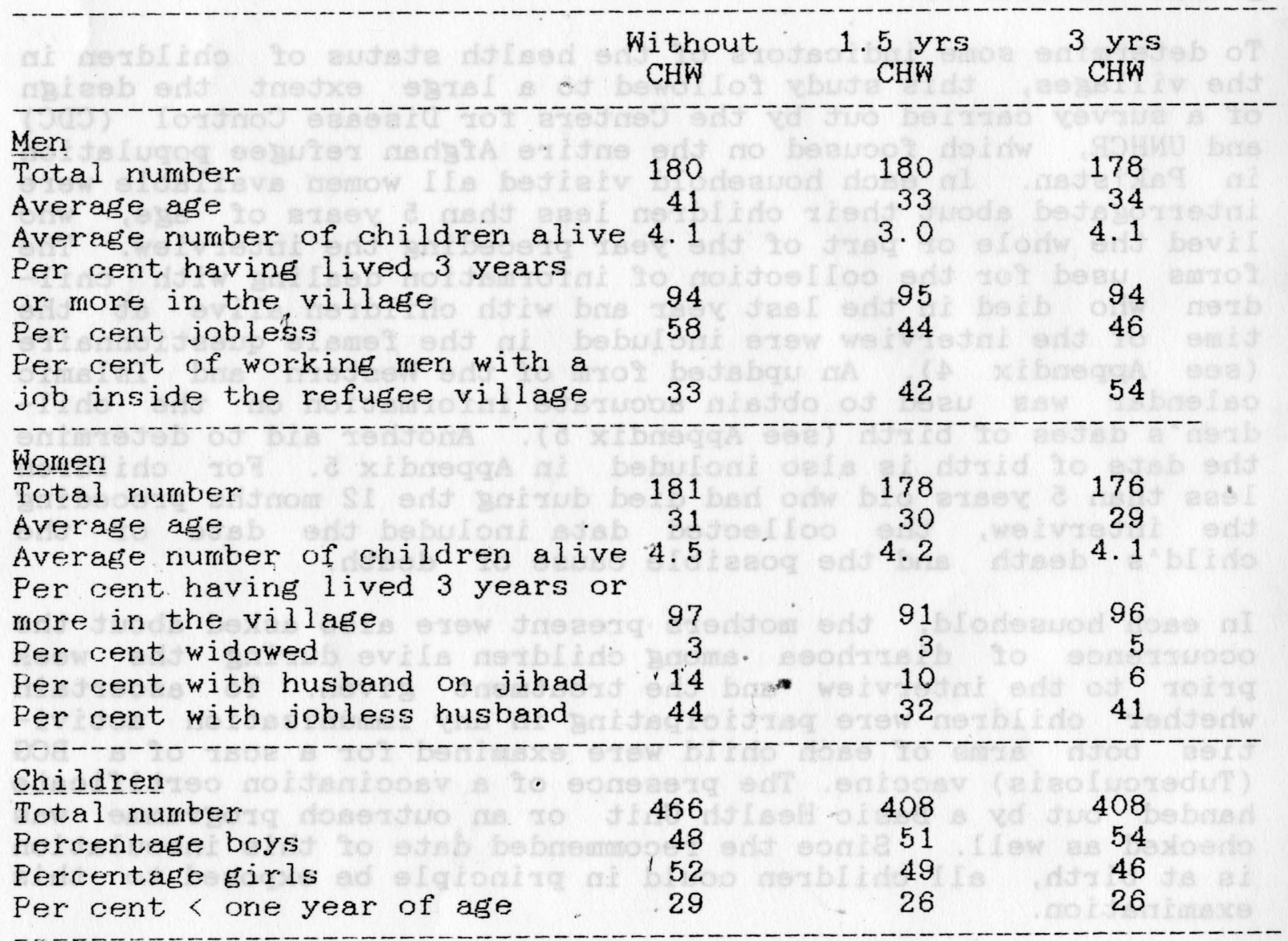

From table 3.1 it appears that a comparison of the villages is justifiable, since the villages do not differ substantially with regard to important characteristics. The number of newly arrived persons in éach village was very low. Less than 2 per cent of the respondents arrived "in the year preceding the interview. About 95 per cent of the respondents lived in, their village for a period 

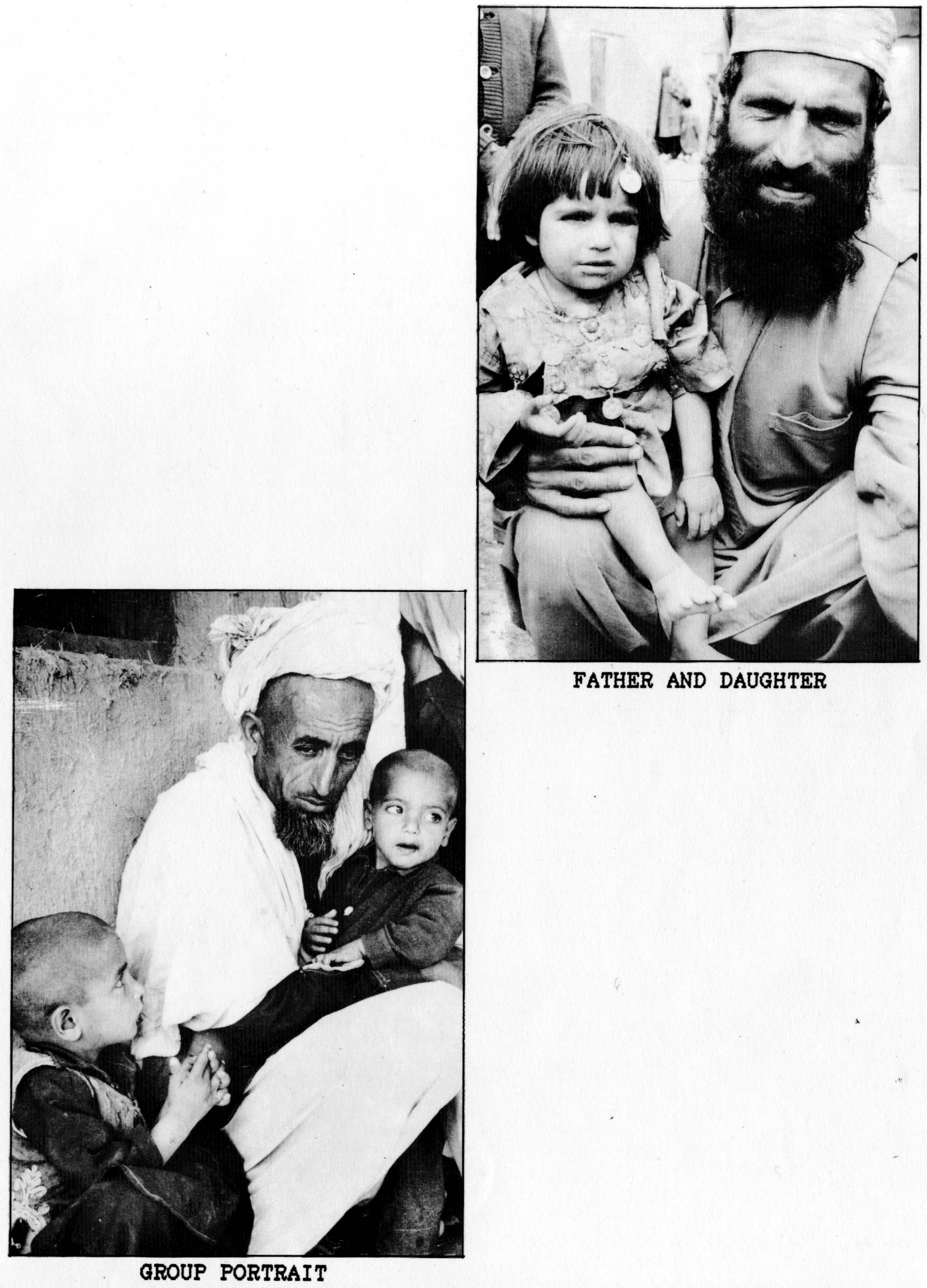

FATHER AND DAUGHTER 
longer than three years. At the time of the interview more than half of all respondents had been living in their village for more than 7 years. Initially the village without CHWs was located in the upper part of Kurram Agency. Around 1980 the entire population of this village was removed to the lower part of Kurram, because of disputes with the local population.

The number of male respondents reporting to be unemployed may be overestimated, since most of the interviews took place during office hours. This probably explains why the percentage men reporting to be jobless is bigger than the percentage women with an unemployed husband. Men were working more often on a daily wage than with a salary. In each village about ten per cent of the men having a job reported to be self-employed.

\section{ACQUAINTANCE WITH THE COMMNITY HEALTH WORKER PROGRAMME}

\subsection{Contacts with the Community Health Workers}

The PHC approach does not only require that the CHSs and CHWs have an understanding of the behavioral and cultural circumstances hampering good health practices in their village. It is important as well that they have easy access to the family groups they serve and vice versa.

In order to examine this accessibility, the respondents in the villages where the CHW programme is runing were asked if they knew the name of their CHW, whether they were visited by him in the month preceding the interview and if they had ever asked the CHW for a health advice. Furthermore they were asked whether they had noticed any change in their family and village since the CHW programme started.

Table 4.1 shows the percentage of respondents who were able to give the name of their CHW. In both villages about 5 per cent of the respondents answered that no CHW was available at the moment,

Table 4.1 Number of respondents who know the name of their CHW as a percentage of the total number of respondents, by village and sex

\begin{tabular}{|c|c|c|c|}
\hline & & ${ }_{\mathrm{CHW}}^{1.5 \text { yrs }}$ & $\begin{array}{c}3 \mathrm{yrs} \\
\mathrm{CHW}\end{array}$ \\
\hline Mer & 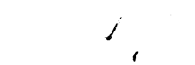 & 98 & 93 \\
\hline Wormen & . & 79 & 76 \\
\hline Total $\therefore$ & $\therefore$ & 89 & 85 \\
\hline
\end{tabular}


but that they were temporarily served by one of the CHSs. The answers of these respondents are also included in table 4.1. It appears that there is no difference between the two villages as far as their familiarity with the CHWs is concerned, i.e. there is no statistically significant difference.

In each village more men are familiar with their CHW, than women. This may either imply that a number of women do not know their CHW, although he is present, or that there is indeed no CHW. Taken into consideration the large percentage of men being acquainted with the CHW one may conclude that a certain number of women just do not know their CHW. A longer period of exposure to the CHW programme appears not to make any difference in this respect. The difficulties in reaching women may be explained by the strict rules of the social custom of purdah (seclusion of women), which is practiced by the majority of the refugees. Yet, having access to all women within the extended family group is a prerequisite, in order to get a the job as CHW. Apparently much more attention should be given to this condition during the selection of CHWs and the implementation of the programme.

About 90 per cent of both men and women who were familiar with their CHW reported that they were visited by him in the month preceding the interview. During the data collection a suspicion arose that the outcome of this topic could easily be influenced by quick visits of the CHWs to all their families. The presence of the survey field team could of course not remain unnoticed by the CHSs and, the CHWs. Therefore, in the course of the fieldwork, a question was included in the questionnaire in which it was asked whether the respondents were visited by their CHW in the month before the month preceding the interview. This provided, however, the same number of visits paid by the CHWs. Besides, more than 70 per cent of all respondents, who were familiar with their CHW, indicated that they themselves had asked their CHW for an health advice in the morith preceding the interview. One may conclude that-the majority of the CHWs, no matter whether the programme has been running for a short or a long period, have indeed regular contacts with approximately 90 per cent of the men and 70 per cent of the women of, their extended family group.

The disease report forms, which are regularly filled in by the CHWs who are usually illiterate give a rough indication of the kind of disease problems the CHWs are facing within the community. An example of these report forms and the outcomes for 1987 of the two villages under study are presented in Appendix 6. In both villages the majority of the CHW-contacts are related to cough, fever and diarrhoea. In the village, where the programme has been active for the longest period relatively more referrals from CHWs to the BHU, and vice versa took place. The medical officers of both/villages told us that they had to get used to the PHC approach, because it differs from the overall curative approach taught at the medical schools. They also pointed out the negative consequences of regular fluctuations in the BHU-staff. 
Table 4.2 Number of respondents having noticed a change in their family, as a percentage of the total number of respondents who are familiar with their CHW, by village and sex

Men
Nothing

Table 4.2 and table 4.3 present the kind of changes which were noticed by the respondents in their village and family since the CHW programme started. Some of the respondents, in particular the male ones, mentioned more than one change so that the total of each column can exceed a hundred per cent. Especially women indicated difficulties in deciding upon noticed changes in their village, because of purdah. One woman stated for instance: "I do not know about the village, because I never leave the household compound. If there is a village, then it is not my responsibility".

In both villages about 75 per cent of the female respondents and almost all male respondents who were familiar with their CHW noticed a change in their family and village. A reduced incidence of disease due to the CHW programme was most often pointed out by men in both villages. Women, and in particular the ones living in the village with 1.5 years $\mathrm{CHW}$, mentioned most often an increase

Table 4.3 Number of respondents having noticed a change in their village, as a percentage of the total number of respondents who are familiar with their CHW, by village and sex

\begin{tabular}{lrrrr} 
& \multicolumn{2}{c}{1.5 yrs } & \multicolumn{2}{c}{3 yrs } \\
& & CHW & & \multicolumn{2}{c}{ CHW } & women & men & women \\
Nothing & 1 & 26 & 2 & 25 \\
A better understanding of health & 15 & 3 & 31 & 10 \\
Irmproved hygiene & 45 & 12 & 27 & 22 \\
Immunization increased & 10 & 42 & 10 & 28 \\
Reduced incidence of diseases & 63 & 15 & 53 & 9 \\
Increased availability of medicines & 5 & 7 & 10 & 8 \\
\hline
\end{tabular}


in immunization. This latter finding might be due to the fact that CHWs are supposed to encourage notably women to visit the BHU's, in order to get their children and themselves vaccinated. For 5-10 per cent of the respondents the main change noticed is an increased availability of drugs.

At the end of the interview about 15 per cent of the respondents gave on their own, accord a remark about the CHW programme. In Appendix 7 an anthology. is given of these remarks. As these remarks are only made by a small number of the respondents, they can not be considered as representative for the opinion of all respondents about the programme. The advantage of having health personnel nearby is pointed out by both men and women, particularly in relation to purdah. Some men seem to be glad that their wifes are saved from going ( $f a r$ ) away. It seems to offer some women the opportunity to have access to at least one health service. None of the women reported that she was not allowed to visit other health services anymore, since the CHW-programme had started. It is also noteworthy that the availability of medicines, or rather the shortage of medicines, is often mentioned in both villages.

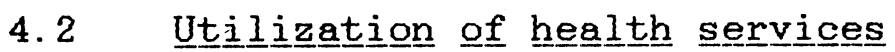

The CHW programme aims at avoiding overcrowding and overutilizing of the BHU's not only by active basic health education but also by treatment of simple diseases at home. Its purpose is not to compete with the existing health services in the refugee villages, but to extend their effectiveness. The respondents in all three villages were asked to indicate which health facility they would firstly consult in case their child was having:

- a bad throat, as an indication of a minor illness;

- a high fever, as an indication of a major iliness; and

- a burn at a time that the BHU is closed, as an indication of sudden distress.

Tables 4.4 to 4.6 present for each village the health care facility firstly chosen by the interviewees, in case of these different kind of illnesses. During the pilot-test of the questionnaires it became clear that not only the medical officers but all other BHU-staff, such as vaccinators and lady health visitors, as well were considered by the refugees as BHU-doctors. Therefore in this and in the following sections the reader has to bear in mind that a reference to BHU-doctors can in principal imply any nember of the BHU-staff.

In the villages where the programme is running, almost 90 per cent of the men and about, 60 per cent of the women intend to ask the CHWs for advice in case of a minor iliness. In the other village most men tend to consult the BHU doctor or other doctors, whereas women tend to consult nobody. In all villages men are more often inclined to ask health personnel for advice than women. 
Table 4.4 Number of respondents who choose a certain health care facility in case of a minor illness, as a percentage of all respondents by village and sex

\begin{tabular}{|c|c|c|c|c|c|c|}
\hline & \multicolumn{2}{|c|}{$\begin{array}{l}\text { without } \\
\text { CHW }\end{array}$} & \multicolumn{2}{|c|}{$\begin{array}{l}1.5 \mathrm{yr} \\
\mathrm{CHW}\end{array}$} & \multicolumn{2}{|c|}{$\begin{array}{c}3 \mathrm{yrs} \\
\mathrm{CHW}\end{array}$} \\
\hline & men & women & men & women & men & women \\
\hline None & 11 & 80 & 2 & 37 & 2 & 31 \\
\hline CHW or CHS & - & - & 94 & 58 & 86 & 62 \\
\hline Doctor of $\mathrm{BHU}$ & 44 & 14 & 3 & - & 10 & - \\
\hline Other doctor & 33 & - & 1 & - & 2 & 1 \\
\hline Medical shopkeeper & 2 & 6 & - & 5 & - & 6 \\
\hline Hakim or mullah & 10 & - & - & $-\cdots$ & - & - \\
\hline Total & 100 & 100 & 100 & 100 & 100 & 100 \\
\hline
\end{tabular}

In case of a major illness almost all respondents report to consult somebody. In both villages with CHWs men intend to consult CHWs to a much greater extent than women. More than half of the women want to ask direct advice from doctors, with a preference for the BHU-doctor. A majority of the women in the village without CHWs are also inclined to consult the nearby BHUdoctor. Men in this village intend to ask advice of the BHUdoctor almost to the same extent as they consult other doctors.

Table 4.5 Number of respondents who choose a certain health care facility in case of a major illness, as a percentage of all respondents by village and sex

\begin{tabular}{|c|c|c|c|c|c|c|}
\hline \multirow{2}{*}{ 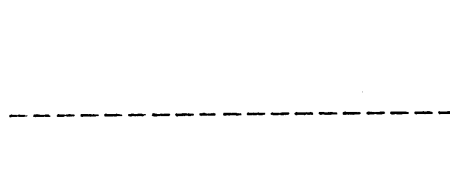 } & \multicolumn{2}{|c|}{$\begin{array}{l}\text { without } \\
\mathrm{CHW}\end{array}$} & \multicolumn{2}{|c|}{$\begin{array}{l}1.5 \mathrm{yrs} \\
\mathrm{CHW}\end{array}$} & \multicolumn{2}{|c|}{$\begin{array}{c}3 \underset{\mathrm{CHW}}{\mathrm{yrs}} \\
.\end{array}$} \\
\hline & men & women & men & women & men & women \\
\hline None & 7 & 2 & 1 & 1 & - & 4 \\
\hline CHW or CHS & - & - & 94 & 34 & 85 & 39 \\
\hline Doctor of $\mathrm{BHU}$ & 44 & 67 & 3 & 40 & 12 & 40 \\
\hline Other doctor & 43 & 16 & 1 & 18 & 3 & 13 \\
\hline Medical shopkeeper & 2 & 13 & - & 7 & - & 4 \\
\hline Hakim or mullah & 4 & 2 & 1 & - & - & - \\
\hline Total & 100 & 100 & 100 & 100 & 100 & 100 \\
\hline
\end{tabular}

Burns are very common in the refugee villages, and therefore they are used as an example of sudden distress. CHWs are taught that burns should be treated immediately. They are supposed to teach the members of their extended family groups that they should never put oil, mud or dung on burns. 
Table 4.6 Number of respondents who choose a certain health care facility in case of emergency, as a percentage of all respondents by village and sex

\begin{tabular}{|c|c|c|c|c|c|c|}
\hline & \multicolumn{2}{|c|}{$\begin{array}{l}\text { without } \\
\text { CHW }\end{array}$} & \multicolumn{2}{|c|}{$\begin{array}{l}1.5 \mathrm{yrs} \\
\text { CHW }\end{array}$} & \multicolumn{2}{|c|}{$3 \underset{\mathrm{CHW}}{\mathrm{yrs}}$} \\
\hline & $\operatorname{men} *$ & women & men & women & men & women \\
\hline None & 16 & 25 & 1 & 12 & 1 & 16 \\
\hline CHW or CHS & - & - & 96 & 45 & 88 & 38 \\
\hline Other doctor & 74 & 36 & 2 & 30 & 9 & 30 \\
\hline Medical Shopkeeper & 3 & 27 & - & 10 & 1 & 7 \\
\hline Hakim or rmullah & 6 & 12 & 1 & 3 & 1 & 9 \\
\hline Total & 100 & 100 . & 100 & 100 & 100 & 100 \\
\hline
\end{tabular}

Note: * The percentages do not sum up to a hundred per cent, due to rounding

Respondents living in the village without CHW programme more often report to consult nobody in case of an emergency, while the BHU is closed, than people in the other two villages. In these villages, especially men are inclined to consult the nearby CHWs for a child's burn. In all three villages about a third of the women are inclined to consult another doctor. Men living in the village without CHWs consult other doctors to a greater extent than men living in the two other villagess. It is remarkable that 27 per cent of the women living in the village without CHW programme want to consult a medical shopkeeper.

Many respondents in all villages reported the treatment of burns at home by putting for instance (kerosen) oil, butter, potata, bread, yolks, cold bandages, and salt/sugar solutions on it.

The analysis presented in this section indicate that the workload and over-utilization of BHU's and other doctors may be substantially eased as a result of the. CHW programe. This would particularly be the case if it were only the wen who decide upon these matters. The intention to consult persons as shopkeepers, hakims (traditional healers) and mullahs decreased as well. 


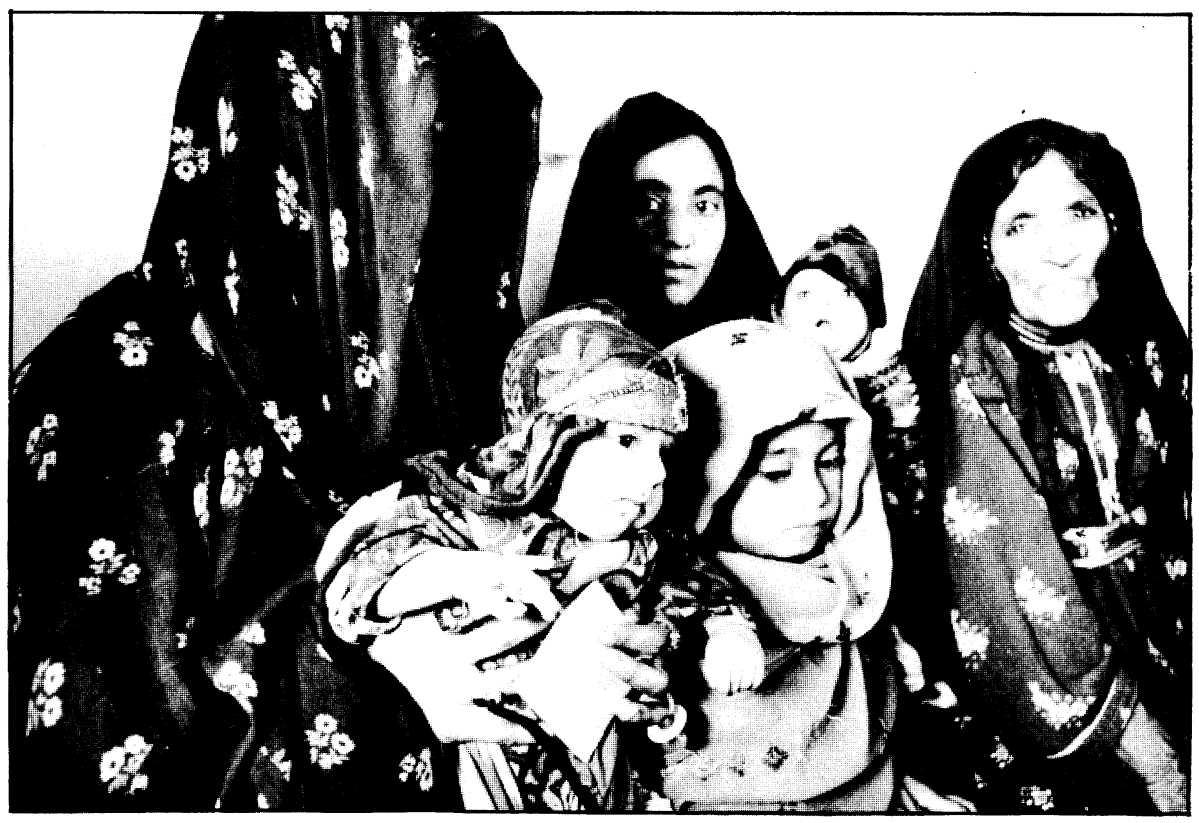

WAITING FOR VACCINATION

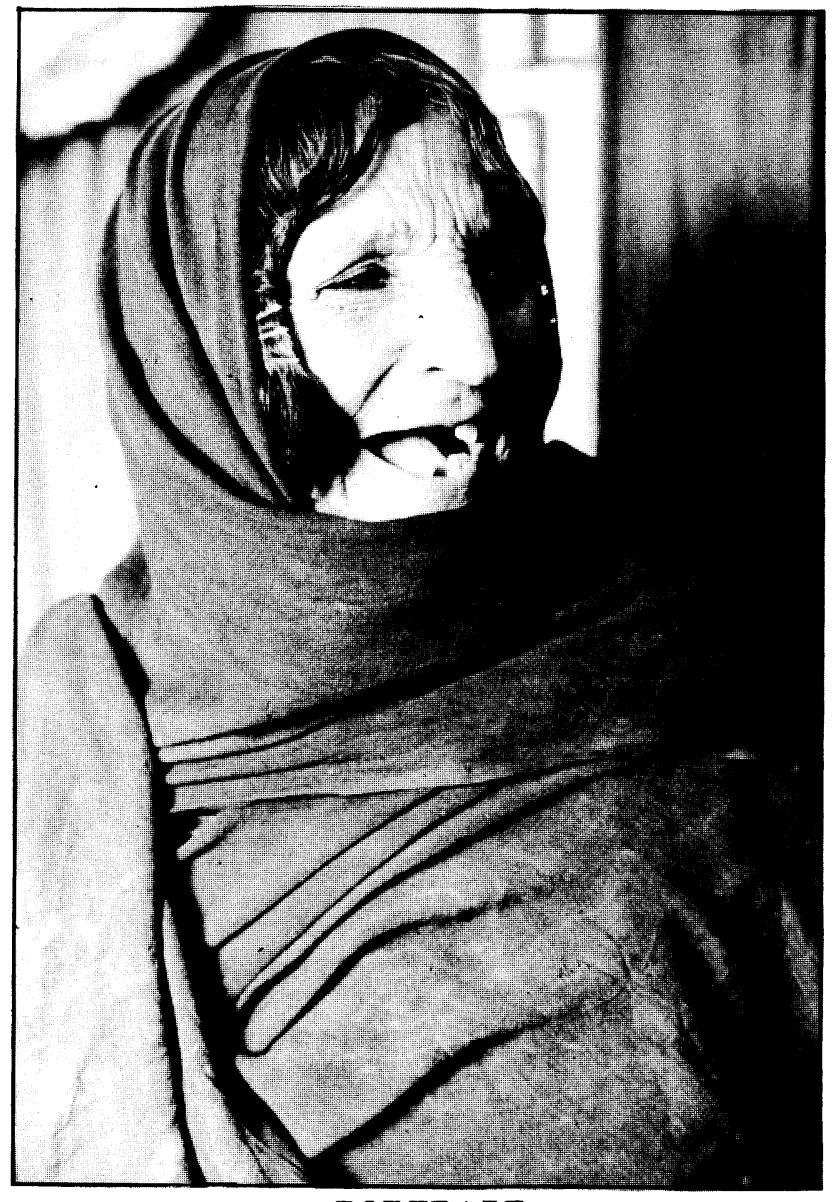




\section{KNOWLEDGE OF SOME TOPICS IMPORTANT TO HEALTH PROMOTION}

\subsection{Prevention of diseases}

Another main aim of the CHW programme is to increase the community's awareness about the possibility to prevent diseases. During the pilot test of the questionnaire the impediments of asking a plain question as "Do you think that diseases can be prevented?" already appeared. Therefore the question was reformulated in "Do you think that people themselves can do something to take care that they do not fall ill?". Nevertheless, even to this reformulated question many respondents, especially in the village without a CHW prograrme, replied in a curative minded way. They answered for example "by visiting the doctors of the BHU" and "by eating medicines". In case of such answers the interviewers were instructed to elucidate the question. Table 5.1 shows the percentage of respondents who were of the opinion that people could prevent themselves from falling ill. In this table we included only respondents, who indeed could mention at least one preventive measure.

It appears that people living in the village without CHWs less often believe that diseases can be prevented than people living in a village where the CHW programme is operating for 1.5 years. On their turn, the community living in this village is less "preventive minded" than the community of the village where the prograrme has been running for three years. There is a difference between, men and women. Men show a considerable increase in preventive directedness within a period of 1.5 year CHW programme, while it appears to take more time to accomplish such an increase for wornen.

Almost all respondents who answered with a definite No to the question about the possibility to prevent diseases gave the same commentary, irrespective of the village: "Diseases are from God. Therefore people can not save themselves from illness." A few other reactions were related to the lack of financial resources and the lack of education.

Table 5.1: Number of respondents who were of the opinion that diseases can be prevented, as a percentage of all respondents, by sex and village

\begin{tabular}{|c|c|c|c|c|}
\hline . & & $\begin{array}{c}\text { Without } \\
\text { CHW }\end{array}$ & 1. 5 CHW & $\begin{array}{c}3 \text { yrs } \\
\text { CHW }\end{array}$ \\
\hline Men & & 75 & 90 & 95 \\
\hline Women & $i$ & 57 & 63 & 82 \\
\hline Total & . & 66 & 77 & 89 \\
\hline
\end{tabular}


Table 5.2 Average number of preventive measures mentioned*

$\begin{array}{lccc} & \begin{array}{c}\text { Without } \\ \text { CHW }\end{array} & \begin{array}{c}1.5 \mathrm{yrs} \\ \text { CHW }\end{array} & \begin{array}{c}3 \text { yrs } \\ \mathrm{CHW}\end{array} \\ \text { Men } & 2.5 & 2.7 & 2.9 \\ \text { Women } & 1.6 & 1.7 & 1.9 \\ \text { Total } & 2.1 & 2.3 & 2.4\end{array}$

Note: * For the calculation of these means only those respondents were included, who could mention at least one preventive measure

The average number of the preventive measures mentioned by both male and female respondents for the villages varied between 2.1 and 2.4 (see table 5.2). To decide whether the data in table 5.2 differ significantly Student's t-tests were applied. These indicated that in all villages men knew on the average more preventive measures; than women. It also appeared that one can conclude with 95 per cent certainty that people living in the village without CHW programme know less preventive measures than people living in the village with 3 years CHW programe.

Table 5.3 givas a review of the kind of preventive ways mentioned by the respondents. In most cases the interviewers had no difficulties in assigning the respondents" answers to the distinguished categories of preventive measures, but sometimes it was

Table 5.3: Number of preventive measures mentioned, as a percentage of all the preventive measures mentioned, by sex and village

\begin{tabular}{|c|c|c|c|c|c|c|}
\hline & wi & $\begin{array}{l}\text { thout } \\
\text { CHW }\end{array}$ & & $\begin{array}{l}3 \text { yrs } \\
H W\end{array}$ & $3 \mathrm{C}$ & \\
\hline & $\operatorname{men} *$ & women & men & women* & men* & women \\
\hline immunization & 3 & 3 & 5 & 14 & 3 & 6 \\
\hline use latrines & 5 & 3 & 4 & 4 & 3 & 4 \\
\hline use safe water & 10 & - & 11 & 5 & 15 & 8 \\
\hline burning rubbish & - & - & 2 & 1 & 1 & 1 \\
\hline fly control & 2 & 4 & 3 & 3 & 6 & 7 \\
\hline domestic hygiene & 23 & 38 & 25 & 37 & 25 & 27 \\
\hline food hygiene & 25 & 6 & 21 & 6 & 22 & 11 \\
\hline personal hygiene & 30 & 46 & 29 & 30 & 26 & 36 \\
\hline Total number & 100 & 100 & 100 & 100 & 100 & 100 \\
\hline
\end{tabular}

Note: * Thie total of the percentages do not always sum up to 100 due to rounding 
difficult. An answer as for instance "By putting occasionally the sleeping quilts and mattresses in the sun, so that the microbes will die" was recorded as a domestic hygiene measure, but it could also be regarded as a fly control measure. Sporadically respondents mentioned the following as preventive measures: "to diet from oily and wrong food", "to protect ourselves from sick people", "we need more health education", "by more wealth", "by drinking ORS" and "to refrain from drinking very cold water".

It appears from table 5.3 that the various kinds of preventive measures which were considered as important did not differ in the villages. It is noteworthy that in all villages measures related to domestic and personal hygiene are mentioned most often and that food hygiene is more often emphasized by men than by women.

To supplement these outcomes all respondents were asked also which way they perceived as the best to improve the health situation in their village. In the village without CHW programme more than half of the women and 22 per cent of the men were not able to give an answer to this question. In the two other villages both men and women had less difficulties in giving an answer. Here people, and especially the men, had difficulties in choosing between two or more measures which were equally important to them. Measures related to water supply and sanitation were most often pointed out by men and measures with regard to hygiene by women. Other measures, which were also mentioned in all villages, but to a smaller extenc, dealt with immunization improvement and the necessity of health education. In a few cases, irrespective of the village, the respondents emphasized the importance of more medicines and/or medical facilities.

One man belonging to the village where the CHW programme had been running for three years reported as the best way to improve the village health situation "to avoid the wrong use of medicines". Another man, living in the village without CHW programme, stressed the importance of forming a health committee. A woman in the village with 1.5 years CHW programme answered: "to take advice from the CHW". A few other answers were: "The best way to improve our health is to behave ourselves and give presents to people, so it makes us happy and we cannot become ill", "To follow the path of Jihad", "If the weather became cold", and "If we had a fan and electricity".

From the data presented in this section it can be concluded that due to the CHW programme the community's awareness about the possibility to prevent diseases and health improvement increases. For men this effect becomes manifest already after a relatively short period, for women it takes more time apparently. The capacity to mention specific preventive measures appears to increase slightly in the long run.

In the following sections of this chapter we shall elaborate on the refugees" knowledge and practices with regard to immunization, water supply and sanitation and Oral Rehydration Therapy. 


\subsection{Irmunization}

The respondents were asked to name all immunizations they could recall. The six immunizations (tuberculosis, diphtheria, whooping cough, tetanus, polio and measles) included by the Afghan Refugees Expanded Programme on Immunizations (EPI Program) were recorded, as well as answers related to pox. During the pilot test of the questionnaires it appeared that the refugees are rather familiar with the latter inoculation, due to campaigns for pox vaccination in Afghanistan in the nineteen-seventies.

Table 5.4: Per cent of respondents who could mention at least one immunization (incl. pox), by sex and village

\begin{tabular}{lccc} 
& $\begin{array}{c}\text { without } \\
\text { CHW }\end{array}$ & $\begin{array}{c}1.5 \mathrm{yrs} \\
\mathrm{CHW}\end{array}$ & 3 yrs \\
$\mathrm{CHW}$ & 98 & 91 \\
Men & 62 & 85 & 89 \\
Total & 59 & 92 & 90 \\
\hline
\end{tabular}

Table 5.4 presents the percentage respondents who could name at least one, of these immunizations. It appears that there is a considerable difference between the village without and the villages with CHWs. There is no difference between the village with CHWs for a short and the one with CHWs for a long period.

Table 5.5 shows the average number of immunizable disepases included by the EPI Programme, which the respondents could recall. Very few people could mention all six vaccines, and of those people who could, most lived in the village with 1.5 years CHW. The results of a Student's t-test show that in the village without CHWs, on the average less vaccines are known than in the other two villages. The respondents in the village where the

Table 5.5 Average number of EPI vaccinations known by the respondents, by sex and village*

$\begin{array}{llll} & \begin{array}{c}\text { without } \\ \text { CHW }\end{array} & \begin{array}{c}1.5 \text { yrs } \\ \text { CHW }\end{array} & \begin{array}{l}3 \text { CHW } \\ \text { Men }\end{array} \\ \text { Women } & 2.0 & 3.5 & 2.9 \\ \text { Total } & 2.0 & 2.4 & 2.2 \\ & 2.0 & 3.0 & 2.5\end{array}$

Note: * While icalculating these means we included only respondents who could recall at least one vaccine 
prograrme has been operating for the shortest time know on the average more vaceines than in the village where the programme is runing for a relatively long period. There is no difference between men and women in the village without CHWs. For the other villages results of a t-test show that men can on the average mention more vaccines than women. Thus one can see a positive effect of the CHW programme on the knowledge about vaccines and notably in the knowledge of men which, however, wanes in the long run.

Table 5.6 presents for each vaccine separately the percentage of respondents which could mention its name. Vaccines against measles and whooping cough were recalled most often in all villages. This is in accordance with the results of a Health Beliefs Survey conducted by SCF in Dir District and Bajaur Agency.

Table 5.6 Number of respondents who recalled vaccines as a percentage of the total number of respondents, by village and sex

\begin{tabular}{|c|c|c|c|c|c|c|}
\hline \multirow{2}{*}{\multicolumn{2}{|c|}{ men }} & \multirow{2}{*}{$\begin{array}{l}\text { without } \\
\text { CHW } \\
\text { women }\end{array}$} & \multicolumn{2}{|c|}{$\begin{array}{l}1.5 \text { yrs } \\
\text { CHW }\end{array}$} & \multicolumn{2}{|c|}{$\begin{array}{l}3 \text { yrs } \\
\text { CHW }\end{array}$} \\
\hline & & & men & women & men & women \\
\hline $\begin{array}{l}\text { Tuberculosis } \\
\text { Diphtheria } \\
\text { Whooping cough } \\
\text { Tetanus } \\
\text { Polio } \\
\text { Measles }\end{array}$ & $\begin{array}{r}43 \\
3 \\
53 \\
2 \\
16 \\
74\end{array}$ & $\begin{array}{r}14 \\
- \\
81 \\
7 \\
11 \\
77\end{array}$ & $\begin{array}{l}71 \\
35 \\
90 \\
20 \\
42 \\
97\end{array}$ & $\begin{array}{r}28 \\
7 \\
84 \\
10 \\
15 \\
91\end{array}$ & $\begin{array}{l}59 \\
14 \\
84 \\
11 \\
27 \\
91\end{array}$ & $\begin{array}{r}27 \\
6 \\
79 \\
9 \\
10 \\
83\end{array}$ \\
\hline $\begin{array}{l}\text { Sraall pox } \\
\text { Chicken pox }\end{array}$ & $\begin{array}{l}13 \\
50\end{array}$ & $\begin{array}{l}13 \\
27\end{array}$ & $\begin{array}{l}27 \\
27\end{array}$ & $\begin{array}{r}9 \\
45\end{array}$ & $\begin{array}{l}31 \\
45\end{array}$ & $\begin{array}{l}16 \\
41\end{array}$ \\
\hline
\end{tabular}

Some respondents in especially the village without CHWs believed that vaccines existed also for the following diseases: malaria, fever (wachaki), diarrhoea, vomiting, cough and cold. Sporadically the respondents mentioned too: mumps, cancer, headache, blood pressure, pneumonia, asthma, stomach pain and plague.

From the data presented in this section one can conclude that although refugees living in a village with CHWs know on the average more names of vaccines than the ones living in a village where no $\mathrm{CHW}$ programme is running, there are still many vaccines they are not acquainted with. The outcome that the extent to which people know vaccines is decreasing after being exposed to the programme for a relatively long period, indicates the importance of continuous educational efforts of CHWs. It also comes into view that these efforts have to be directed towards women in particular. 


\subsection{Sanitation and water supply}

In the Afghan refugee villages several activities take place with regard to the construction and improvement of appropriate water sources and latrines. It is commonly recognized that the availability of improved sources of water supply and latrines alone are not sufficient for health improvement. The dissemination of information about the advantages and the use of these facilities is important as well.

Before focusing on a possible influence of the CHW programme on the refugees' awareness about the importance of a safe water supply and sanitation, we will briefly describe the present state of these environmental factors in the villages under study. There was a difference between the villages with regard to the activities that have taken place related to water supply and sanitation. The refugee village administrations in both villages with CHWs reported that more has been done in their village in the field of water supply than in the field of construction and improvement of latrines. The Refugee Village Administrator in the village without CHWs told us that it was the other way around in his village. After having made inquiries it was confirmed by the Danish Committee for Aid to Afghan Refugees (DACAAR) that more wells are improved in the two villages with CHWs than in the one without CHWs. It also appeared that in the village, where the CHW programme has been running for a long time, activities have taken place on piped water systems. The Pakistan Red Crescent Society (PRCS), which is running a Sanitation and Health Education programme in the Afghan refugee villages, informed us that recently they had constructed and improved many latrines in the village without CHWs.

Table 5.7 gives information about the availability of improved water sources and latrines in the three villages, as reported by the respondents. As improved water sources were recorded pakha (cemented) shallow wells, piped water supply schemes, water tankers and springs. Katcha wells, streams and rivers were recorded as unimproved water sources.

In the village where the CHW programme had been running for 3 years, more than half of the respondents mentioned that a surface tank is their main source of water supply. The fact that water was not available from time to time was mentioned as a disadvan-

Table 5.7 Number of respondents having improved water sources and latrine, as a percentage of all respondents, by village

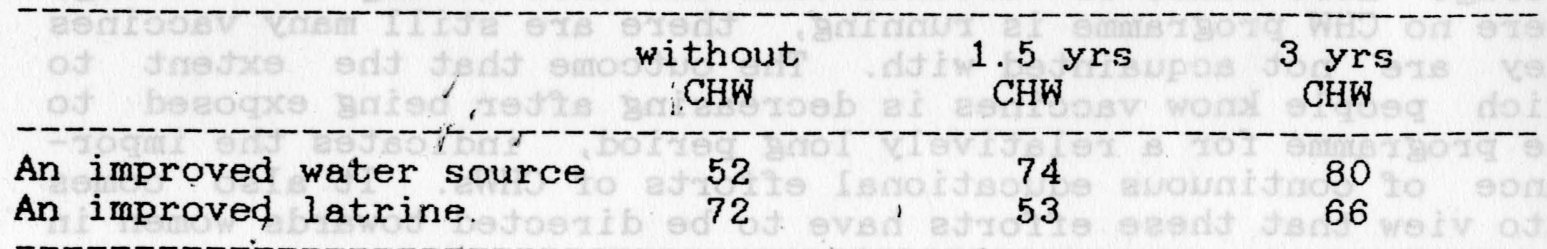




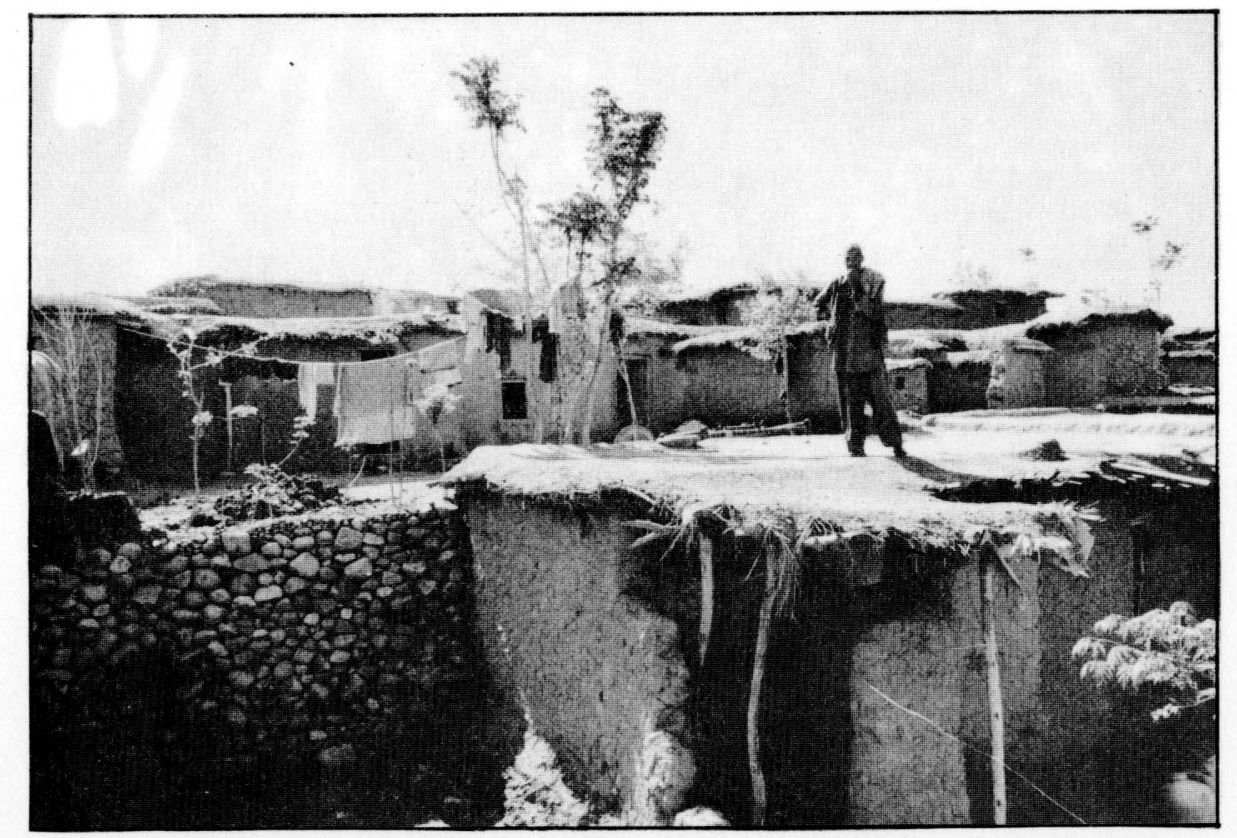

VIEW OF REFUGEE VILLAGE

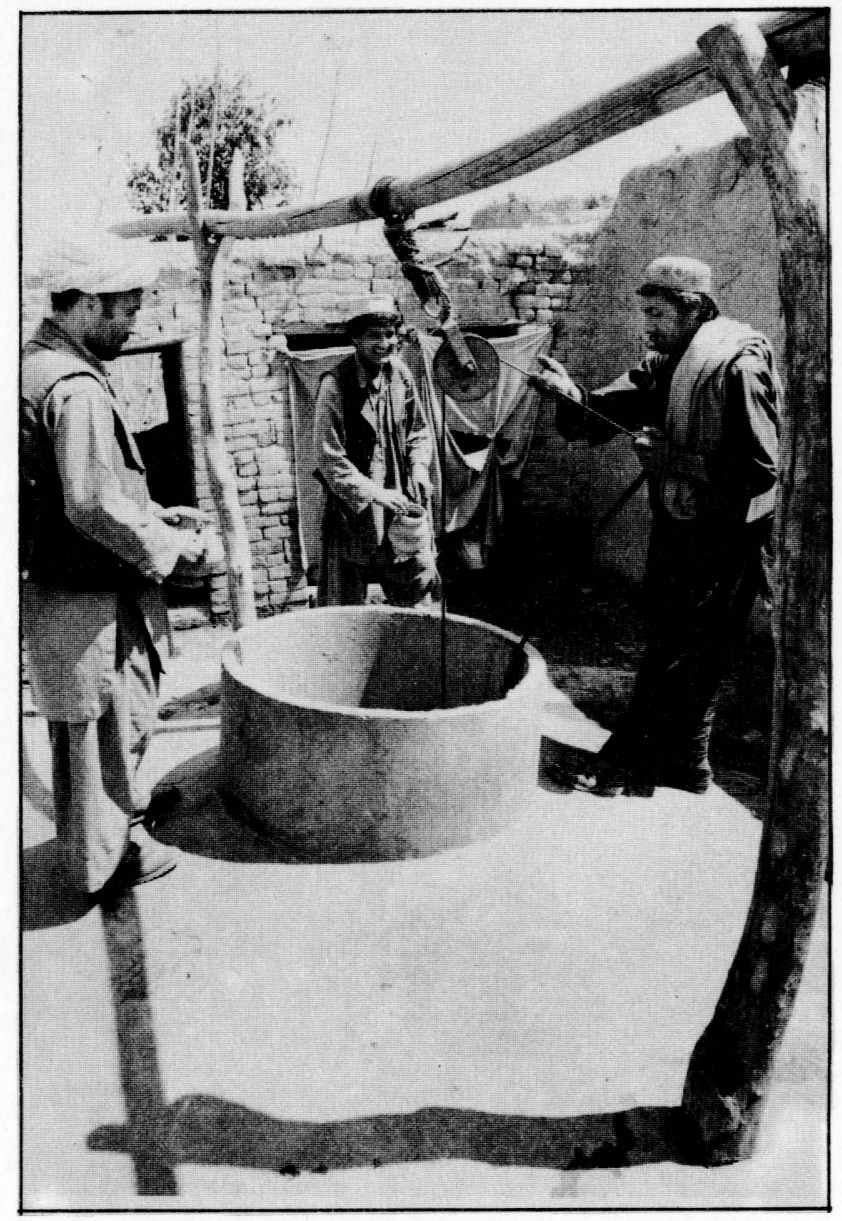

DRAWING WATER FROM A WELL

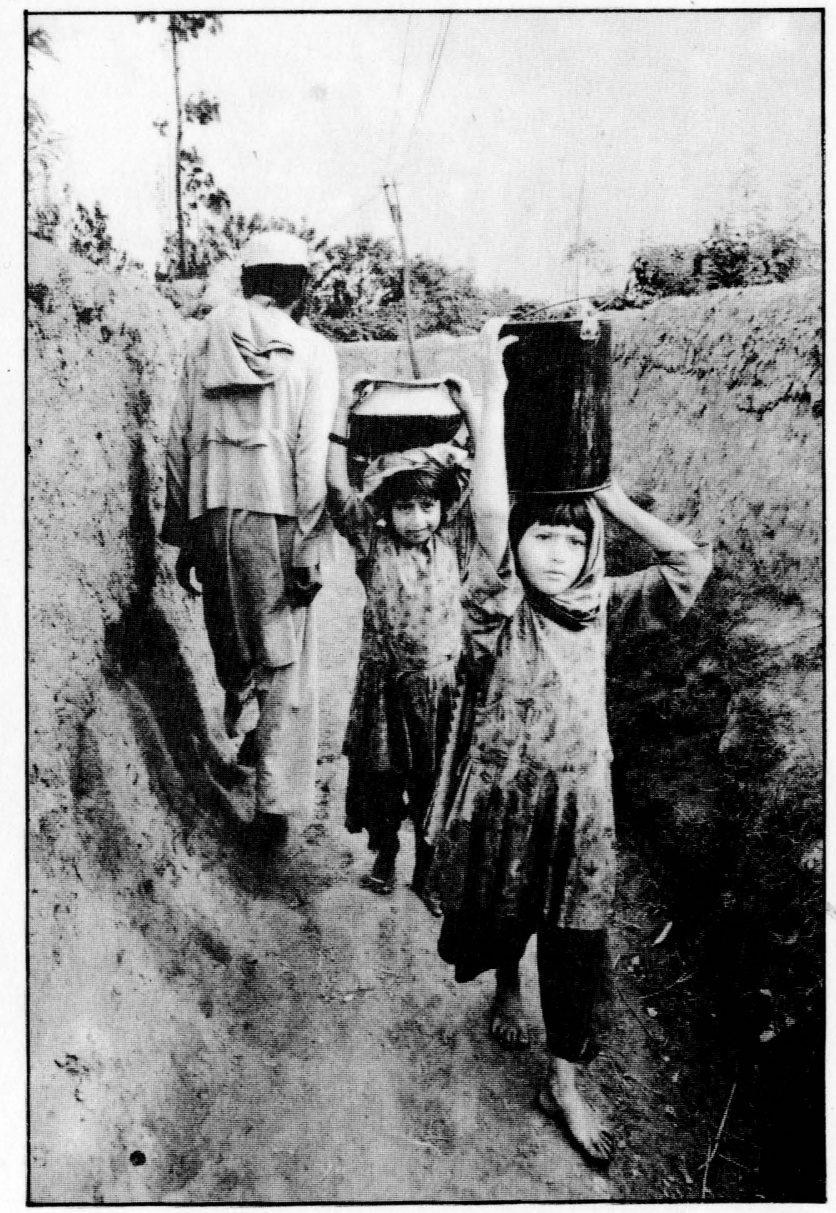

GIRLS WITH WATER POTS 
tage of this kind of water supply. In the two other villages the non-availability of water was hardly mentioned. Especially in the village without CHW programme many problems related to the dirtiness of water and the distance to the water source were reported.

In all three villages almost 100 per cent of the male respondents and about 90 per cent of the fernale respondents indicated the importance of safe water for their health. Some respondents reacted in terms as "It makes the body healthy", "The heart accepts it". In a few cases the importance of clean water for prayers and for the taste of water was emphasized as well.

About half of all respondents mentioned that they consider privacy (purdah) as the main advantage of having latrines, irrespective of their village or sex. Reasons related to the prevention of diseases, hygiene and fly control were mentioned by approx. 40 per cent of the male respondents and a quarter of the female respondents in each village. A few women mentioned protection from rain as another advantage of latrines.

In all three villages almost all respondents have a latrine, be it improved or unimproved. Most of these latrines were located inside the dwellings. In all three villages the latrines were used by 99 per cent of the women and by many children, according to both ferale and male respondents. However there is a difference between the villages with and the one without CHWs as far as the use of latrines by men is concerned. About eighty per cent of the men in the village without CHWs report to make use of a latrine, whereas only approx. 65 per cent of the men in the two other villages indicated they made use of this facility. This difference, is probably a result of the educational efforts of PRCS during the installation phase of the latrines in this village. Another explanation might be the phenomenon of different latrines for men and women, which was most often mentioned in this village, namely by one quarter of the respondents. Taking into consideration the considerable number of persons who perceive purdah as the main advantage of having latrines, one might conclude that, setting aside the financial feasibility, installing separate latrines in the same household is the solution to increase the use of latrines by al b refugees.

The interpretation of the data presented in this paragraph is rather hampered by the differences in environmental facilities in the villages. One cannot clearly ascertain whether the CHW programme is having much influence on the refugees" knowledge about the advantages of having safe water and on their sanitary practices. Refugees seem to have some basic knowledge of the importance of clean water, even without CHWs. However, it should be noted that the impact of PRCS" programme on not only the sanitation but perhaps also on the basic knowledge about a clean water source may also be substantial. In the field of basic health education we can learn from the differences between the villages with and without CHWs that the CHWs should pay more attention to the sanitary practices of men. 


\subsection{Qregl Rehydration Therapy}

Diarrhoea is an important cause of mortality among Afghan refugees. It is also a major cause of child undernutrition which makes children susceptible to other diseases. Oral Rehydration Therapy (ORT) is recommended by the World Health Organization (WHO), since it is proven to be highly effective in preventing death from dehydration caused by episodes of acute watery diarrhoea. However its role in preventing death from dysentric or chronic diarrhoea is believed to be low (Feachem, 1986).

ORT is considered as a main topic of the CHW programme. The CHWs are taught to promote the use of oral rehydration salts (ORS) and salt-sugar-solutions (SSS) among their extended family group. ORS is made from packages containing glucose and salts which must be mixed in clean water. Tkese packages are easily available at pharmacies and are also given out by the BHUs. Packages for preparing one litre of ORS known under the name NIMKOL are commonly used in the refugee villages. There are various recipes for preparing SSS proposing different ways of measuring the ingredients salt, sugar and water. The ORS and SSS recipes taught by the CHWs are briefly described in Appendix 8.

SSS is believed to be promoted in particular by the CHWs. In the villages under study no other organization than SCF is operating in the field of CHWs. The BHUs are generally believed to promote the use of ORS rather than the use of SSS. Therefore the use of SSS may be considered as an important indicator of the extent to which CHWs reach the cormunity.

To compare the knowledge about ORT, the respondents were asked:

1) which action was firstly undertaken at home in the imaginary case that one of their children was suffering from diarrhoea;

2) whether the existence of ORS and SSS was known to them;

3 ) to describe how to prepare these solutions; and

4) by whom they were taught in these solutions.

The female respondents were also asked who in their household normally prepared these solutions.

The criteria used in this study to decide whether descriptions were correct are also included in Appendix 8. Of course it was taken into account that when a recipe is followed by different individuals, the composition of the resulting mixtures will vary to some extent, but on the basis of the formulated criteria a distinction is made between correct, tolerable and incorrect descriptions. For SSS a category "lconfused" was distinguished as well, as this solution required a more extensive description than ORS. The descriptions were evaluated at the office by at least two persons after all the fieldwork was completed. In the few cases opinions differed a, third person was consulted.

Table 5.8 shows which dotion is firstly reported to be undertaken at home in case a child is suffering from diarrhoea. It appears that in bath villages where the CHW programme is running the refugees, and especially men, are inclined to treat their child 
with a kind of Oral Rehydration Therapy. Men appear to prefer SSS to ORS, and for women it is the other way round. There is also a reduction in the reported use of medicines in the villages with CHWs. For men it has almost vanished, whereas approx. one fifth of the women in both villagess still chose for medicines. In the village where the programme has been ruming for the longest period more women are inclined to prepare SSS than in the other village with CHWs. It seems that it takes more time to teach women in the subject of SSS and to encourage them to use it than for men.

Table 5.8 Number of respondents by their first action against diarrhoea, as a percentage of the total number of respondents, by village and sex

\begin{tabular}{|c|c|c|c|c|c|c|}
\hline & \multicolumn{2}{|c|}{$\begin{array}{c}\text { without } \\
\text { CHW }\end{array}$} & \multicolumn{2}{|c|}{$\begin{array}{c}1.5 \mathrm{yrs} \\
\mathrm{CHW}\end{array}$} & \multicolumn{2}{|c|}{$\begin{array}{c}3 \text { yrs } \\
\text { CHW }\end{array}$} \\
\hline & men & women* & men & women* & men & women* \\
\hline No action at all & 26 & 12 & - & 6 & 5 & 6 \\
\hline Household concoction & 26 & 13 & 3 & 5 & 3 & - \\
\hline Salt-Sugar-Solution & 5 & 2 & 61 & 18 & 59 & 31 \\
\hline Oral-Rehydration-Solution & 9 & 28 & 35 & 48 & 33 & 44 \\
\hline Medicines & 31 & 44 & 1 & 20 & - & 18 \\
\hline Other actions & 3 & - & - & 2 & - & - \\
\hline A11 & 100 & 100 & 100 & 100 & 100 & 100 \\
\hline
\end{tabular}

Note: * the total of the percentages do not sum up to hundred due to rounding

Refugees living in the village without CHWs report more often that they undertake no action at all against diarrhoea than those living in the two other villages. In comparison one can see a preference for medicines. The use of household concoctions is also most often reported in this village. Household concoctions which were mentioned for the treatment of diarrhoea are: green tea, pomegranate's skin, sometimes together with yoghurt and sperki (a traditional herbal medicine made of small green seeds). In a few cases other actions were described as a remedy, such as religious rituals; and the withholding of food and/or fluid. It is remarkable that in the village without CHWs twice as many women as men report that they are inclined to use oral rehydration therapy, most of them indicating ORS. The question arises whether men rely more on other remedies than ORS, or that they are just less familiar with it than women.

Figure 1 shows the percentage of all respondents who have heard of ORS. The difference in acquaintance with ORS is considerable between the village without and the two with CHWs. It also appears that men in the village without CHWs are indeed less acquainted with OKS than women. Women are familiar with ORS to a 


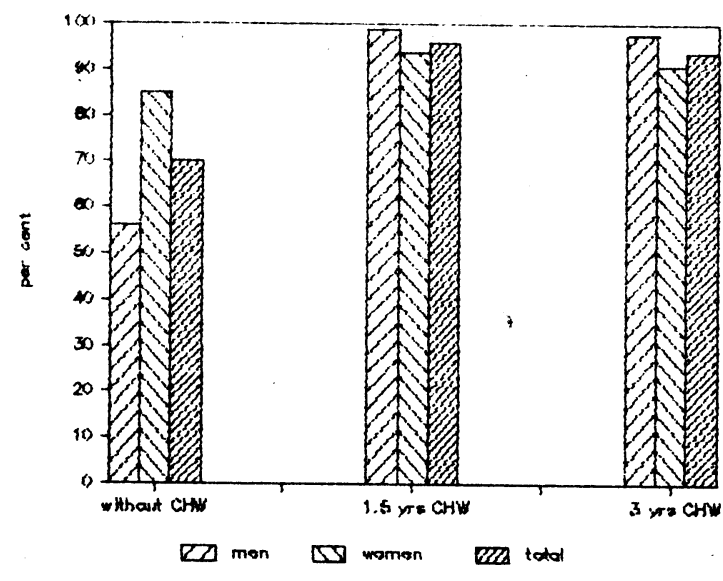

fig 1: Percentage of all respondents who wave heard of ORS

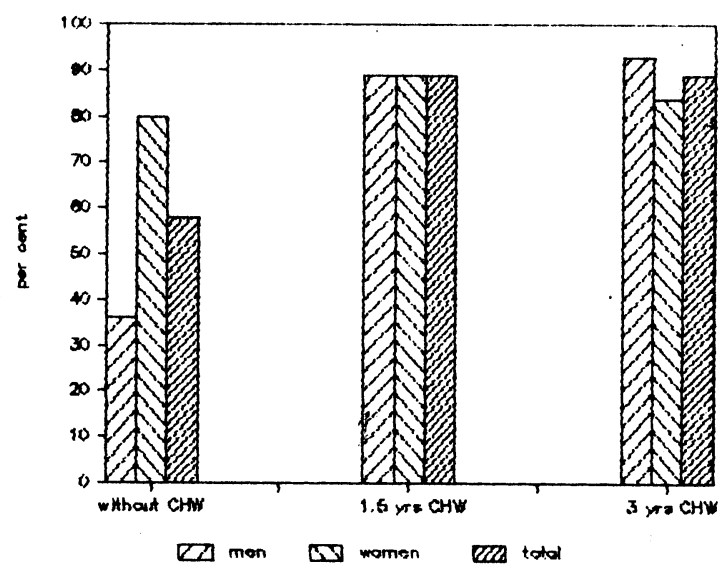

fig 2: Percentage of all respondents able to give a description of how to prepare ORS

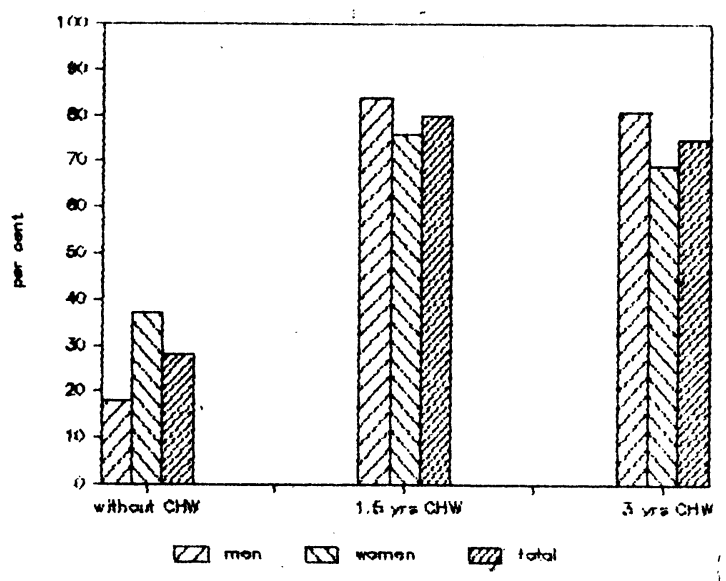

fig 3: Percentage of all respondeots who know how to prepare ons correctly high extent, even without a $\mathrm{CHW}$ programme. An explanation for this finding may be that it is usually the women who are taking their children to the BHUs, the place where these packages are given out. After 1.5 years of $\mathrm{CHW}$ programme the awareness about ORS of men appears to increase enormously. Almost all men indicate to be familiar with ORS. In view of the women's initial lead in awareness about ORS, one can observe clearly that more men than women are reached by the CHWs. A prolonged period of $\mathrm{CHW}$ programme does not result in a rise in the number of persons reached.

From figure 2 it appears that not all respondents who have heard of ORS can actually give a description of preparing ORS. This is especially the case for men living in the village without $\mathrm{CHW}$ programme. From figure 3 it appears that not all people who were able to give a description know how to prepare ORS in a correct way. This is particularly true for the village without the CHW programme.

In table 5.9 we included the number of tolerable and incorrect descriptions of ORS, in addition to the correct answers. An answer was. considered tolerable if only the use of clear pakha well water or of cooled boiled water was not mentioned, but if the rest of the description was correct. Nearly all respondents who gave an incorrect answer described that they put a whole package in just orie teacup or one glass of water. Thiss may cause a dangerously high concentration of sodium in the ORS solution, especially if a one litre package is used (Mustaque et. al, 1986). 
Table 5.9 Number of correct, tolerable and incorrect ORS descriptions, as a percentage of all descriptions given, by village

\begin{tabular}{lccc} 
& $\begin{array}{c}\text { without } \\
\text { CHW* }\end{array}$ & $\begin{array}{c}1.5 \text { yrs } \\
\text { CHW }\end{array}$ & $\begin{array}{c}\text { yrs } \\
\text { CHW }\end{array}$ \\
\hline correct & 48 & 90 & 85 \\
tolerable & 2 & 1 & 1 \\
incorrect & 51 & 9 & 14 \\
\hdashline Total & 100 & 100 & 100 \\
\hline
\end{tabular}

Note: * the total of the percentages do not sum up to 100 due to rounding

It seems that people living in the villages with the CHW programme know better how to prepare ORS than the people in the village without CHWs. To determine whether this finding is statistisignificant a Chi-square test was applied. However, this test requires a minimum of 5 cases per cell. Therefore the categories correct and tolerable were combined. The results of this test pointed out that there is indeed a significant difference between the viliages with and the one without CHW programme. This is true for both men and women.

In the village without CHWs the main sources of information about ORS are the BHU-doctors and other doctors. Eighty-four percent of the women reported to be informed by the BHU doctor; for men this percentage is about half of that. Sixteen per cent of the men in this village told that they were taught in ORS by the radio. Some of them mentioned that they had listened to the $B B C$ Pashtu programme "Good Health", others mentioned a programme of Radio Pakistan.

In the other two villages most men (resp. 93 and 87 per cent) are taught in ORS by the CHWs and CHSs. In these villages one can see an interesting trend that the longer the programme is runing the more women mention the CHW as their main teacher (resp. 46 and 62 per cent). However, the doctor of the BHU remains an important informant on ORS as well. None of the respondents in the villages with CHWs reported that a radio programme was their main source of information.

In 94 per cent of the cases in the village without CHWs the ORS is reported to be prepared by the mothers, the remaining 6 per cent by female relatives (mainly the mother in law). When the CHW programme has started we can observe, in the long run, a decrease of the women who prepare the solution, while 10 per cent of the ORS is prepared by the CHWs and 4 per cent by the fathers, who seem to replace the role of the female relatives. 


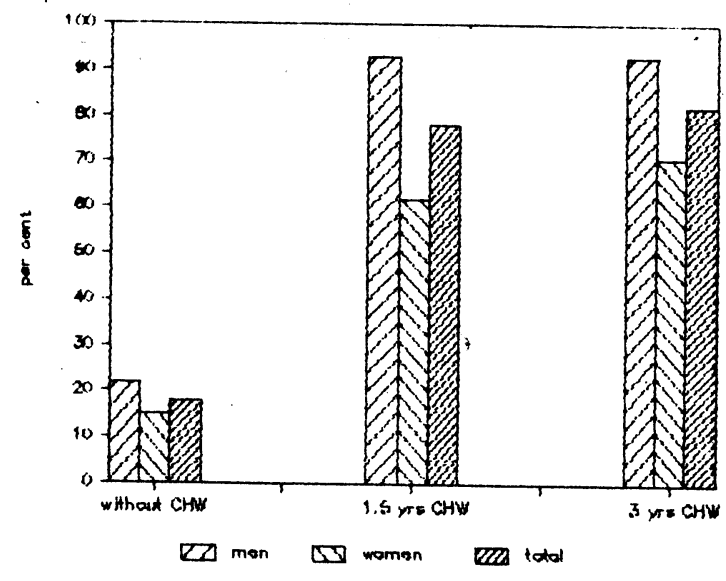

fig 4: Percentage of all respondents who have heard of SSS

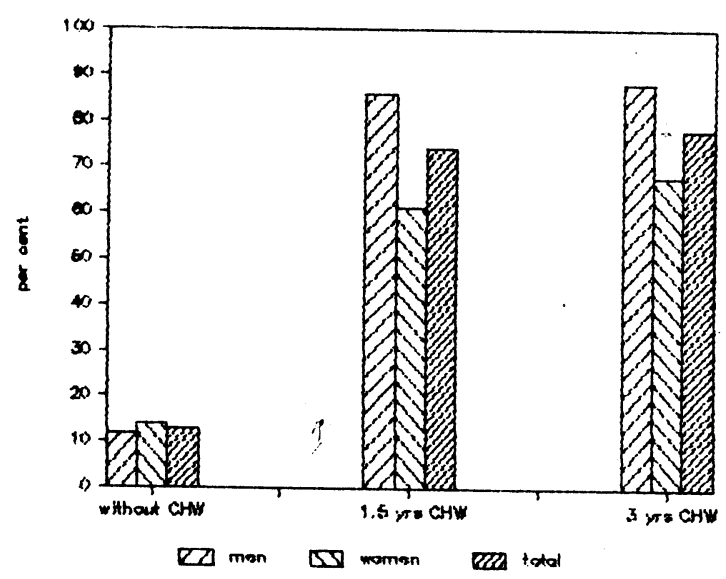

fig 5: Percentage of all respondents able to give a description of SSS

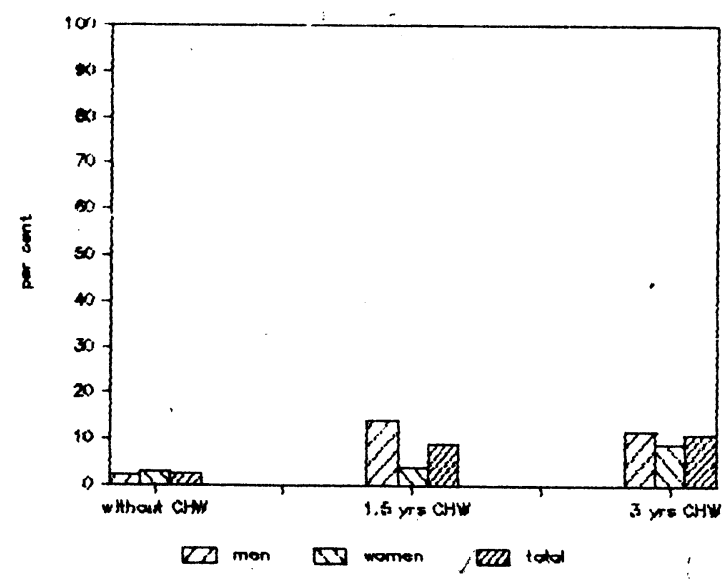

fig 6: Percentage of all respondents who know how to prepare SSS correctly
Figure 4 presents the number of respondents who have heard about SSS. The difference between the village without CHWs and the ones with CHWs is striking. It is also remarkable that in both villages, where the CHW programme is running more men than women are familiar with SSS. An exposure to the CHW programme for a period of 3 years does not result in an increase of the number of men having heard about SSS and results in an increase by about 10 per cent of women who are familiar with it. Cormpared with ORS it appears that in the village without CHW prograrme the population is hardly familiar with SSS and women do not have the edge over men any longer which may be explained by the fact that SSS is less promoted by the staff of BHUs than ORS.

Figure 5 shows once more that having heard of does not necessarily mean being able to give a description. This is again most evident for the male respondents in the village without CHWs. From figure 6 it appears that the proportion of persons knowing how to prepare SSS correctly is very low in all three villages. Many respondents did know that they had to use clean or boiled water, but very few people could mention the required procedure of leveling the teaspoon.

However, as table 5.10 shows, the percentage of respondents knowing how to prepare SSS in a tolerable way is relatively high in both villages with CHWs. The results of a Chi-square test indicate that SSS is significantly more often prepared in a correct or tolerable way in the villages with CHWs than in the village without CHW programme. 
Table 5.10 Number of correct, tolerable, confused and incorrect SSS descriptions as a percentage of all descriptions given, by village

$\begin{array}{lccc} & \begin{array}{c}\text { without } \\ \text { CHW* }\end{array} & \begin{array}{c}1.5 \text { yrs } \\ \text { CHW* }\end{array} & 3 \text { yrs } \\ \text { CHW }\end{array}$

Note: * the total of the percentages do not sim up to 100 due to rounding

Most (67\%) of the SSS descriptions given in the village without CHWs were incorrect or confused. In the villages with CHWs this percentage is much lower, but still far from negligible.

An anthology of incorrect SSS descriptions is given in Appendix 9 . If the solutions are made badly they will often taste awful and the sick child will refuse to drink it. As a consequence one might expect that solutions will be thrown away. However, the CHWs are instructed to teach parents that they should never take NO for an answer, because the child has to drink. This may imply that children are forced to drink very unsafe mixtures, for instance a solution of 4 teaspoons of salt and 5 teaspoons of sugar mixed in six teacups of cooled boiled water. It also happened that the respondents described preparing SSS with 8 leveled teaspoons of salt and one of sugar, not the other way round as they are probably instructed. The fact that CHWs have to teach the parents that the taste of the solution should not be too salty will reduce the dangerous practices of unsafe mixtures, but unfortunately not many respondents added a remark about the saltness of the solution to their description.

The women in the village without CHWs were almost all taught in SSS by a doctor of the BHU, whereas the men by other doctors, relatives and the radio. In the villages with CHWs especially the men (resp. 98 and 92 per cent) pointed out that they were mainly informed about SSS by the CHWs. In the long run, there is hardly an increase in the number of women being mainly infors med about SSS by the CHWs (resp. 69 and 72 per cent). This is the opposite of our findings for ORS. Other informants for these women were mostly the staff of the BHU and other doctors. None of the women reported that they were taught in SSS by the radio.

Our surmise that women are informed about SSS by their husband fell flat, as this occurred only sporadically. Thus, in this respect we can reject the notion of husbands acting as a kind of intermediary between their wives and the CHWs. 
The preparation of SSS, as of ORS, is mainly the responsibility of the mothers. In the villages without CHWs 90 per cent of the mixtures is made by the mother, 10 per cent by female relatives. When the CHW programme starts we can observe the same trend for SSS as we have seen for ORS in the long run: the role of the female relatives seems to be replaced by CHWs and, to a smaller extent, by the fathers as well.

The data presented in this section indicate that the CHWs have a great potential to reach the community. This holds surely for men, but the CHWs'power to reach women, who can be considered as a very important target group in the field of ORT, is also substantial. One can conclude that due to the CHW programme the acquaintance with especially SSS has increased. It is noteworthy as well that in the villages where the programme is operating a majority of the refugees is inclined to treat their child with ORT if it is suffering from diarrhoea.

If a CHW is available, ORT is more often prepared properly, but still the number of persons who prepare SSS in a wrong way is not negligible. A condition for the use of ORT is however that fluids are safe and that the ingredients are used in the right proportions. In general the less precise measurements are required, the more accurate a preparation is expected to be. ORS requires only the measurement of water. SSS as taught by the CHWs, on the other hand, requires three accurate measurements, thus increasing the risk of preparing dangerous compositions. Parents often do not remember how much salt, sugar and water to mix.

On the basis of these results, one could decide that CHWs should only promote the use of ORS. Yet, there might come a time, and perhaps in the very near future, that these packages are not as easy available as at present. Therefore, only promoting the use of ORS seems not to be a very good option. There is for instance a much more simpler method for preparing SSS than the one taught by the CHWs, namely the pinch and scoop method (see for instance WHO, 1985). Less than 5 per cent of the respondents described this method, but in almost all of these cases the descriptions were correct. Therefore, we recommend to reconsider the SSS method promoted by the CHW programme. In this context, we also would like to stress the importance of a similarity in the methods taught by both the BHU-staff and the CHWs. The community's interests are not served by any discrepancies between these important informants in ORT, as this will only increase the confusion.

In this section we discussed the knowledge of the refugees about ORT and their intention to use it. In the first paragraph of the next chapter we will compare data on the prevalence of diarrhoea among the children in the three villages and the actual treatment given. 


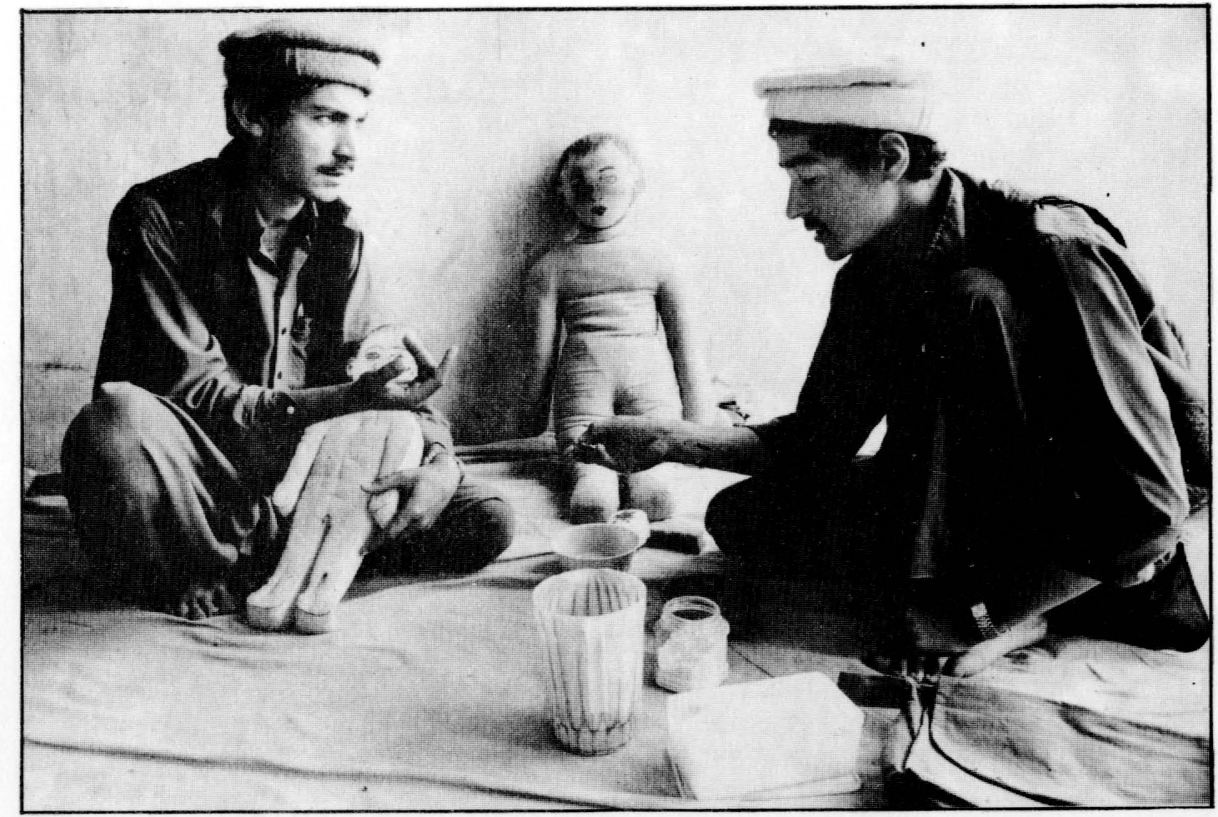

COMMUNITY HEALTH WORKER ASSESSMENT

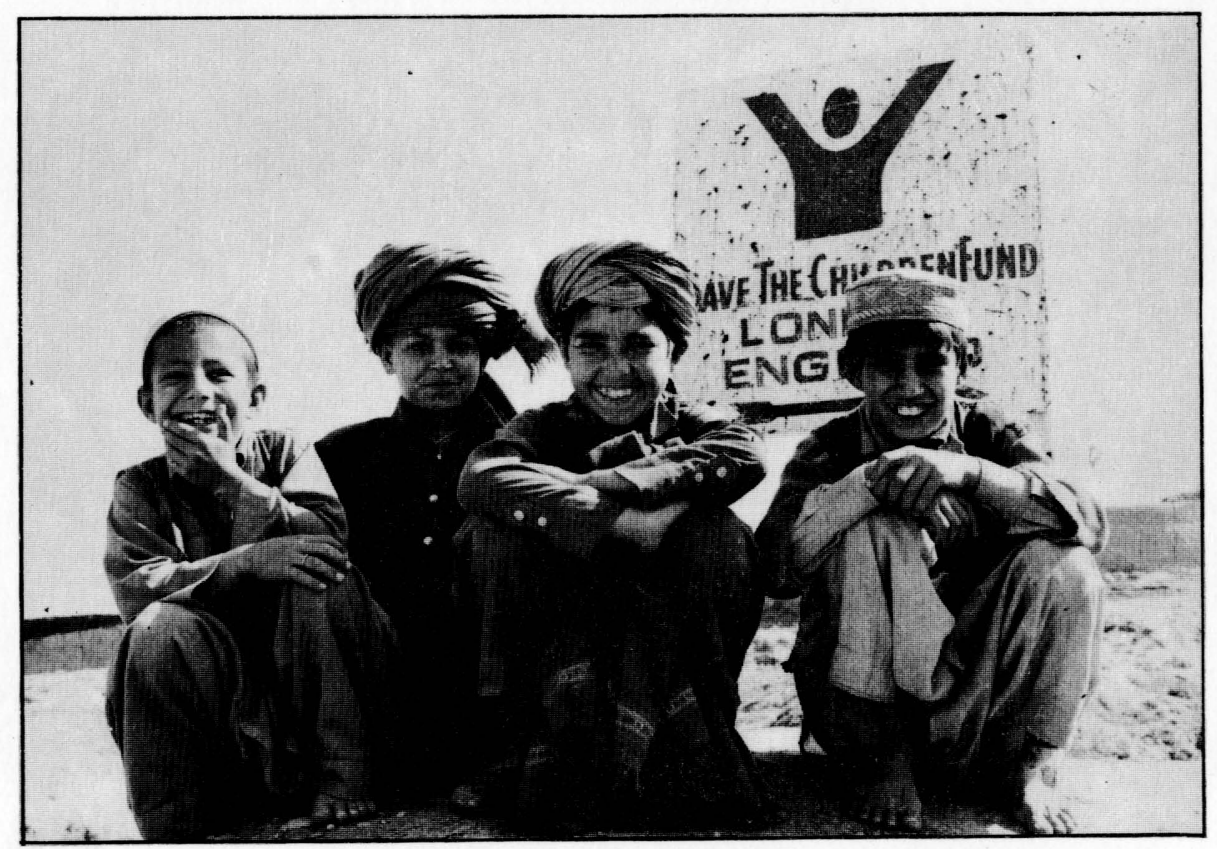

GROUP PORTRAIT 


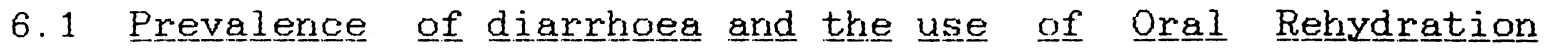 Thererapy}

If oral rehydration therapy (ORT) is properly implemented and if oral-rehydration-salts or salt-sugar-solutions are commonly used, then there may be an appreciable reduction of mortality caused by scute watery episodes of diarrhoea (Feachem, 1986). According to figures of UNICEF (1987) it could prevent approximately 20 to 25 per cent of the 14 millions deaths a year among world"s children below five years of age.

In section 5.4 of this report, it appeared that refugees living in the villages with CHWs are more familiar with ORT, do more often intend to use it and more often give a proper description for preparing it, than refugees not being exposed to the programme. Yet, an intention to use something does not necessarily have to result in a manifest behavior. And only the latter can have an impact on the health status of children. Therefore we may consider the actual use of ORT as a more important indicator of the success of the CHW programe, than the acquaintance with it.

In this study ORT-usage is defined as the proportion of diarrhoeal episodes in the week preceding the interview, which is treated with ORS or SSS. A case of diarrhoea was defined as a child who had more than three watery stools per day for two successive days of the last week preceding the interview. The ideal reference period for diarrhoeal events would be one year, but this is not used because of inaccuracies of the respondents" memories. The best reference would have been one day. However, to ask "Does your child have diarrhoea at this moment?" would result in the identification of a very small number of cases, as there were restrictions on the sample frame. Therefore a reference period of one week was chosen. In case a mother reported that a child had suffered from diarrhoea during the last 7 days, she was also asked what kind of treatment was given to the child.

It seemed that the prevalence of diarrhoea among all the children alive seemed to be lower in the village without the CHW programme (18 per cent) than in the two other villages (resp. 25 and 21 per cent). However, no significant differences can be claimed between the villages. Therefore, we can not conclude that the CHW programme is having a positivel nor a negative impact on the morbidity from diarrhoea.

Both the 1986-CDC/UNHCR survey and the 1987-IRC survey found a diarrhoea prevalence of 28 per cent among children less than five years of age. A factor contributing to the lower prevalence of diarrhoea we found is probably the cooler period of the year in which our fieldwork took place.

Table: 6.1 presents data on the actual treatment given to children who suffered from diarrhoea. In the villages where the CHW pro- 
Table 6.1: Number of first treatment given to children suffering from diarrhoea, as a percentage of all reported diarrhoeal episodes, by village

\begin{tabular}{lccc} 
& $\begin{array}{c}\text { Without } \\
\text { CHW }\end{array}$ & $\begin{array}{c}1.5 \text { yrs } \\
\text { CHW }\end{array}$ & $\begin{array}{c}3 \text { yrs } \\
\text { CHW }\end{array}$ \\
\hline No action at all & 34 & 38 & 20 \\
Religious rituals & 3 & 5 & 1 \\
Household concoctions & - & 3 & 1 \\
Salt-sugar solution & 1 & 28 & 49 \\
Oral-rehydration solution & 23 & 19 & 14 \\
Pills and tablets & 38 & 1 & - \\
Injections & 1 & 100 & 100 \\
Total & 100 & & 15 \\
\hline
\end{tabular}

gramme has been operating for the longest period more children are treated with ORT than in the other two villages. Therefore, one can conclude that the CHW progranme has in the long run a positive impact on the usage of ORT.

Even though 64 per cent of the diarrhoeal episodes in the village with 3 years CHWs were treated with ORT, there appears to be considerable scope to increase the use of ORT. In all three - villages much more refugees intend to use ORT in the imaginary case of diarrhoea, then they actually do (cf. table 6.1 and table 5.8 on p. 21). More attention should be paid to the question what has to be done to reduce the period before the lessons taught by the CHWs are put into practice.

From table 6.1 it appears also that medicines are more often used as a remedy against diarrhoea in the village without CHWs than in the two other ones. None of the respondents in the three villages mentioned that they stopped giving the child food and/or fluid. It is noteworthy that 38 per cent of the respondents in the village with 1.5 year CHWs report to give no treatment at all. In the village with 3 yrs CHWs, this percentage is considerably reduced, but it is still relativel'y high: The necessity of continuous efforts to reach, teach and motivate all women in the use of ORT is again apparent.

The 1987-IRC survey conducted in 10 refugee villages in Kohat region, also covered ORT usage. The IRC has been providing health services to the refugee population in this district in several ways, including a Traditional Birth Attendant Training Programme and a Community Health Worker Programe. SCF has trained various staff members for IRC in order to implement these programmes. The results of the IRC-rsurvey indicated that ORT was actual used by 57 per cent of the'mgthers in case children were having diarrhoea. ORS was reported to be used in 55 per cent and SSS in only 2 per cent of the diarrhoeal episodes. This is in accordance with our results: in the sense that in all three villages under study ORS is much more used than home made salt-sugar solutions. An 
explanation for this preference for ORS might be, beside the fact that people are more familiar with it, that ORS is considered more as a genuine medicine than SSS. Taken into consideration that the proportion of people preparing ORS properly is considerably greater than the one preparing SSS properly (see paragraph 5.4), one can welcome this preference for ORS. But, as already stated before, in view of the return of the Afghan refugees to their home land the question looms up what will happen when oRS packages are no longer as easy available as at present.

\subsection{Irmunization coverage}

The CHWs are supposed to pay much attention to the promotion of immunization among their extended family. "Not only many deaths among children can be prevented by immunization, but it also has a considerable impact on their nutritional status and normal growth (UNICEF, 1987)

In this study we used the presence of a scar resulting from BCG (Tuberculosis) vaccine ass an indication of a child's exposure to at least one of the immunization activities in the villages. Although we were aware of the fact that there is a chance that different outreach activities may have taken place in the villages, we assumed that their situations were comparable. It would have been very difficult to find out for a period of five years which kind of activities have exactly taken place. The female interviewers succeeded in ascertaining the presence or absence of a BCG-scar in 1,234 casses of the 1,251 children examined. In the village without CHW-programme 47 per cent of the children show the evidence of a BCG-scar; in the two other villages these percentages amount to 69 and 84 resp. The $1986-$ CDC/UNHCR survey found an average BCG-evidence of 55 per cent among all refugee children in Pakistan. Consequently one may conclude that the immunization status of children has improved as a result of the activities of the CHWs. However, it must be taken into account that, in most of the developing countries, BCG vaccination coverage is the highest of the vaccines which are included in the WHO Expanded Programme on Immunization (CCAR/ UNHCR, 1986).

To supplement the findings about the $B C G$ vaccination coverage, the presence of vaccination certificates was also checked by the interviewers. These cards are given out by the BHUs or during outreach programmes. A card was only considered present, if the mother could indeed show it and if the name of the child was written on it. This checking by the interviewers was important, as the mothers sometimes showed other cards, for instance the ones dealing with rations. A card was considered "lost" if a mother was not able to find it, but insisted that she had one.

In the village with 1.5 year CHWs a relatively large number of cards were recorded as lost (see table 6.2). During the interviews, it appeared that in this village some CHWs (in co-operation with the BHU) had taken in vaccination cards of members of 
Table 6.2: Status of the vaccinations cards, as a percentage of the total number of children checked

\begin{tabular}{|c|c|c|c|c|}
\hline & & $\begin{array}{l}\text { No } \\
\text { CHW }\end{array}$ & $\begin{array}{l}1.5 \text { yrs } \\
\text { CHW }\end{array}$ & $\begin{array}{c}3 \text { yrs } \\
\text { CHW }\end{array}$ \\
\hline \multirow[t]{2}{*}{ Card } & $\begin{array}{l}\text { - present } \\
\text { - absent } \\
\text { - lost } \\
\text { - taken in by CHW/BHU }\end{array}$ & $\begin{array}{r}33 \\
58 \\
9 \\
-\end{array}$ & $\begin{array}{r}33 \\
43 \\
20 \\
4\end{array}$ & $\begin{array}{r}68 \\
21 \\
11 \\
-\end{array}$ \\
\hline & all & 100 & 100 & 100 \\
\hline
\end{tabular}

their family groups in order to check them. It might be possible that a number of the cards reported last in this village are actually included in this checking campaign. The father may have given them to the CHWs, without the mother knowing it. Therefore, it seems justifiable to conclude that for the presence of vaccination certificates one car probably discern the same trend as noticed for the presence of the BCG scar, but not as evidently. From these results it can also be concluded, that there is still an important task for CHWs to teach people in the importance of keeping these cards. In this respect there seems to be a need for better integration with BHU-based activities.

Table 6.3 giyes an overview of all children's health indicators included by this study. The mortality rates are dealt with in Appendix 10 to this report.

Table 6.3: Indicators of children's health, by village

\begin{tabular}{|c|c|c|c|}
\hline 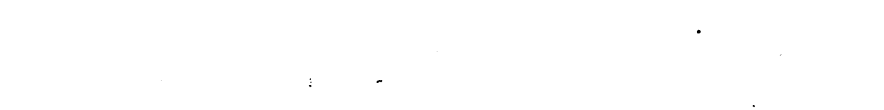 & $\begin{array}{l}\text { without } \\
\text { CHW }\end{array}$ & 1. $\underset{\mathrm{CHW}}{5 \mathrm{yrs}}$ & $\begin{array}{l}3 \text { yrs } \\
\text { CHW }\end{array}$ \\
\hline $\begin{array}{l}\text { No. of children < } 5 \text { yrs old } \\
\text { Alive at the time of interview } \\
\text { Died last year } \\
\text { No. of live birth in last year } \\
\text { Children < } 1 \text { yrs., died last year }\end{array}$ & $\begin{array}{r}466 \\
448 \\
18 \\
130 \\
15\end{array}$ & $\begin{array}{r}408 \\
403 \\
5 \\
104 \\
5\end{array}$ & $\begin{array}{r}408 \\
400 \\
8 \\
102 \\
7\end{array}$ \\
\hline $\begin{array}{l}\text { Infant mortality rate (per } 1000 \text { ) } \\
\text { confidence limits } 95 \%\end{array}$ & $\begin{array}{c}115 \\
60-170\end{array}$ & $\begin{array}{c}48 \\
7-89\end{array}$ & $\begin{array}{c}69 \\
20-118\end{array}$ \\
\hline $\begin{array}{l}\text { Under-5 mortality rate (per } 1000 \text { ) } \\
\text { confidence limits } 95 \%\end{array}$ & $\begin{array}{c}138 \\
75-201\end{array}$ & $\begin{array}{c}48 \\
7-89\end{array}$ & $\begin{array}{c}78 \\
26-130\end{array}$ \\
\hline Percentage with $B C G$ scar & 47 & 69 & 84 \\
\hline Per cent with diarrhoea in last week & 18 & 25 & 21 \\
\hline Per cent using ORT in case diarrhoea & 24 & 33 & 64 \\
\hline
\end{tabular}


Tuberculosis (TB) is a very contagious disease if it is not treated. Only complete and daily use of prescribed TB drugs cures the patient and stops the infection from spreading. Therefore education and motivation of the patients is very important. The objectives of the TB Control Programme, which is operating in the Afghan refugee villages, are (UNHCR-CCAR, 1986):

- to identify, treat and follow people with pulmonary or extrapulmonary cases of TB;

- to protect family members of the TB patients against infection;

- to educate the community about the way TB is transmitted and the ways to prevent TB.

CHWs are assigned to the duty of having regular contact with the TB patient and her or his family and of direct supervision of the treatment. Patients are supposed to be encouraged by the CHWs to continue treatment even though they start feeling better after a few months of treatment.

Figure 7 presents the TB defaulting rates for the villages under study. These data are provided by the Italian Cooperation for Development (ICD), which funds the TB Control Programme among the
Afghan refugees under an agreement of technical cooperation between the Pakistan and Italian governments. A standardized methodology in TB recording and reporting has been applied in NWFP since June 1985. Patients are defined as "defaulters" if they fail to collect their drugs in two weeks after due date. Patients defaulting for six or more consecutive months are defined as "lost" The data for the village without CHW programme are reported to be affected by some unstable social situa-tions in Kurram Agency.

Fig 7 TB Defaulting Rates, by village (July 1985-December 1987)

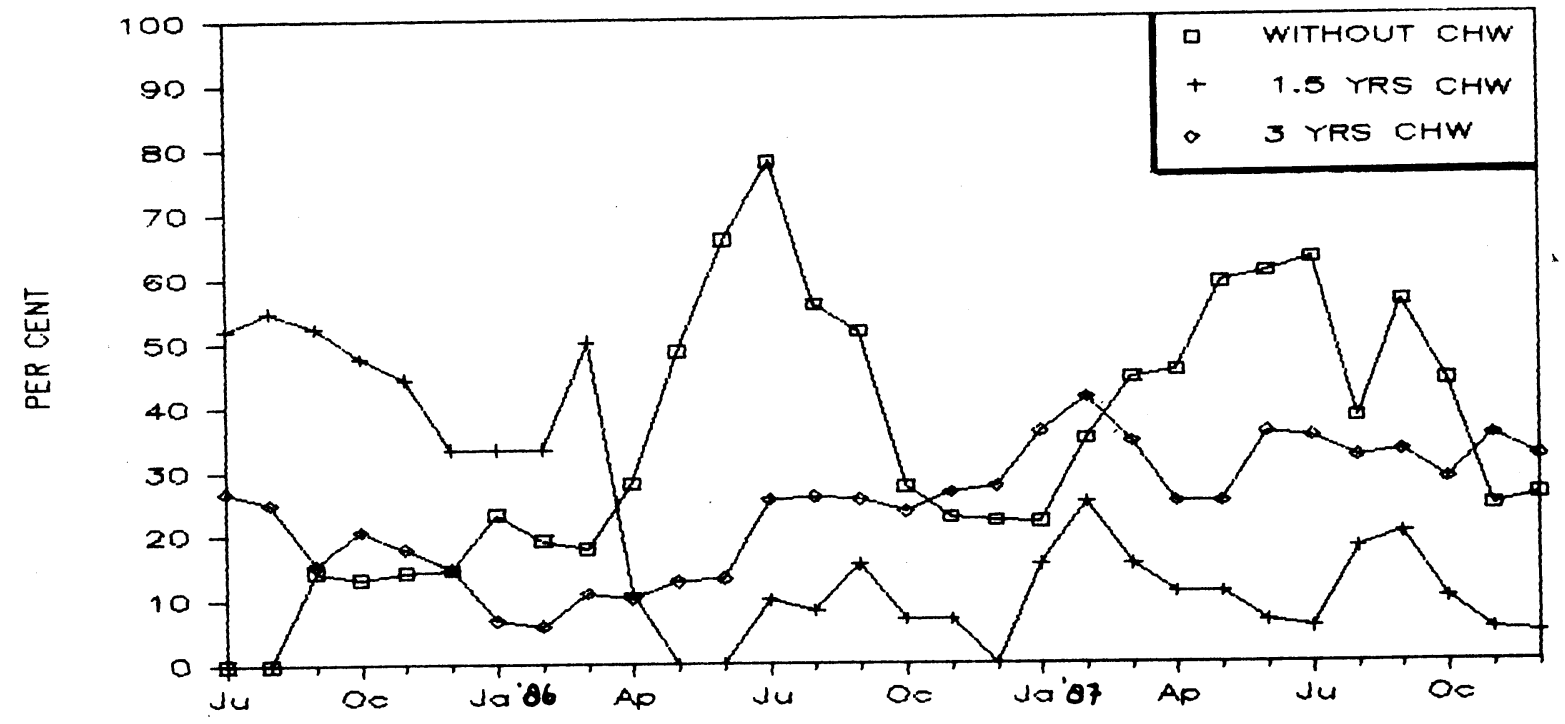


From figure 7 it appears that in both villages where the CHW programme is operating a reduction of the $\mathrm{TB}$ defaulting rates can be noticed. However, it can also be observed that on the short term the effects of the programme seems to be greater than on the long term. For the year 1987 the average percentage patients defaulting their treatment was:

- 43 per cent for the village without CHWs;

- 12 per cent for the village, which by that time was having CHWs for a period of .5-1.5 year;

- 33 por cent for the village, which in 1987 was exposed to 2-3 years CHW programe.

The average defaulting rate for this latter village, when it was exposed to a period of .5-1.5 year CHWs, was 15 per cent.

Despite the fact that these differences are not statistically significant, the trend discernible accords precisely with the one found by ICD for TB defaulters in 15 refugee villages in Bajaur Agency. Therefore, it seems justifiable to conclude that during the starting phase of the CHW programme the TB defaulting rates are reduced considerably, but that this effect is fading on the long term.

The dedication of the CHWs to their work or their persuasive power seems to weaken as time lapses. It might be possible that people are disappointed in the capacities of the CHWs in the long run, and therefore they are less inclined to follow his advices. Another explanation for this tendency might be a possible lost of interest of the CHWs themselves in their (voluntary) job, which has its impact on the CHW' initial power to encourage people to continue treatment. The necessity of a continuous system of support, motivation and follow-up of the CHWs becomes apparent, because if they themselves are not motivated anymore how can one expect them to continue their important community motivation work?

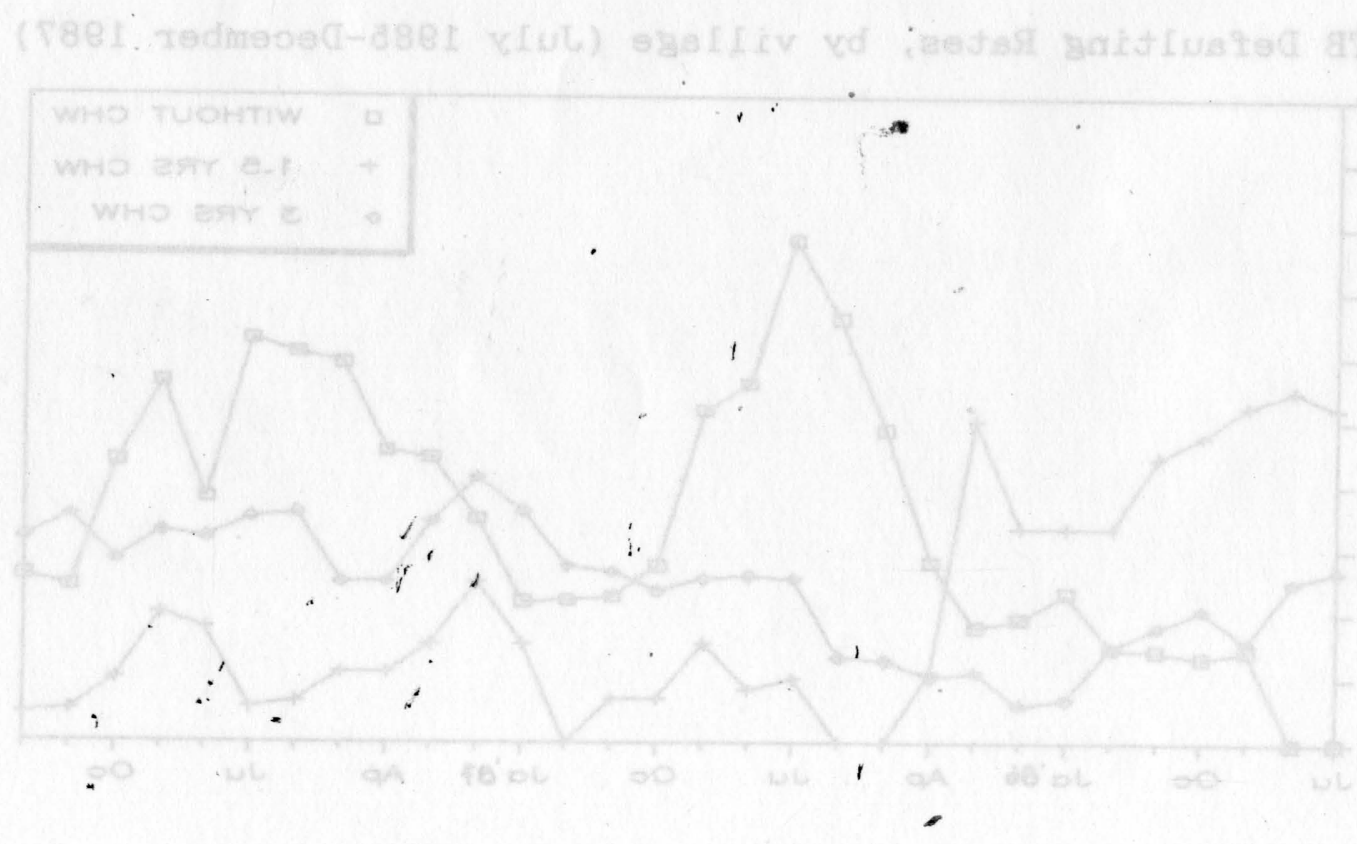




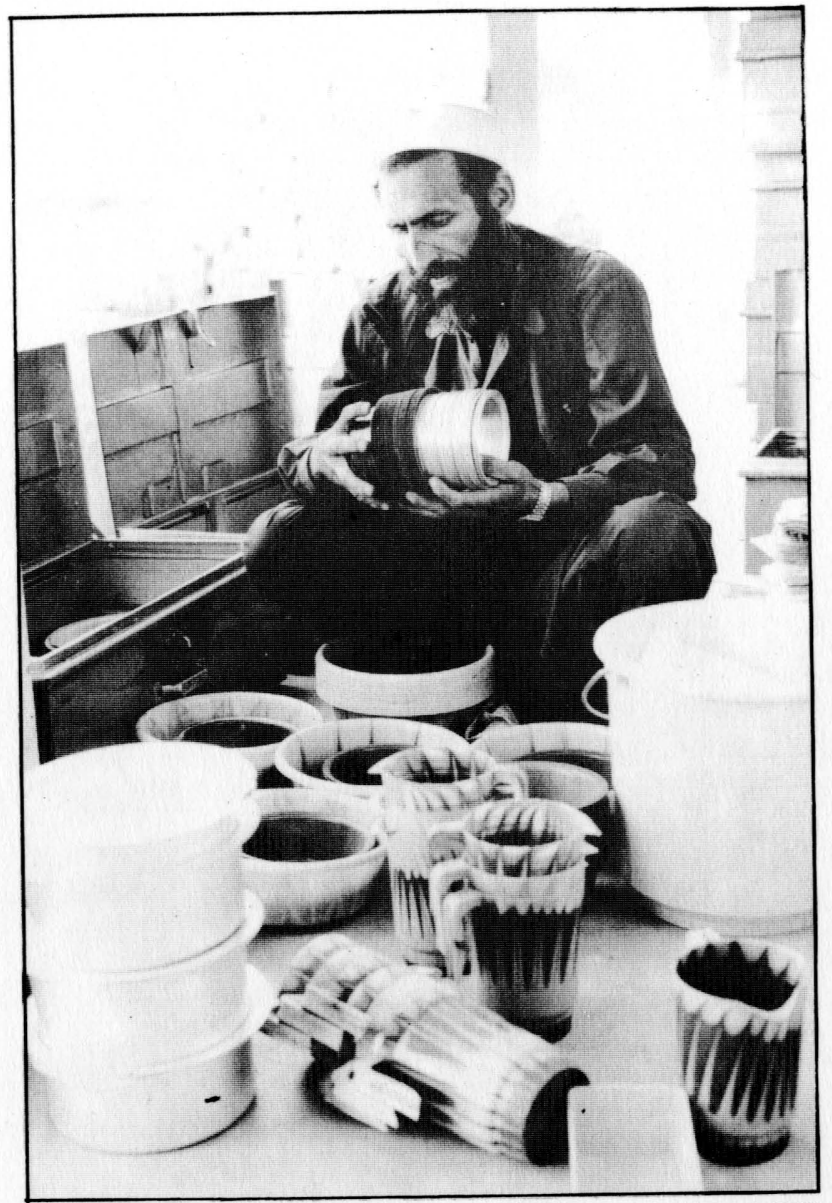

PACKING KITS FOR COMMUNITY HEALTH WORKERS, BADABER TRAINING CENTRE

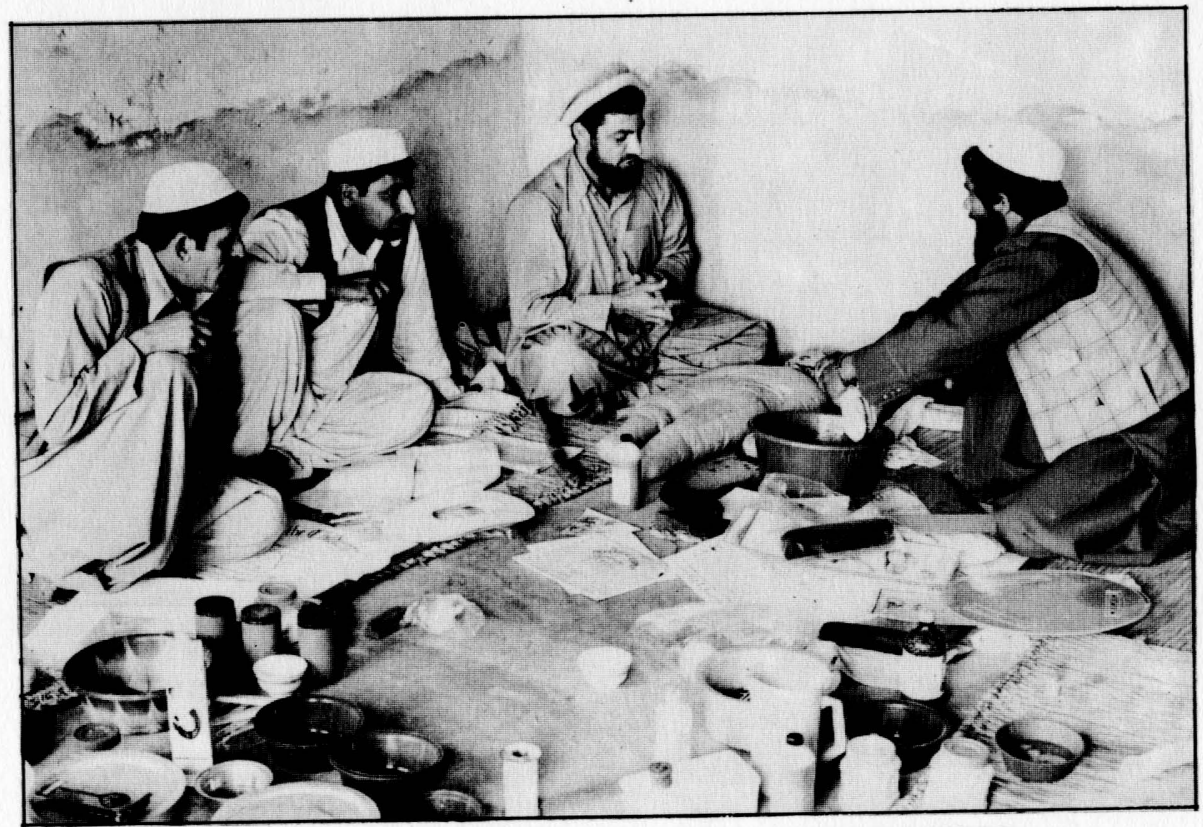

COMUNITY HEALTH WORKER ASSESSMENT 
The preceding chapters of this report have shown that the Male Primary Health Care programme has brought about an improvement in the health knowledge and practices of the population living in Afghan Refugee Villages. The Community Health Workers and their supervisors can play very important roles amongst the returning refugees as well. The following recommendations are made to strenghten the present programme.

\section{General recommendations}

1. A primary condition for the effectiveness of the programme is that the Community Health Workers must be in touch with their target group, comprising the male and female members of their extended family.

It came to light that CHWs indeed reach many men, but that the structure for disseminating health information among women is less successfull. This is a main obstacle of the present programme. If during the selection of $\mathrm{CHWs}$ as well as during the entire implementation of the programme greater emphasis would be given to the fact that the CHWs should have access to all women, then the potential of the programme would be more likely to be realized. Another way to reach more women is to decrease the number of families per CHW. Consequently, each CHW will better be able to circumvent the restrictions of the social custom of purdah. In this respect, the importance of female CHWs comes in view as well. SCF runs a Female Primary Health Care programme already, which is currently being expanded. Beside speeding up the implementation of that programme, it may be useful, as for the male programme, to focus only on the most important basic health issues to ensure an effective utilization of the outreach activities. Simultaneously attention should be given to improvement of the coordination of both male and female programme.

2. It appeared from the analysis of the knowledge of immunizations that the positive impact of the CHW programme diminishes after a couple of years. This may be due to the fact that the refugees as well as the CHWs may need their knowledge base reinforced. To prevent the impact of the programme from subsiding in the long run it is necessary to organize regular refresher courses and workshops for the CHWs and their supervisors. Continuous support and feedback are important to encourage them to maintain their enthusiasm and to keep their skills up to the desired level. Given its extensive scope and contents the programe has to be careful not to bite off more than it can chew, to warrant its potential to have a lasting impact, on the health status of the Afghan refugees. 
3. The programme positively influences the refugees' attitude towards prevention of diseases. Still, many refugees consider medicines as panacae to cure all ills, which may even lead to drug abuse. More efforts should be put on the counteracting of this attitude.

4. The role CHWs play in the follow-up of defaulters (TB patients, immunizations) needs to be enhanced. In this respect there is an urgent need for an adequate and identical system for all BHU's to monitor the activities of both CHWs and CHSs, which would facilitate the evaluation of their performances on a regular basis. A thorough assessment of the integration of the programme in the existing health structure in the refugee villages requires contiruous attention.

5. In order to increase the programme's effectiveness, especially in view of the refugees' return to Afghanistan, it is recommendable to reconsider the relevance of the curriculum and the appropriateness of the CHW training to the perceived needs of the community. In this respect, there is also a reed for detailed collaboration between the Government of Pakistan, UNHCR and all voluntary agencies working in the field of Primary Health Care.

Recommendations in detail with regard to Oral Rehydration Therapy:

6. The CHWS' efforts to promote the use of Oral-RehydrationTherapy lare successful in the long run. Interventions must be developped to shorten the period it takes to put the lessons taught by the CHWs into practice.

7. About 25 per cent of the refugees, living in a village where the programme is operating, do not know how to prepare SaltSugar-Solution properly. The teaching of a simpler, more appropriate method e.g. the pinch and scoop method may be more effective. Especially in view of the return of the refugees to their homeland, where Oral-Rehydration-Salts packages are probably not as easy available as at present, it is necessary to review the policies with regard to ORT with all parties concerned. It is essential that everyone working in the health sector with Afghan Refugees gives the same messages and uses identical teaching aids in order to avoid confusion.

Some final suggestions:

8. The results indicate that the workload in the Basic Health Units may be reduced in the areas where there are CHWs. It needs to be investigated whether this finding can be borne out by $\mathrm{BHU}$ records as well.

9. Depending. on the situation in the future, it may be useful to replicate this survey in one or two years and use as a benchmark the data of this study for the village where the programrue stiarted in "mid 1988. 
APPENDICES

1 


\section{Description of the Sampling Procedure}

In order to conduct the sampling of the units of investigation a multi-stage cluster sampling method was used, with the following stages:

\section{Selection of the villages}

a. Refugee villages which could be placed in one of the following "Treatment Groups" were selected from a listing of all Fefugee villages in NWFP with one GOP/UNHCR Basic Health Urit: Treatment Group I:

Refugee villages where SCF's Male Programme has been running for more than three years; (i.e. started before January 1985) Treatment Group II:

Refugee villages where SCF's Male Programe has been runing for a period of 1-1.5 years (i.e. started between July 1986 - January 1987).

Treatment Group III:

Refugee villages where SCF's Male Programme is due to start very soon, bit not within 4 months (i.e. not to start before May 1988).

b. From each group were eliminated, Refugee villages:

- with a very unequal sex-composition (e.g. widow and orphan Refugee villages);

- where SCF's Female FHC Programme is presently running;

- in the neighbourhood of urban centres (assumingly with many private medical services. and hospitals);

- with many inhabitants of a tribal minority;

- with a lot of new arrivals;

- with more than 15,000 inhabitants.

c. For all three groups together a listing was made of the remaining Refugee villages with their (estimated) number of inhabitants.

d. Each Refugee Village on this list of remaining Refugee villages received an unique number 1 to $N$. Lot:s were numbered from 1 to $N$ as well. Subsequently all these lots were mixed in a chitrali cap and one lot wass chosen at randomly. The Refugee village with this lot-number was selected first, no matter to which treatment group it belonged (I, II or III). Of each of the two remaining groups of Refugee Villages one village was selected, which had the closest number of inhabitants, in relation to the first at random chosen village. In .this way the Refugee villages from each treatment group were also matched by their number of inhabitants (*).<smiles>[3H][13CH3]</smiles>

* source for the no. of inhabitants: CAR, Peshawar, NWFP, 20.12.87. 
2. Selection of compound토

a. Each Refugee village was divided into 5 geographical areas, with the BHU in the same relative position. These areas were delineated as much as possible according to easily recognizable features, such as roads and streams.

b. From each area thirty-five compounds were selected: The first one in each area at randomly and the succeeding ones by simply shifting to the next one to the right of the preceding one until 35 compounds were visited. In case there was no compound to the right, the next closest compound was selected.

3. Selecction of resspondente within each compound

a. Only one father was interviewed per household.

b. In each compound the first mother encountered was asked the questions of both questionnaires (women and children forms).

c. The other women in the compound with children younger than 5 years of age were interviewed using only the questionnaire with regard to children. Sometimes some additional compounds were surveyed using only the children forms until the number of completed questionnaires for children emounted to 80 per cluster.

Table Al shows the sample sizes for the subgroups of the survey.

The data collection for the male and the female part of the survey took place independently of one another. The children's part overlapped the female part of the survey partly. Only persons were selected with at least one child less than 5 years old, who lived the whole, or part of the last year preceding the interview. Men were mostly interviewed in so called hujras (Buest rooms); women in their compound.

Table A1 : The sample size for each subgroup of the survey

\begin{tabular}{|c|c|c|c|}
\hline . & $\begin{array}{l}\text { Group I } \\
\text { without } \\
\text { program }\end{array}$ & $\begin{array}{l}\text { Group II } \\
1-1.5 \text { yrs } \\
\text { program }\end{array}$ & $\begin{array}{l}\text { Group III } \\
3 \text { yrs } \\
\text { program }\end{array}$ \\
\hline No. of male respondents & 175 & 175 & 175 \\
\hline No. of female respondents & 175 & 175 & 175 \\
\hline Minimum no. of children-forms & 400 & 400 & 400 \\
\hline
\end{tabular}




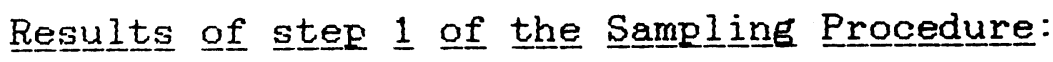

The lot chosen at randomly was of Refugee village Parachinar-2 (Kurram) belonging to group III.

The number of inhabitants of Parachinar-2 amounts 12,459 (amongst whom 5, 459 children younger than 12 years).

After matching on the number of inhabitants the following Refugee villages were also included in the survey:

Group I : Mayar (Dir), with 10,287 inhabitants (amongst whom 4,284 children < 12 years〉.

Group II: Jahangir Abad (Bajaur) with 9,472 inhabitants (amongst whom 5,711 children <12 years). 
APPENDIX 2

\section{CALCULATIONS}

Calculation of 95 per cent confidence limits of the mortality rates and "the proportions of successes":

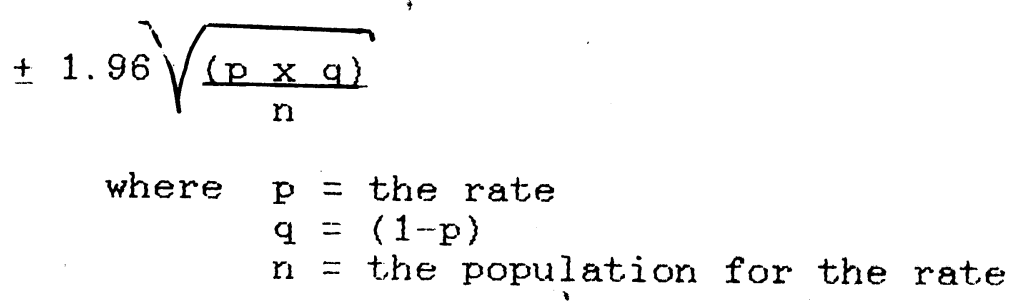

Furthermore the following test statistics are used by this study (Mendenhal1, 1974) :

Student's $T$ : to test differences in means.

Chi-square : to test the null hypothesis of "independence" for two classifications of a contingency table. 
APPENDIX 3

\section{CURRICULUM VITAE EVALUATOR}

Family Name

First Names

Date of Birth

Place of Birth

Sex

Nationality
: Jongsma

: Desiree Monique

: March 16, 1960

: Coevorden, The Netherlands

: Fernale

: Dutch

\section{Educatiㅡㅁㅡ}

1978-1985

University of Gronngen (RUG), The Netherlands

Faculty

B. A.

M. A.

Principal Subject

Minor Subjects

: Social Sciences

June, 1981

: November, 1985

: Andragogics (Adult Education)

: Medical Sociology; General Health Care and Epidemiology; Educational Training.

\section{Employment Record}

\section{7}

Consultant for Pak Holland Metal Project (Srmall Industries Development Board) in Peshawar, Pakistan.

$1985-1987$

Researcher at the working group Educational Innovations of the Institute for Educational Research (RION) in Groningen, The Netherlands.

$1984-1985$

Assistant-researcher at the working group Evaluation of Educational Prograrmes of RION in Groningen.

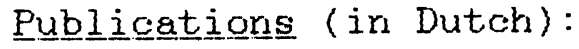

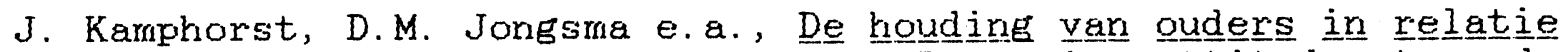
tot wiskunde voor hun kinderen (Parent"s attitude towards. Mathematics for their childrens, Educational Research Conference (ORD), Utrecht, 1986

J. Korf, D.M. Jongsma e. a. Meisjes en Wiskunde: Het HEWET-project (Girls and Mathematics: the HEWET-project), RION, Groningen, 1986

D.M. Jongsma, De keuzze van wis ken door jongens en meisjes in het Avo $\angle$ Wwo (The choice of Mathernatics and Physics by girls and boys in secondary school), RION, Groningen, 1985 
D.M. Jongsma \& M.F. Roeloffs; Handigaps en hulpverlening by arematuur en dysmatuur geboren kinderen (Disabilities and the attendance to prematurely and dysmaturely born infants), Andragogisch Instituut, University of Groninger, 1984

Contributions to:

J.E. Klok \& M.P.C. van der Werf, Prestatieverschilien tussen meisjes en jongens in het basisonderwijs (Differences in achievements of girls and boys in primary education), RION, Groningen, 1987

C.E. Clason \& M.P.C. van der Werf, Onderwijis emancipatie en onderzoek, tweede probleemverkenning ten behoeve van de programerme van onderzoek (Education, emancipation and research), SVO/RION, Groningen, 1986 
APPENDIX 4

\section{SAYE THE CHILDREN FUND}

\section{QUESTIONNAIRE FOR FEMALES}

\begin{tabular}{l} 
Q.no "question" \\
\hline 1
\end{tabular}$\quad \begin{array}{ll}\text { No. of interviewer } \\
\text { Date of interview } \\
\text { (day/month) }\end{array}$

\begin{tabular}{|c|c|c|c|}
\hline 4 & $\begin{array}{l}\text { Cluster no. } 1,2,3,4 \text { or } 5 \\
\text { (look on your map) }\end{array}$ & . & 7 \\
\hline 5 & $\begin{array}{l}\text { House no. } 01,02, \ldots, \ldots \\
\text { (give your own sequence for } \\
\text { each cluster, start with } 01 \text { ) }\end{array}$ & . & 8,9 \\
\hline 6 & $\begin{array}{l}\text { Refusal? } \\
\qquad \text { If YES, reason: }\end{array}$ & $\begin{array}{l}\text { no } \\
\text { too busy } \\
\text { not allowed } \\
\text { not in the mood } \\
\text { yields no benefit } \\
\text { other, } \ldots \ldots \ldots \ldots \ldots \ldots \\
\ldots \ldots \ldots \ldots \ldots \ldots \ldots \ldots \\
\text { unknown }\end{array}$ & 10 \\
\hline
\end{tabular}




\begin{tabular}{|c|c|c|c|}
\hline Q. no & Question & Ans & Column \\
\hline & What is your name? & & \\
\hline 7 & $\begin{array}{l}\text { What is your age? } \\
\text { (approximate) }\end{array}$ & $9 \dot{9}$ & $\begin{array}{ll}\text { unknown/no answer } & 11,12\end{array}$ \\
\hline 8 & $\begin{array}{l}\text { How long have you lived } \\
\text { in this camp? } \\
\text { (round off) }\end{array}$ & $\begin{array}{l}0 \\
1 \\
2 \\
3 \\
4 \\
5 \\
9\end{array}$ & $\begin{array}{l}\text { arrived this month } \\
1-5 \text { month } \\
6-11 \text { month } \\
1-2 \text { year } \\
3-6 \text { year } \\
7 \text { years or more } \\
\text { unknown } \text { no answer }\end{array}$ \\
\hline 9 & $\begin{array}{l}\text { Does your husband live } \\
\text { also in this same house? }\end{array}$ & $\begin{array}{l}0 \\
1 \\
2 \\
8 \\
9\end{array}$ & $\begin{array}{l}\text { no, (died) } \rightarrow \text { Q.11 } \\
\text { no, (jihad) } \rightarrow \text { Q.11 } \\
\text { yess } \\
\text { other, } \ldots \ldots \ldots \ldots \\
\text { unknown } / \text { no answer }\end{array}$ \\
\hline 10 & $\begin{array}{l}\text { Does he have work at the } \\
\text { moment? (If YES ask:) } \\
\text { Does he get a salary or } \\
\text { does he work on a daily } \\
\text { wage? }\end{array}$ & $\left\{\begin{array}{l}0 \\
1 \\
2 \\
8 \\
9\end{array}\right.$ & $\begin{array}{l}\text { no } \\
\text { yes, with a salary } \\
\text { yes, on daily wage } \\
\text { other, .......... } \\
\text { unknownino answer }\end{array}$ \\
\hline 11 & $\begin{array}{l}\text { How many chjldren do you } \\
\text { have? (living ones only!) }\end{array}$ & 99 & unknown/no answer \\
\hline 12 & $\begin{array}{l}\text { What is your main source } \\
\text { of drinking water? }\end{array}$ & $\begin{array}{l}0 \\
1 \\
2 \\
3 \\
4 \\
5 \\
8\end{array}$ & 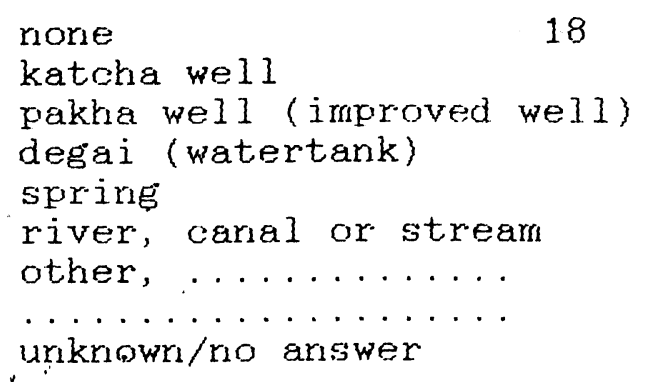 \\
\hline 13 & $\begin{array}{l}\text { Do you have any problems } \\
\text { with your drinking water } \\
\text { supply? } \\
\text { (If YES ask:) } \\
\text { What is your main } \\
\text { problem? }\end{array}$ & $\left\{\begin{array}{l}0 \\
1 \\
2 \\
3 \\
4 \\
8 \\
9\end{array}\right.$ & 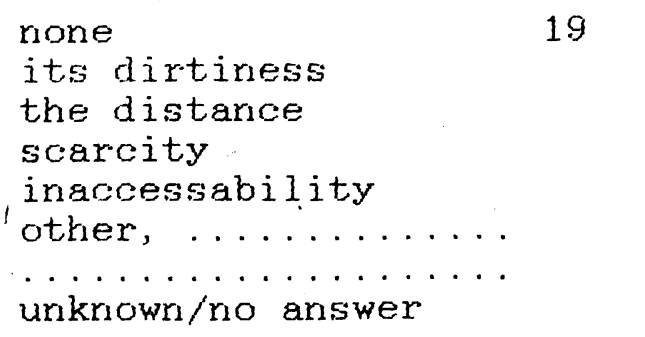 \\
\hline 14 & $\begin{array}{l}\text { What is the main ladvantage, } \\
\text { of having a clean 'wgter } \\
\text { supply? } \\
\qquad \therefore \quad \therefore\end{array}$ & $\begin{array}{l}0 \\
1 \\
2 \\
8 \\
9\end{array}$ & $\begin{array}{l}\text { none } \\
\text { prevention of diseases } \\
\text { (health reasons) } \\
\text { prayer reasonss } \\
\text { other }, \ldots \ldots \ldots \ldots \ldots \ldots \\
\text { unknown } / \text { no answer }\end{array}$ \\
\hline
\end{tabular}




\begin{tabular}{|c|c|c|c|}
\hline 15 & $\begin{array}{c}\text { What kind of latrine do } \\
\text { you have? } \\
\text { Where? }\end{array}$ & $\begin{array}{l}2 \\
3 \\
4 \\
8 \\
9\end{array}$ & $\begin{array}{l}\text { none } \rightarrow \text { Go to } Q .17 \\
\text { katcha/inside house } \\
\text { pakha/inside house } \\
\text { katcha/outside house } \\
\text { pakha/outside house } \\
\text { other, ............ } \\
\text { unknown/no answer }\end{array}$ \\
\hline 16 & $\begin{array}{l}\text { Who uses the latrine } \\
\text { in your family? }\end{array}$ & $\begin{array}{l}0 \\
1 \\
2 \\
3 \\
4 \\
5\end{array}$ & $\begin{array}{l}\text { nobody } \\
\text { women } \\
\text { women and children } \\
\text { women and men } \\
\text { whole family } \\
\text { men and women use seperate } \\
\text { latrines in the house } \\
\text { other, . . . . . . . . . } \\
\text { unknown no answer }\end{array}$ \\
\hline 17 & $\begin{array}{l}\text { What is the main advantage } \\
\text { of having a latrine at } \\
\text { home, according to you? }\end{array}$ & $\begin{array}{l}0 \\
1 \\
2 \\
3\end{array}$ & $\begin{array}{l}\text { none } \\
\text { it prevents disease } \\
\text { to maintains purdah/privacy } \\
1+2 \text { together (prevent } \\
\text { diseases and purdah) } \\
\text { bad smel cannot spread } \\
\text { protection during rain } \\
\text { other, . . . . . . . . . . . . . . . . . . } \\
\text { unknowno answer }\end{array}$ \\
\hline $18 a$ & $\begin{array}{l}\text { Can people themselves do } \\
\text { something to take care that } \\
\text { they don"t fall ill? }\end{array}$ & $\begin{array}{l}1 \\
9\end{array}$ & $\begin{array}{l}\text { no, because } \ldots \ldots \ldots \text { Q } 24 \text { Q } \\
\ldots \ldots \ldots \ldots \\
\text { yes } \\
\text { unknown/no answer } \rightarrow \text { Q. } 28 \mathrm{a}\end{array}$ \\
\hline 18 & If YES, How? & & ationed by respondent? \\
\hline 19 & By immunization & 1 & $\begin{array}{l}\text { not mentioned } \\
\text { mentioned }\end{array}$ \\
\hline 20 & By using latrines & 0 & $\begin{array}{l}\text { not mentioned } \\
\text { mentioned }\end{array}$ \\
\hline 21 & By using safe water & $\begin{array}{l}0 \\
1\end{array}$ & $\begin{array}{l}\text { not mentioned } \\
\text { mentioned }\end{array}$ \\
\hline 22 & By burning rubbish & $\begin{array}{l}0 \\
1\end{array}$ & $\begin{array}{l}\text { not mentioned } \\
\text { mentioned }\end{array}$ \\
\hline 23 & By fly/insects control & 0 & $\begin{array}{l}\text { not mentioned } \\
\text { mentioned }\end{array}$ \\
\hline 24 & By domestic hygiene & $\begin{array}{l}0 \\
1\end{array}$ & $\begin{array}{l}\text { not mentioned } \\
\text { mentioned }\end{array}$ \\
\hline 25 & By personal hygiene & $\begin{array}{l}0 \\
1\end{array}$ & $\begin{array}{l}\text { not mentioned } \\
\text { mentioned }\end{array}$ \\
\hline 26 & By food hygiene & $\begin{array}{l}0 \\
1\end{array}$ & $\begin{array}{l}\text { not mentioned } \\
\text { mentiioned }\end{array}$ \\
\hline 27 & $\begin{array}{l}\text { (Write exactly down other } \\
\text { answers to Question } 18 \mathrm{~b} \text { ) }\end{array}$ & & $\begin{array}{l}\ldots \ldots \ldots \ldots \ldots \ldots \ldots \\
\ldots \ldots \ldots \ldots \ldots \ldots \ldots \ldots\end{array}$ \\
\hline
\end{tabular}




$\begin{array}{llll}28 \mathrm{a} \text { Could you name diseases, } & 0 & \text { no } \rightarrow \text { Q. } 38 & 34 \\ \text { for which vaccines exist? } & 1 \text { yes } & \end{array}$

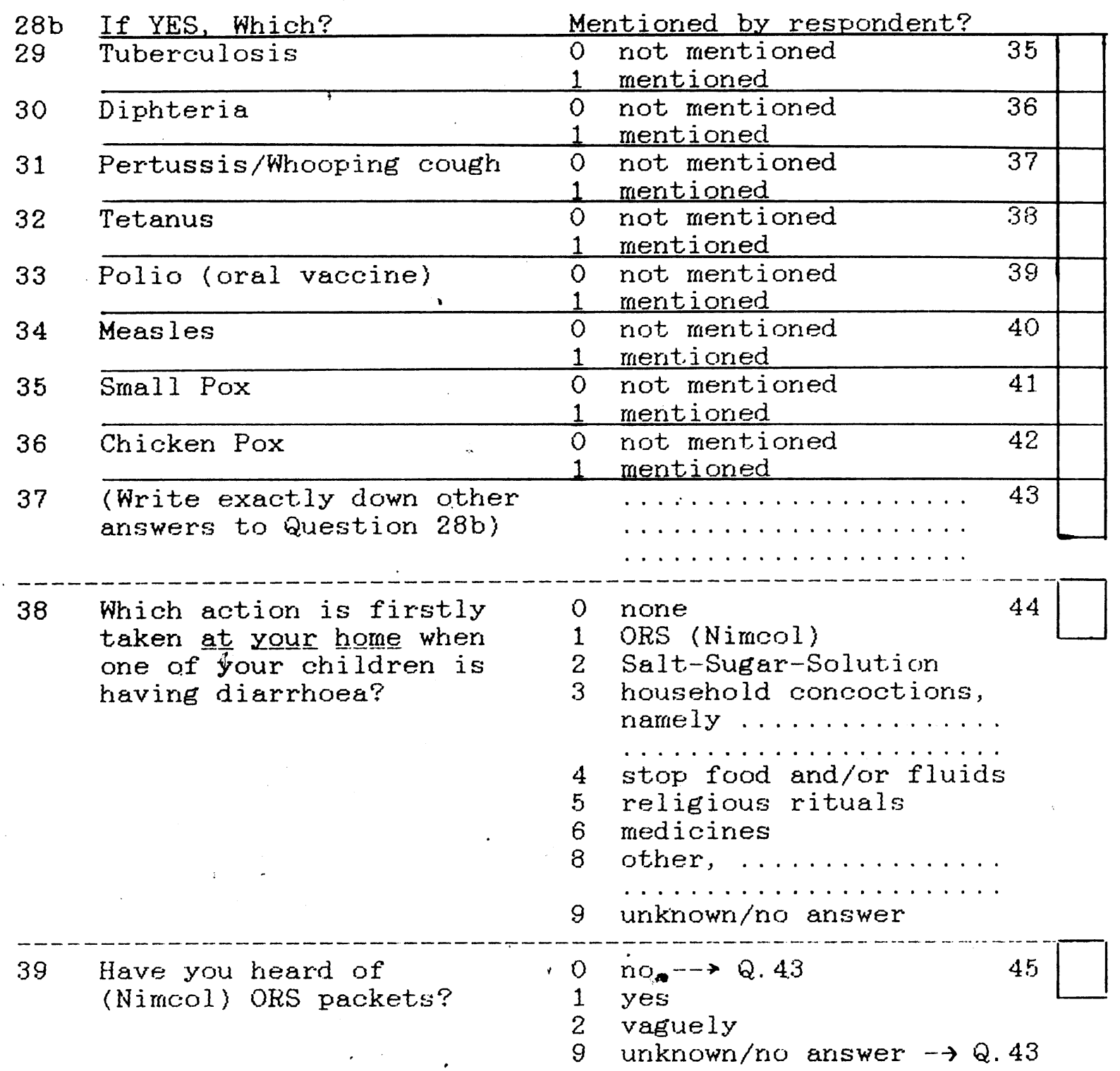

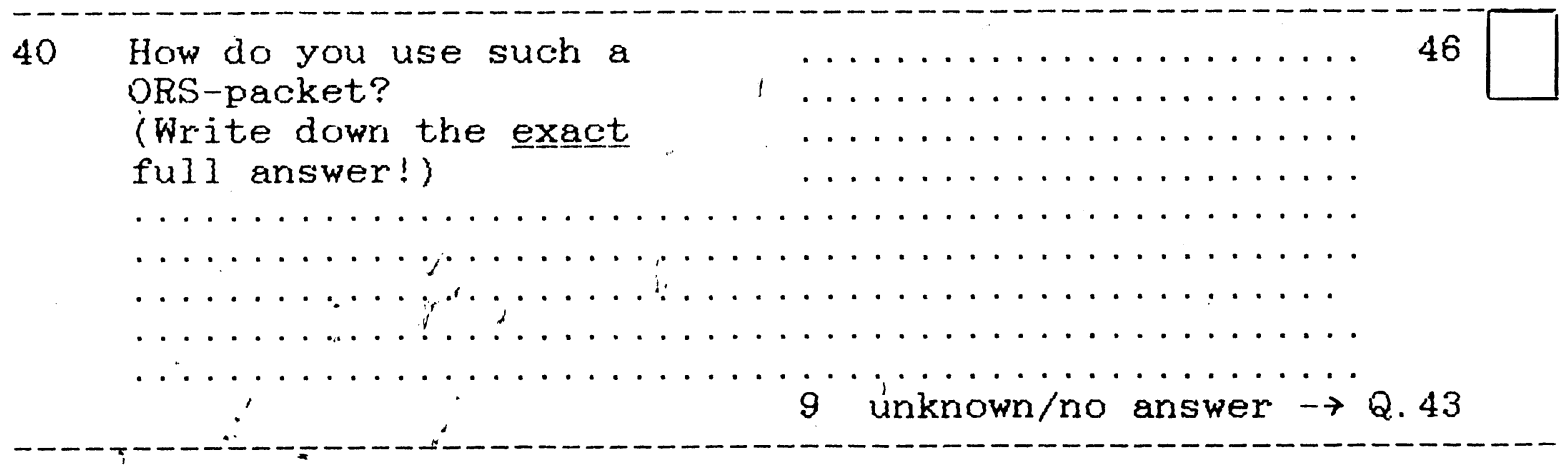


41 Who taught you how to prepare (Nimcol) ORS?
$\begin{array}{llr}0 & \text { nobody } & 47 \\ 1 & \text { a Community Health Worker }\end{array}$
2 a Community Health Supervisor
3 a doctor of $\mathrm{BHU}$
4 other doctor(s)
5 the radio ( $\mathrm{BBC}$ )
6 my husband
7 mother in law

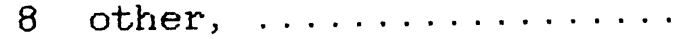
9 unknown/no answer

42 Who prepares in your house 0 nobody the (Nimeol) ORS, when one 1 I of your children needs it?

I

my husband

mother in law

other.$\ldots \ldots \ldots \ldots \ldots$

unknown $/$ no answer

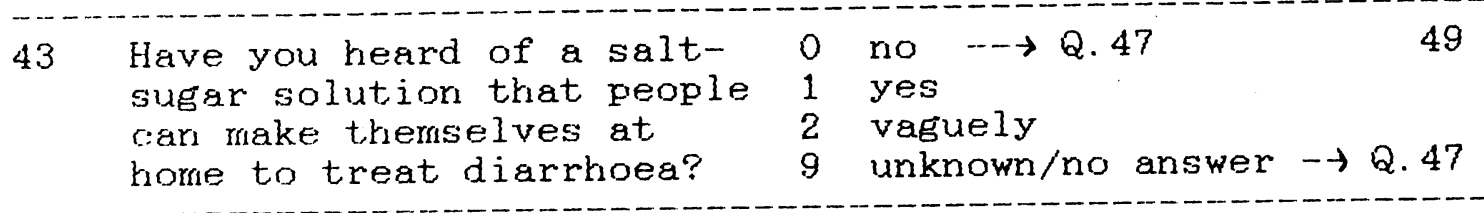

44 How do you prepare this salt-sugar-solution?

(Write down the exact

full answer!)

$\ldots \ldots \ldots \ldots \ldots \ldots \ldots \ldots$

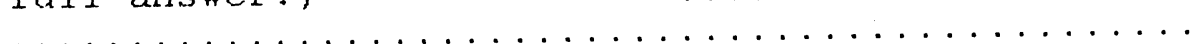

48

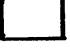

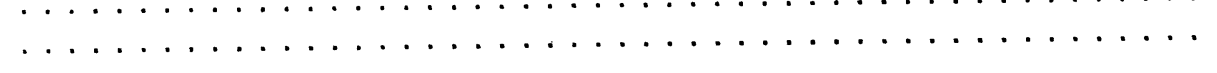

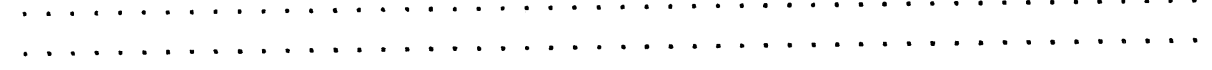

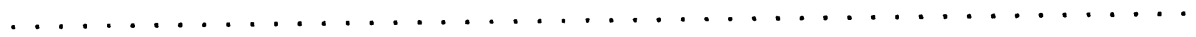

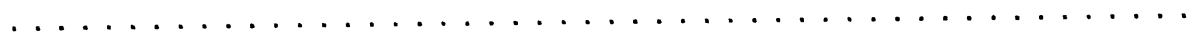

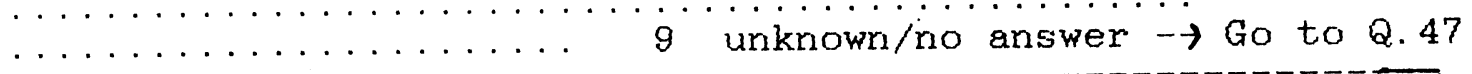

45 Who taught you how to make this Salt-Sugar

0 nobody

51

Solution?

1 a Community Health Worker

2 a Community Health Supervisor

3 a doctor of $\mathrm{BHU}$

4 other doctor(s)

5 the radio ( $B B C$ )

6 my husband

7 mother in law

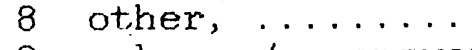

9 unknown/no answer

$\begin{array}{lll}46 \text { Who prepares in your house } & 0 & \text { nobody } \\ \text { the Salt-Sugar-Solution, } & 1 \text { I } \\ \text { when one of your children } & 2 \text { my husband } \\ \text { needs it? } & 3 \text { mother in law } \\ & 8 \text { other } \ldots \ldots \ldots \ldots \ldots \ldots\end{array}$


47 If one of your children is having a sore throat, who rust be asked for advice, besides your relatives?
0 nobody

1 a Community Health Worker

2 a Cormunity Health Supervisor

3 a doctor of $\mathrm{BHU}$

4 other doctors

5 a hakim/traditional healer.

6 a medical shopkeeper

7 a mullah

8 other,

$\ldots \ldots \ldots \ldots \ldots \ldots$

9 unknown/no answer

48 If one of your children is: having a high fever, who must be asked for advice, besides your relatives?

\section{nobody}

1 a Community Health, Worker

2 a Community Health Supervisor

3 the doctor of $\mathrm{BHU}$

4 other doctors

5 a hakim/traditional healer

6 a medical shopkeeper

7 a mullak

8 other,

other,

9 unknown/no answer

49 If the BHI is closed and
your chjld is having a
severe burn, who do you
ask for advice, besides
your relatives?

o nobody

1 a Community Health Worker

2 a Community Health Supervisor 3 other doctors your relatives?

\section{4 a hakim/traditional healer}

5 a medical shopkeeper.

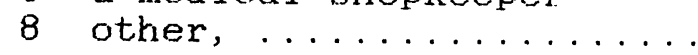

$\ldots \ldots \ldots \ldots \ldots$

9 unkrown/no answer

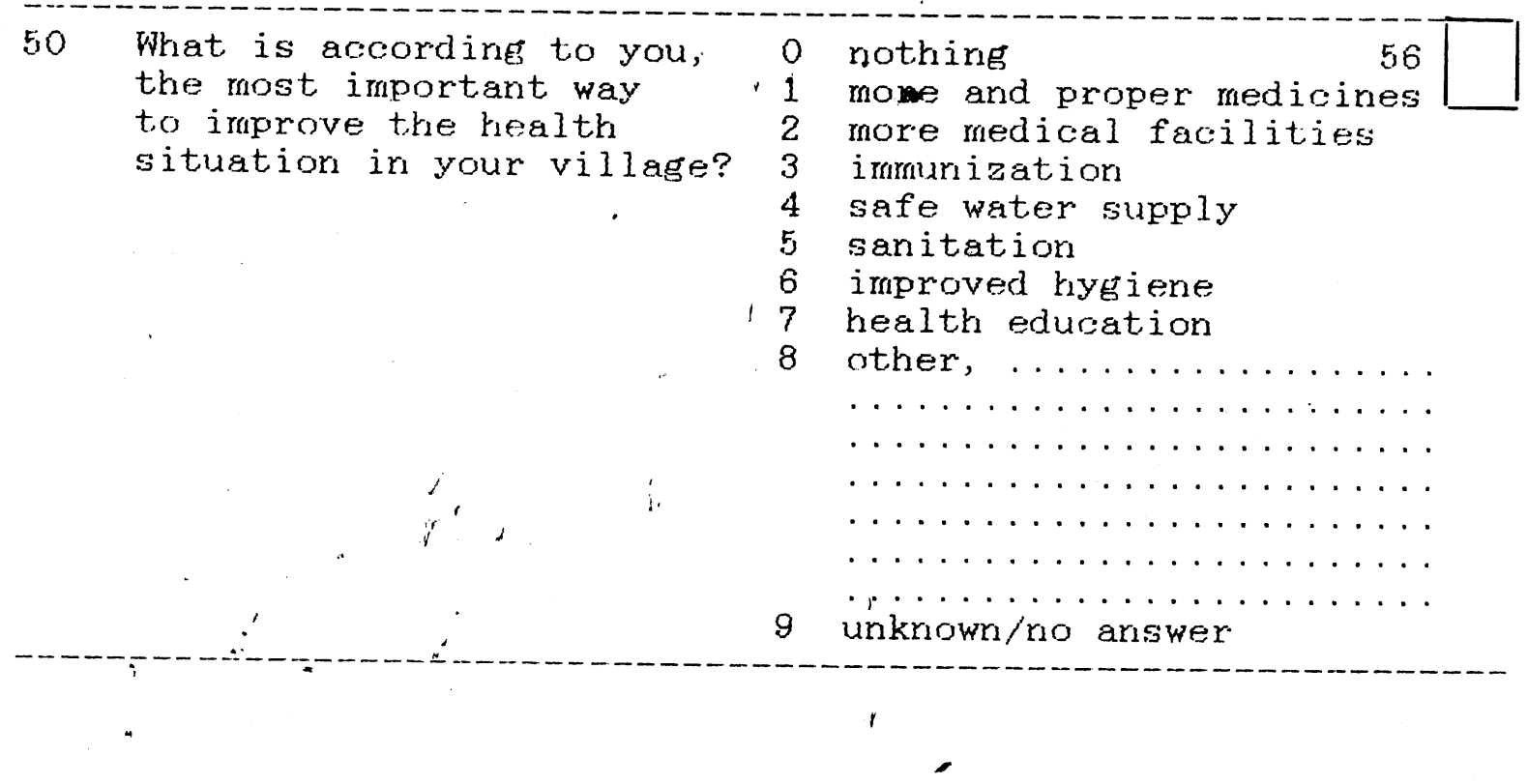




\section{QUESTIONS NOT TO BE ASKED EOR PARACHINAR-2. BUT DON'T FORGET TQ ASK THE QUESTIONS ON THE NEXT PAGE}

51 Who is your Community

Health Worker (CHW)?
0 there is none

$1 \ldots \ldots \ldots$ (name)

2 vaguely known (not by rame

8 other, ...........

9 unknown/no answer

52 Has your Commuity Health Worker visited you in the last month?

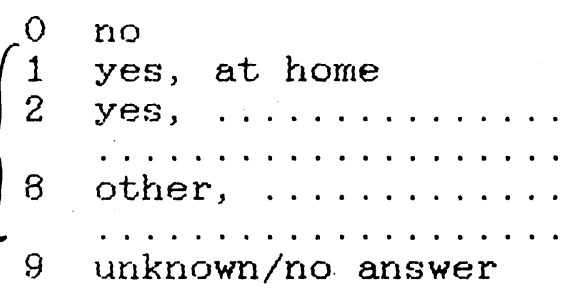

9 unknown/no answer

53 Have you ever asked the CHW advice for a health problem in your family? IF YES, When?

in the last week

2 in the last month

\section{(n)}

58

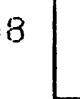

1-2 months back

43 months or more ago

5 can't remember when

8 other, ...........

9 unknown/no answer.

54 Have you noticed any change in your family since the Community Health Worker Programme started in your viliage?

(If YES ask:)

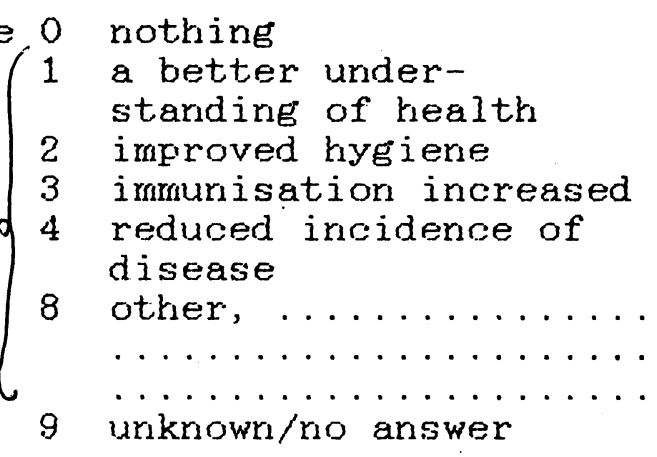

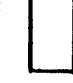

55 Have you noticed any change in this $\underline{\text { in }}$ ligage since the Community Health Worker Progranme started? (If YES ask:) What changed?

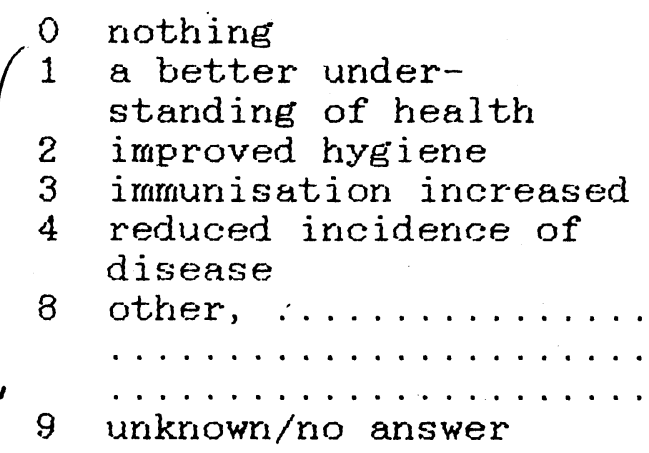


Fill in:

56 Number of children who died in the last year and who were less than 5 years old at the time of

O none death

ter the exact number, and complete for each dead child the seperate questions on page 8 !)

$57 \quad$ Fill in:

Number of children

less than 5 years of

0 none

63

age, who are now alive

- (enter the exact number, and complete for each child the the seperate questions on page 9!)

Space to record possible additional remarks of the respondent, with regard to SCF's Primary Health Care/Community Health Worker programme:

\section{Qne seperate last question for the respondents in all three \\ villages:}

-With regard to $B B C-P A S H T O$ radio-programe:

58 Have you heard the BBC Pashto 0 no

Service programme "Good Health"?

If YES, when did you last hear it? 
COMPLETE BELOW IF ANY CHILDREN LIYING IN THIS COMPOUND LFSS THAN 5 YEARS OF AGE DIED IN THE LAST 12 MONTHS

A child must have cried at birth to be condidered a live birth! ( 9 =uriknown $/$ no answer)

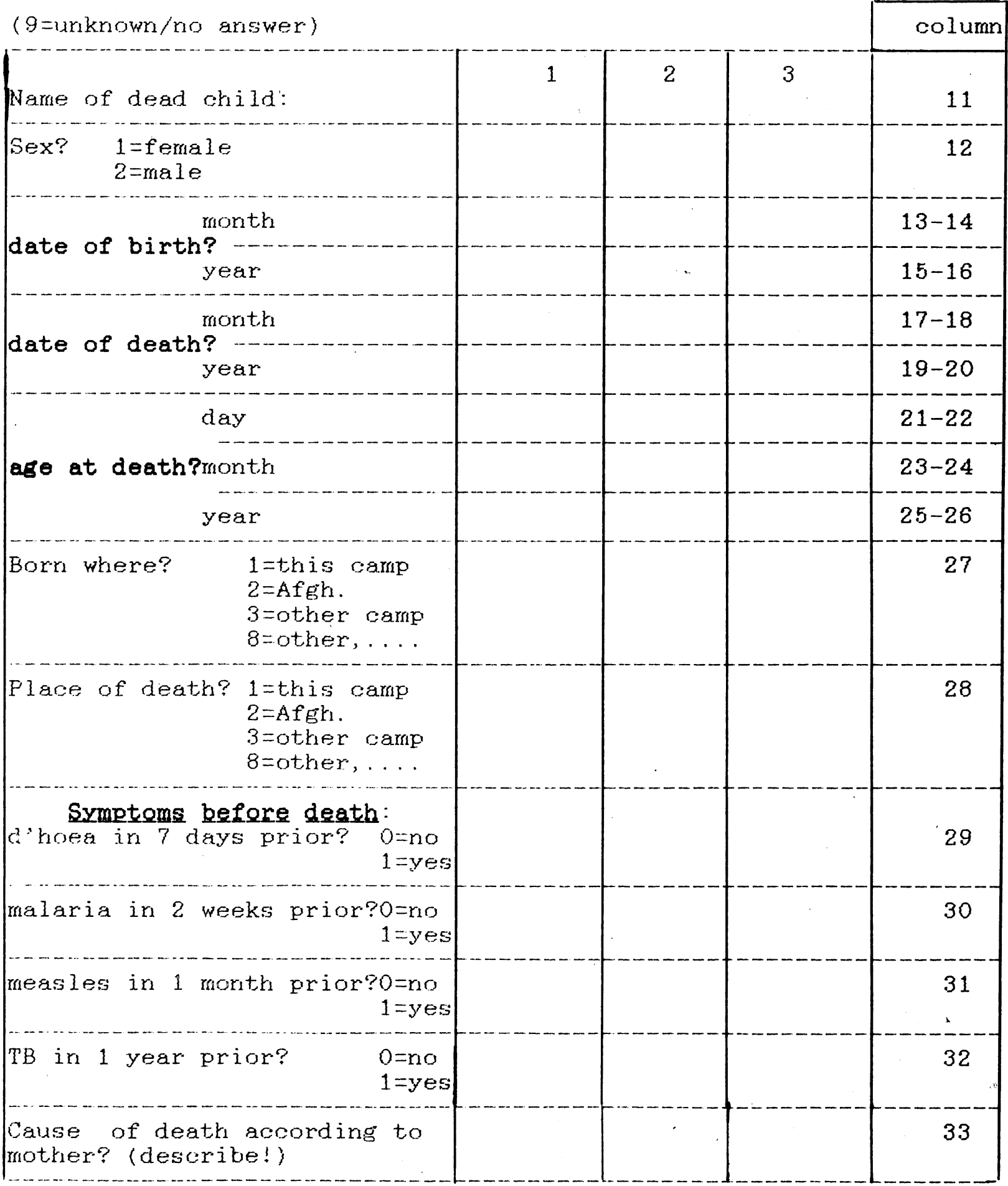

$\left.\left.\left.\prod_{1}\left[\begin{array}{l}{ }_{3} \\ 4\end{array}\right]_{6}\right]_{8}\right]_{9}\right]_{10}$ 


\section{COMPLETE FOR ALL CHILDREN ALIYE WHO ARE LESS THAN 5 YEARS LIYING IN THIS COMPOUND}

( $9=$ unknown $/$ no arsswer)
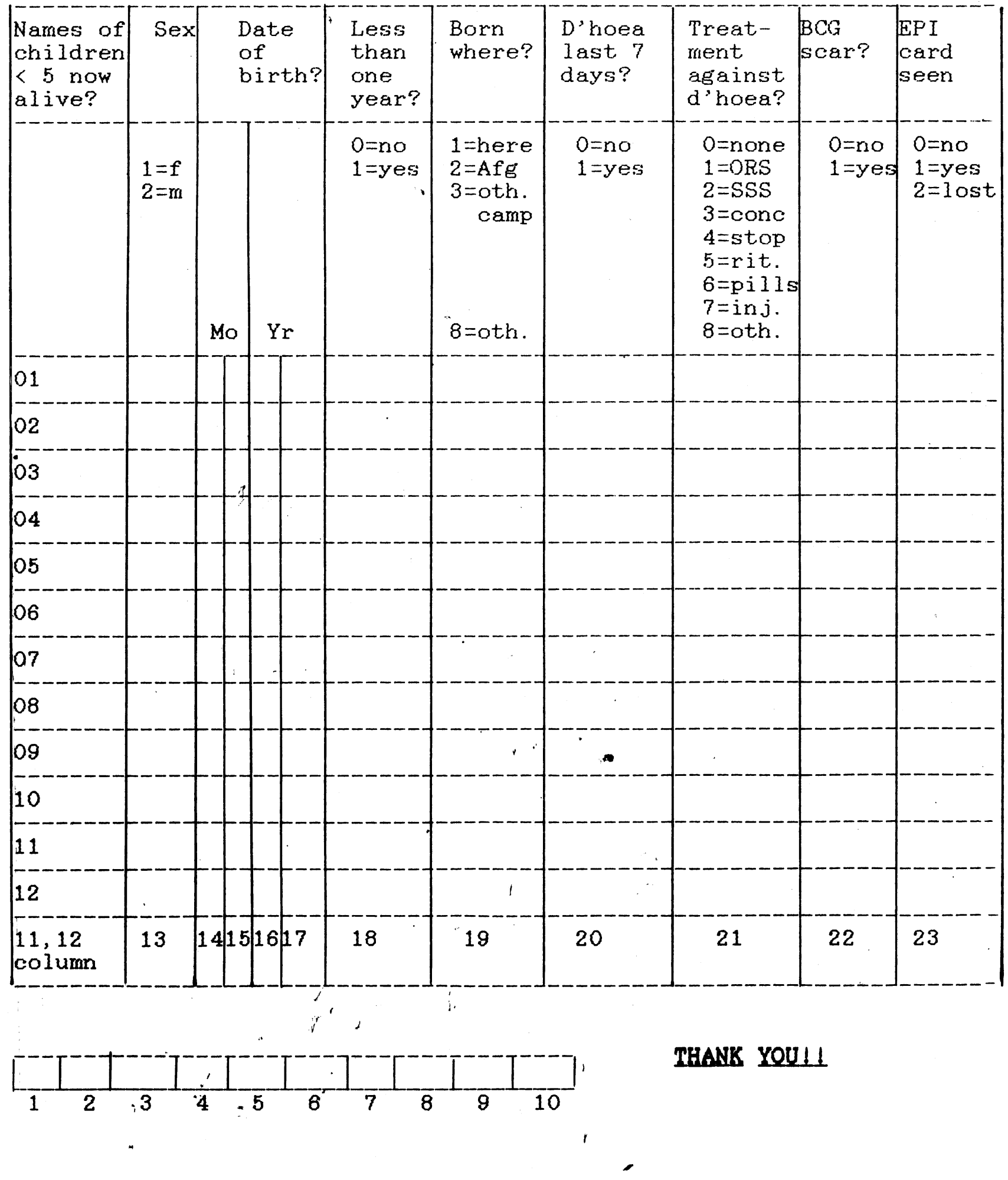

THANK YOU!1 
AFPENDIX 5

Aids to assist in determining dates of birth and death

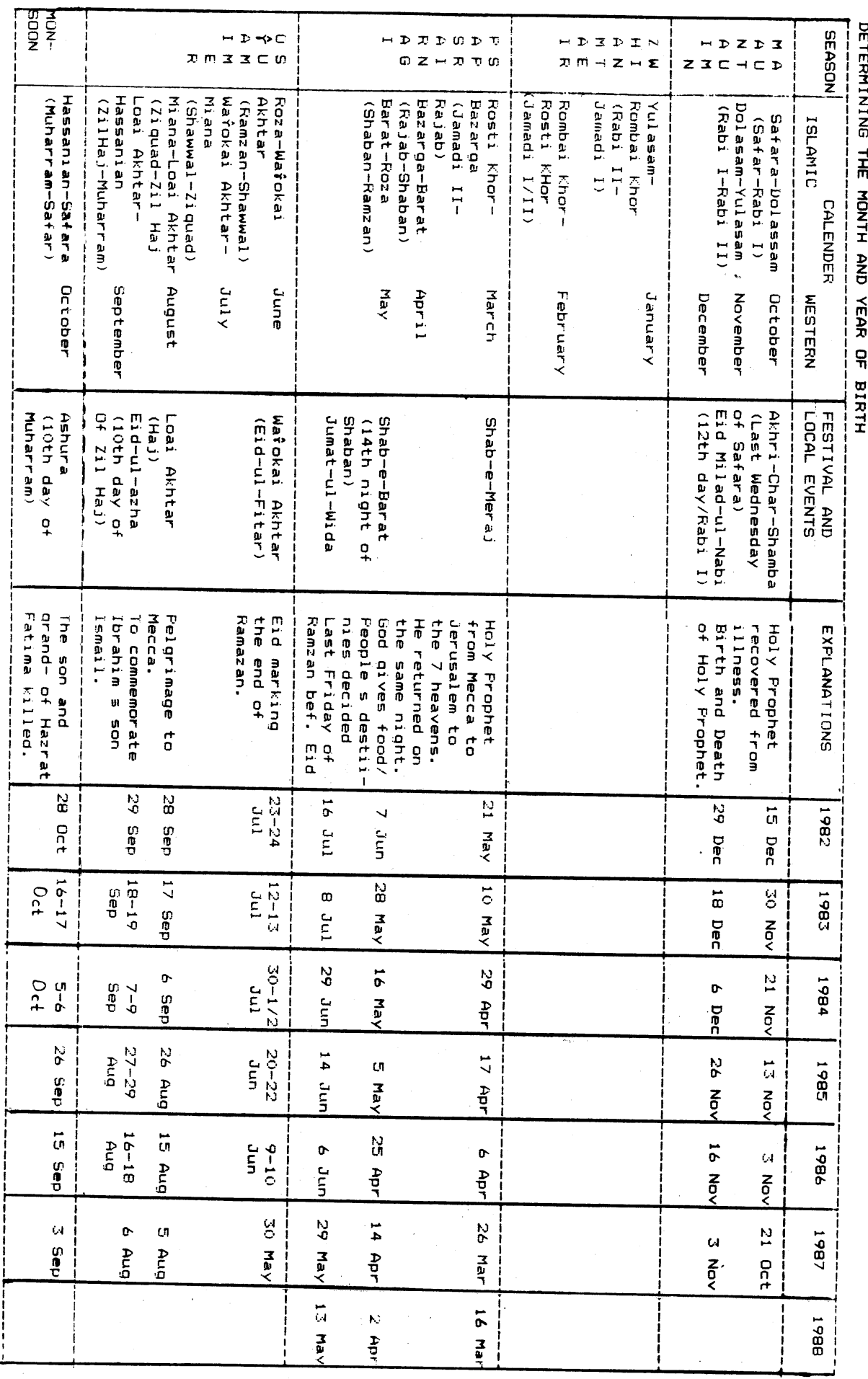




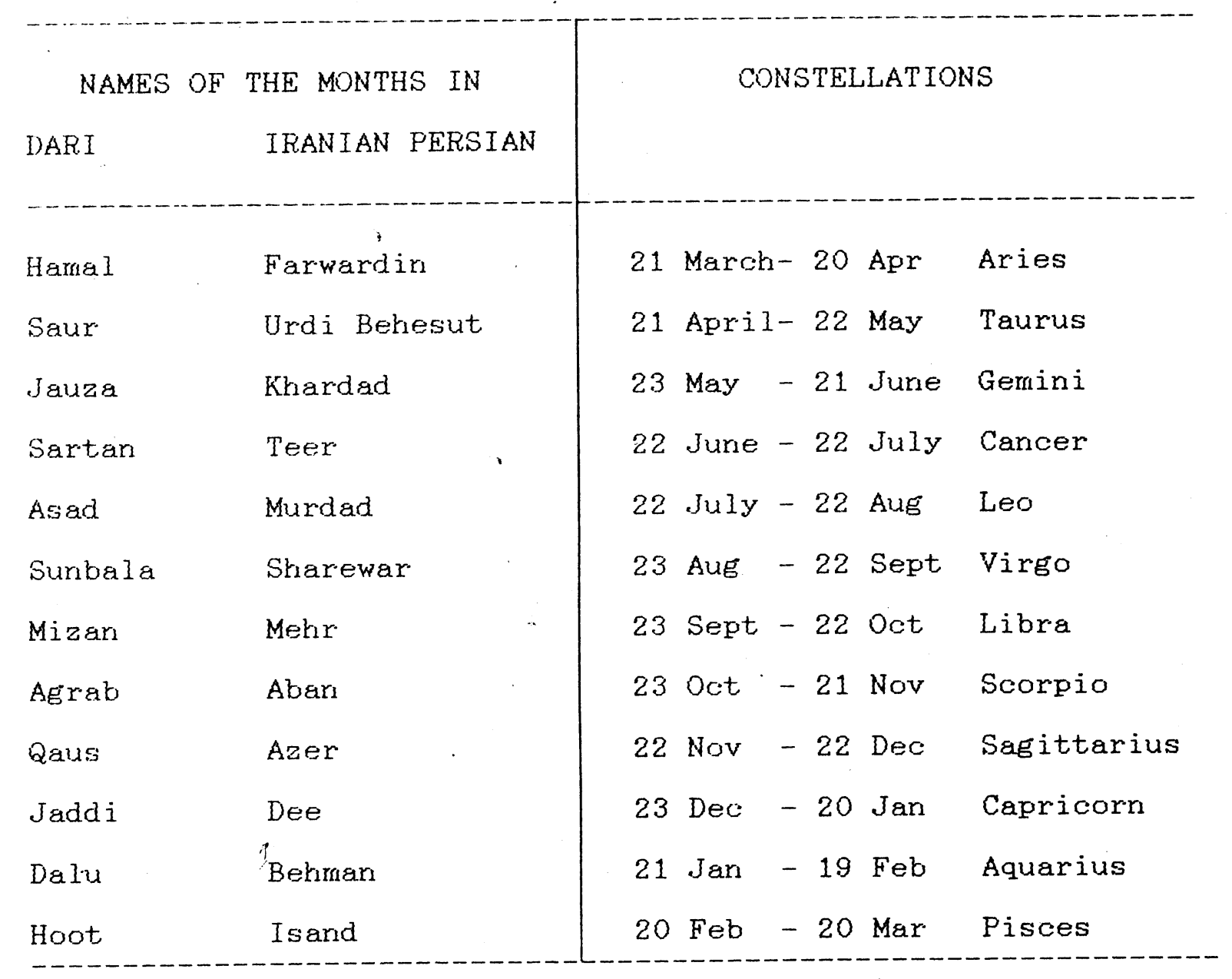

$\cdot$

"AFGHAN LOCAL FEMALE PASHTU":
Jurna
Khali
- Friday
Edbar
Qul
Saeeshanba
- Saturday
Charshariba
Pang Shanba
- Sunday
- Monday
- Tuesday
- Wedriesday
- Thursday
Naw Roze
- First day of the year 


\section{Statistios for 1887 based on SCF"' Disease Report Forms}

Example of the dis $\underline{\text { sease }}$ report form:

\begin{tabular}{|c|c|c|c|c|c|c|c|c|}
\hline & & & & & & & & \\
\hline $\begin{array}{l}00000 \\
00000 \\
00000 \\
00000 \\
00000\end{array}$ & 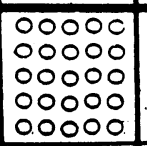 & $\begin{array}{l}000000 \\
000000 \\
00000 \\
000000 \\
000000\end{array}$ & 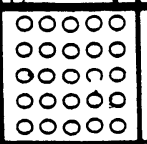 & $\begin{array}{l}00000 \\
00000 \\
00000 \\
00000 \\
00000\end{array}$ & 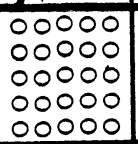 & $\begin{array}{l}00000 \\
00000 \\
00000 \\
00000 \\
00000\end{array}$ & $\begin{array}{lllll}0 & 0 & 0 & 0 & 0 \\
0 & 0 & 0 & 0 & 0 \\
0 & 0 & 0 & 0 & 0 \\
0 & 0 & 0 & 0 & 0 \\
0 & 0 & 0 & 0 & 0 \\
\end{array}$ & \\
\hline 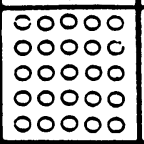 & $\begin{array}{l}00000 \\
00000 \\
00000 \\
00000 \\
00000\end{array}$ & $\begin{array}{l}00000 \\
00000 \\
00000 \\
00000 \\
00000\end{array}$ & 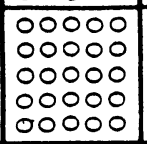 & $\begin{array}{l}00000 \\
00000 \\
00000 \\
00000 \\
00000\end{array}$ & $\begin{array}{l}00000 \\
00000 \\
00000 \\
00000 \\
00000\end{array}$ & $\begin{array}{l}00000 \\
00000 \\
00000 \\
00000 \\
00000\end{array}$ & $\begin{array}{llllllll}0 & 0 & 0 & 0 & 0 \\
0 & 0 & 0 & 0 & 0 \\
0 & 0 & 0 & 0 & 0 \\
0 & 0 & 0 & 0 & 0 \\
0 & 0 & 0 & 0 & 0\end{array}$ & \\
\hline 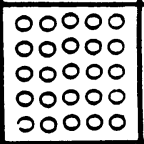 & 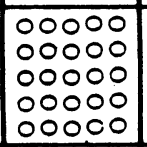 & $\begin{array}{l}00000 \\
00000 \\
00000 \\
00000 \\
00000\end{array}$ & 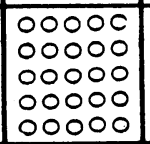 & $\begin{array}{l}00000 \\
00000 \\
00000 \\
00000 \\
00000\end{array}$ & $\begin{array}{l}00000 \\
00000 \\
00000 \\
00000 \\
00000\end{array}$ & $\begin{array}{l}00000 \\
00000 \\
00000 \\
00000 \\
00000\end{array}$ & 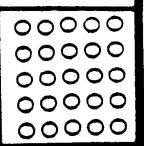 & \\
\hline $\begin{array}{l}00000 \\
00000 \\
00000 \\
00000 \\
00000\end{array}$ & $\begin{array}{l}00000 \\
00000 \\
00000 \\
00000 \\
00000\end{array}$ & $\begin{array}{l}00000 \\
00000 \\
000000 \\
000000 \\
000000\end{array}$ & $\begin{array}{|lllll|} & 0 & 0 & 0 & 0 \\
0 & 0 & 0 & 0 & 0 \\
0 & 0 & 0 & 0 & 0 \\
0 & 0 & 0 & 0 & 0 \\
0 & 0 & 0 & 0 & 0 \\
\end{array}$ & $\begin{array}{l}00000 \\
00000 \\
00000 \\
00000 \\
00000\end{array}$ & $\begin{array}{lllll}0 & 0 & 0 & 0 & 0 \\
0 & 0 & 0 & 0 & 0 \\
0 & 0 & 0 & 0 & 0 \\
0 & 0 & 0 & 0 & 0 \\
0 & 0 & 0 & 0 & 0 \\
\end{array}$ & $\begin{array}{lll}00000 \\
000000 \\
000000 \\
000000 \\
000000\end{array}$ & 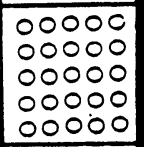 & \\
\hline $\begin{array}{l}00000 \\
00000 \\
00000 \\
00000 \\
00000\end{array}$ & $\begin{array}{l}00000 \\
00000 \\
00000 \\
00000 \\
000000\end{array}$ & $\begin{array}{l}00000 \\
00000 \\
00000 \\
00000 \\
00000\end{array}$ & 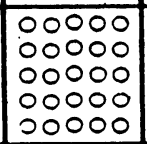 & $\begin{array}{lllll}0 & 0 & 0 & 0 & 0 \\
0 & 0 & 0 & 0 & 0 \\
0 & 0 & 0 & 0 & 0 \\
0 & 0 & 0 & 0 & 0 \\
0 & 0 & 0 & 0 & 0\end{array}$ & $\begin{array}{l}00000 \\
00000 \\
00000 \\
00000 \\
00000\end{array}$ & 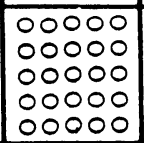 & 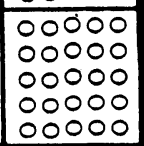 & \\
\hline $\begin{array}{l}00000 \\
00000 \\
00000 \\
00000 \\
00000\end{array}$ & $\begin{array}{l}00000 \\
00000 \\
00000 \\
00000 \\
00000\end{array}$ & \begin{tabular}{ll|}
0 & 00000 \\
00000 & 0 \\
00000 \\
000000 \\
00000
\end{tabular} & \begin{tabular}{ll|}
000000 \\
000000 \\
000000 \\
000000 \\
000000
\end{tabular} & 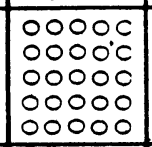 & $\begin{array}{lllll}0 & 0 & 0 & 0 & 0 \\
0 & 0 & 0 & 0 & 0 \\
0 & 0 & 0 & 0 & 0 \\
0 & 0 & 0 & 0 & 0 \\
0 & 0 & 0 & 0 & 0 \\
\end{array}$ & 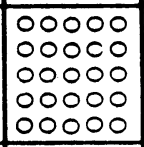 & $\begin{array}{l}00000 \\
00000 \\
000000 \\
000000 \\
000000 \\
\end{array}$ & \\
\hline $\begin{array}{l}00000 \\
00000 \\
00000 \\
00000 \\
00000\end{array}$ & $\begin{array}{lllll}0 & 0 & 0 & 0 & 0 \\
0 & 0 & 0 & 0 & 0 \\
0 & 0 & 0 & 0 & 0 \\
0 & 0 & 0 & 0 & 0 \\
0 & 0 & 0 & 0 & 0\end{array}$ & $\begin{array}{l}00000 \\
00000 \\
000000 \\
00000 \\
00000\end{array}$ & 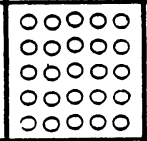 & \begin{tabular}{lllll|} 
& 0 & 0 & 0 & 0 \\
0 & 0 & 0 & 0 & 0 \\
0 & 0 & 0 & 0 & 0 \\
0 & 0 & 0 & 0 & 0 \\
0 & 0 & 0 & 0 & 0 \\
\end{tabular} & $\begin{array}{lllll}0 & 0 & 0 & 0 & 0 \\
0 & 0 & 0 & 0 & 0 \\
0 & 0 & 0 & 0 & 0 \\
0 & 0 & 0 & 0 & 0 \\
0 & 0 & 0 & 0 & 0 \\
\end{array}$ & 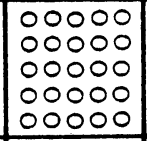 & \begin{tabular}{ll|}
000000 \\
000000 \\
000000 \\
000000 \\
000000 \\
000
\end{tabular} & \\
\hline $\begin{array}{l}00000 \\
00000 \\
00000 \\
00000 \\
00000\end{array}$ & $\begin{array}{l}00000 \\
00000 \\
00000 \\
00000 \\
00000\end{array}$ & 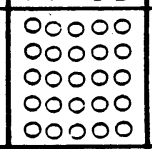 & \begin{tabular}{|l|l|}
000000 \\
000000 \\
000000 \\
000000 \\
0000000
\end{tabular} & 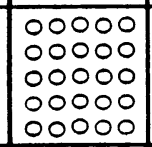 & $\begin{array}{l}00000 \\
00000 \\
00000 \\
00000 \\
00000\end{array}$ & $\begin{array}{lllll}0 & 0 & 0 & 0 & 0 \\
0 & 0 & 0 & 0 & 0 \\
00 & 0 & 0 & 0 \\
0 & 0 & 0 & 0 & 0 \\
0 & 0 & 0 & 0 & 0 \\
\end{array}$ & 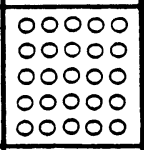 & \\
\hline $\begin{array}{l}00000 \\
00000 \\
00000 \\
00000 \\
00000\end{array}$ & 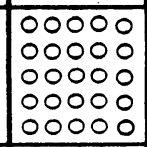 & 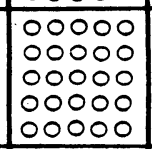 & 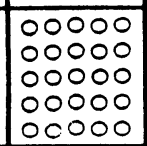 & 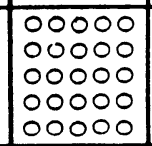 & 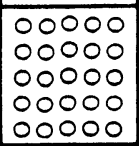 & $\begin{array}{|lllll|}0 & 0 & 0 & 0 & 0 \\
0 & 0 & 0 & 0 & 0 \\
0 & 0 & 0 & 0 & 0 \\
0 & 0 & 0 & 0 & 0 \\
0 & 0 & 0 & 0 & 0 \\
\end{array}$ & $\begin{array}{llllll}0 & 0 & 0 & 0 & 0 \\
0 & 0 & 0 & 0 & 0 \\
0 & 0 & 0 & 0 & 0 \\
0 & 0 & 0 & 0 & 0 \\
0 & 0 & 0 & 0 & 0 \\
\end{array}$ & \\
\hline $\begin{array}{l}00000 \\
000000 \\
000000 \\
000000 \\
000000\end{array}$ & $\begin{array}{l}00000 \\
00000 \\
00000 \\
00000 \\
00000\end{array}$ & $\begin{array}{|lllll|} & 0 & 0 & 0 & 0 \\
0 & 0 & 0 & 0 & 0 \\
0 & 0 & 0 & 0 & 0 \\
0 & 0 & 0 & 0 & 0 \\
0 & 0 & 0 & 0 & 0 \\
\end{array}$ & \begin{tabular}{|lllll}
0 & 0 & 0 & 0 & 0 \\
0 & 0 & 0 & 0 & 0 \\
0 & 0 & 0 & 0 & 0 \\
0 & 0 & 0 & 0 & 0 \\
0 & 0 & 0 & 0 & 0 \\
\end{tabular} & \begin{tabular}{|lllll}
0 & 0 & 0 & 0 & 0 \\
0 & 0 & 0 & 0 & 0 \\
0 & 0 & 0 & 0 & 0 \\
0 & 0 & 0 & 0 & 0 \\
0 & 0 & 0 & 0 & 0 \\
\end{tabular} & 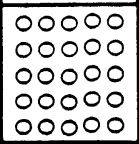 & $\begin{array}{lllll}0 & 0 & 0 & 0 & 0 \\
0 & 0 & 0 & 0 & 0 \\
0 & 0 & 0 & 0 & 0 \\
0 & 0 & 0 & 0 & 0 \\
0 & 0 & 0 & 0 & 0 \\
\end{array}$ & 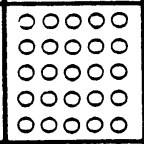 & \\
\hline $\begin{array}{l}00000 \\
00000 \\
00000 \\
00000 \\
00000\end{array}$ & \begin{tabular}{|l|l|l|}
00000 \\
000000 \\
000000 \\
000000 \\
00000 \\
\end{tabular} & \begin{tabular}{ll|}
00000 \\
00000 \\
00000 \\
00000 \\
00000 \\
\end{tabular} & $\begin{array}{llllll}0 & 0 & 0 & 0 & 0 \\
0 & 0 & 0 & 0 & 0 \\
0 & 0 & 0 & 0 & 0 \\
0 & 0 & 0 & 0 & 0 \\
0 & 0 & 0 & 0 & 0\end{array}$ & $\begin{array}{lllll}0 & 0 & 0 & 0 & 0 \\
0 & 0 & 0 & 0 & 0 \\
0 & 0 & 0 & 0 & 0 \\
0 & 0 & 0 & 0 & 0 \\
0 & 0 & 0 & 0 & 0 \\
\end{array}$ & $\begin{array}{lllll}0 & 0 & 0 & 0 & 0 \\
0 & 0 & 0 & 0 & 0 \\
0 & 0 & 0 & 0 & 0 \\
0 & 0 & 0 & 0 & 0 \\
0 & 0 & 0 & 0 & 0 \\
\end{array}$ & $\begin{array}{|lllll|}0 & 0 & 0 & 0 & 0 \\
0 & 0 & 0 & 0 & 0 \\
0 & 0 & 0 & 0 & 0 \\
0 & 0 & 0 & 0 & 0 \\
0 & 0 & 0 & 0 & 0 \\
\end{array}$ & $\begin{array}{l}00000 \\
000000 \\
000000 \\
000000 \\
000000\end{array}$ & \\
\hline $\begin{array}{l}00000 \\
00000 \\
00000 \\
00000 \\
00000\end{array}$ & 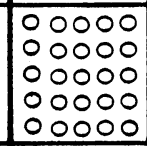 & 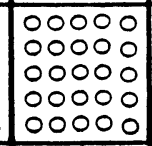 & $\begin{array}{|lllll|}0 & 0 & 0 & 0 & 0 \\
0 & 0 & 0 & 0 & 0 \\
0 & 0 & 0 & 0 & 0 \\
0 & 0 & 0 & 0 & 0 \\
0 & 0 & 0 & 0 & 0 \\
\end{array}$ & \begin{tabular}{|lllll}
0 & 0 & 0 & 0 & 0 \\
0 & 0 & 0 & 0 & 0 \\
0 & 0 & 0 & 0 & 0 \\
0 & 0 & 0 & 0 & 0 \\
0 & 0 & 0 & 0 & 0 \\
\end{tabular} & 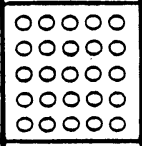 & $\begin{array}{|lllll|}0 & 0 & 0 & 0 & 0 \\
0 & 0 & 0 & 0 & 0 \\
0 & 0 & 0 & 0 & 0 \\
0 & 0 & 0 & 0 & 0 \\
0 & 0 & 0 & 0 & 0 \\
\end{array}$ & $\begin{array}{l}00000 \\
00000 \\
00000 \\
00000 \\
00000\end{array}$ & \\
\hline $\begin{array}{l}00000 \\
000000 \\
000000 \\
000000 \\
000000\end{array}$ & 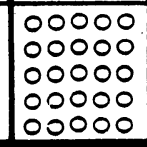 & 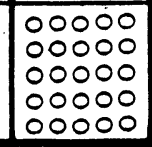 & \begin{tabular}{l|l|}
000000 \\
000000 \\
000000 \\
000000 \\
000000
\end{tabular} & $\begin{array}{l}00000 \\
00000 \\
00000 \\
00000 \\
00000\end{array}$ & $\begin{array}{l}00000 \\
00000 \\
00000 \\
00000 \\
00000\end{array}$ & 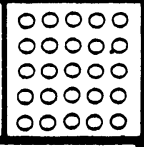 & $\begin{array}{l}00000 \\
00000 \\
00000 \\
00000 \\
00000 \\
0000\end{array}$ & \\
\hline $\begin{array}{l}00000 \\
000000 \\
000000 \\
000000 \\
000000\end{array}$ & $\begin{array}{l}00000 \\
00000 \\
00000 \\
00000 \\
00000\end{array}$ & 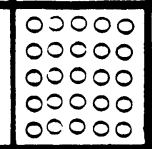 & & 5.3 & & & $\begin{array}{lllll}0 & 0 & 0 & 0 & 0 \\
0 & 0 & 0 & 0 & 0 \\
0 & 0 & 0 & 0 & 0 \\
0 & 0 & 0 & 0 & 0 \\
0 & 0 & 0 & 0 & 0\end{array}$ & \\
\hline
\end{tabular}


Table A-3 1987-Statistics for the two villages under study, based on SCF's Disease Report Forms

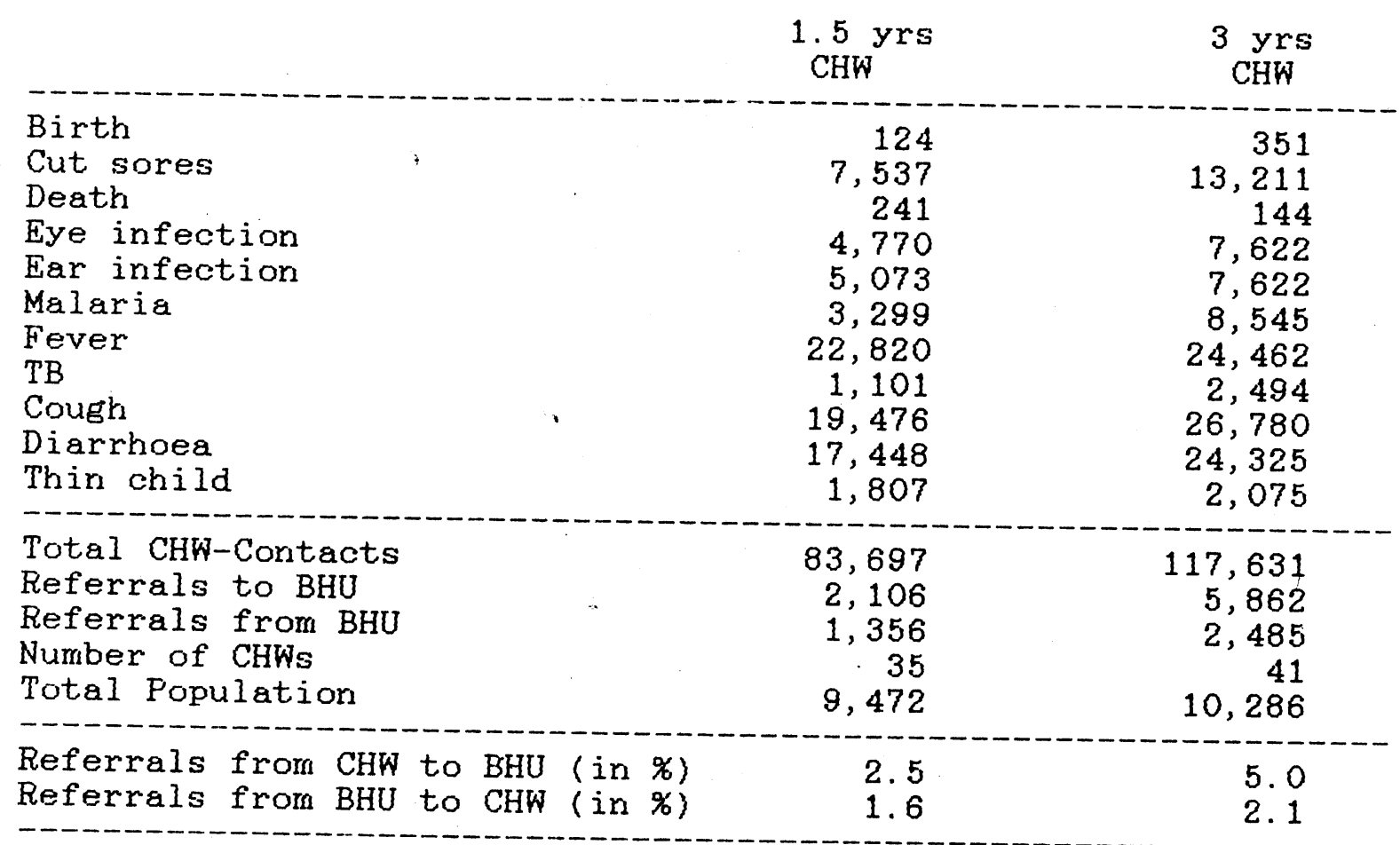

\section{DISEEASEE WISE SPLIT-U모}

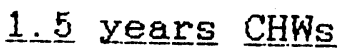

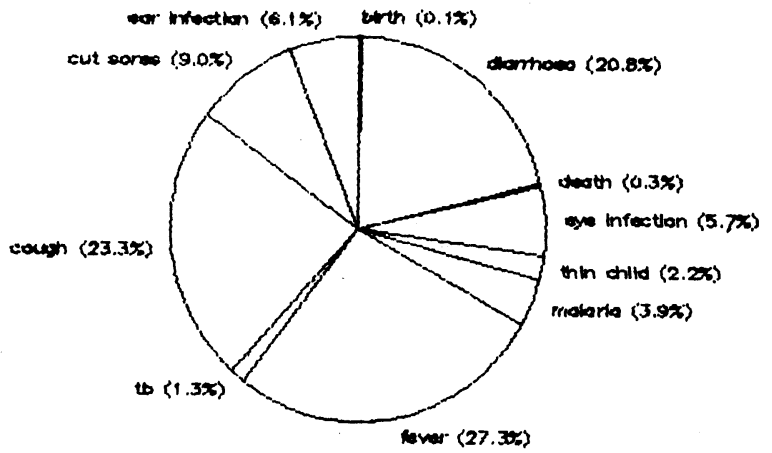

$\underline{3}$ ye $\underline{a} \underline{\underline{S}}$ 대토오

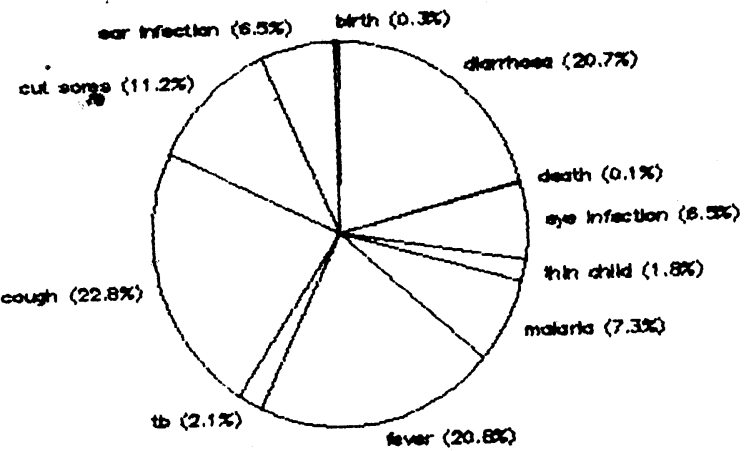


APPENDIX 7

An anthology of remarks about the Community Health Worker proBramme, made by a small number of the respondents at the end of the interview

"If our CHW received drugs on time, so the programme will Ins"allah more improve". (Man, 1.5 years CHW programme)

"We can learn lessons of hygiene". (Woman, 1.5 years CHW programe)

"My opinion regarding to this programme is that the drugs are very less and they should therefore be increased". (Mar,, 1.5 years CHW programme)

"We can get medicines easily". (Woman, 1.5 years CHW programme)

"Some wells of this camp are Katcha, if we are assisted, to make them pakha". (Man, 1.5 years CHW programme)

"We don"t have our own CHW, but the CHS is helping and guiding us. We request you to train a CHW for us". (Man, 1.5 years CHW programme)

"There is less disease." (Woman, 1.5 years CHW programme)

"When the hospital is closed and we need medicines, so we get them from the CHW". (Mar, 1.5 years CHW programme)

"We are saved from trouble going far away". (Man, 1.5 years CHW programme)

"In case of illness, tablets are given in our home, so we do not need to buy them". (Mar, 1.5 years CHW programme)

"It is useful for us, because we can get medicines easily from them. We are not able to go to the bazaar ourselves". (Woman, 3 years. CHW programme)

"They provide us medicines without any payment, and easily available". (Woman, 3 years CHW programme)

"The programe is useful for improving our health". (Woman, 3 years CHW prograrme)

"We don"t have a CHW, but the rest of the camp has. We request" you to train a CHW for our part, so our problems will be solved". (Mar, 3 yearss CHW programre)

"It will be kind of you if our CHWs are supplied more quantity of medicine". (Man, 3 years CHW programe)

"If the CHWs of this programme are paid some, then this programme car go ahead. Other point is, if the streets are improved, so we will get rid of dirt". (Man, 3 years CHW programme) 
"The CHW has never given me any advice, neither medicines and he doesn't serve us". (Man, 3 years CHW programe)

"Diseases have beer decreased due to this programme". (Man, 3 years CHW programe)

"The programme is very good for us. It provides a better. understanding of health". (Woman, 3 years CHW programe)

"It is a very good programme and it has helped us a lot, but the point is that the amount of drugs in this programme is decreasing lay by day. If drugs are supplied more the programme will be better". (Man, 3 years; CHW programme)

"Our medicine problem is somehow solved". (Man, 3 years CHW programme)

"We want much attention to be paid to the programme and better drugs and advice should be given to the CHWs". (Man, 3 years CHW proetramme)

"If the drug supply is increased, so the programme will be more" improved". (Man, 3 years CHW programme)

"If cleaness and sanitation improve in this camp, so the health condition will be better, Ins"allah". (Man, 3 years CHW programme)

"It is useful, they teach us to be clean and they give uss medicines". (Woman, 3 years CHW programme)
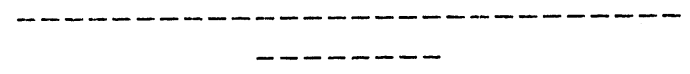
APPENDIX 8

\section{Judgment of the Oral Rehydration Therapy descriptions}

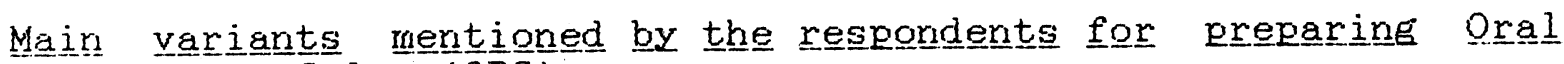

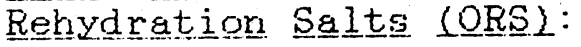

VARIANT I: For preparing one litre of ORS

Mix well in:

Step 1 - a container with one litre (clean/boiled) drinking water

Step 2 - all the powder from one 1-litre ORS package

VARIANT II: For preparing half a litre of ORS

Mix well in:

Step 1 - a container with half a litre (clean/boiled) drinking water

Step 2 - all the powder from one 1/2-1itre ORS package

VARIANT III: For preparing one glass of ORS

Mix well in:

Step 1 - a glass or cup with (clear/boiled) drinking water

Step 2 - 1/4-1/8 the powder from one 1-litre package ORS

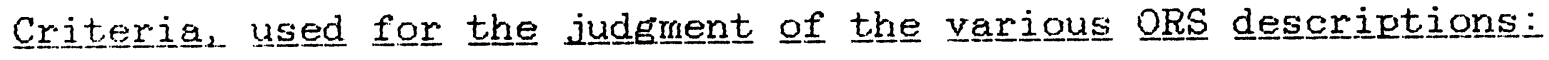

The ORS-method described was considered correct when both steps were mentioned (so including the text between brackets).

The ORS-method described was considered tolerable when both steps were mentioned, without the text between brackets.

The ORS-method described was considered incorrect when one or both of the above mentioned steps were missing or fault.

Brief summary of the method taught to the chHWs for preparing ORS:

1 Take ore packet of . ORS

2 Ore jug

3 Ore glass or teacup

4 Clean Pakha well water or cooled boiled water

5 Should the ORS packet be made in 1 litre or $1 / 2$ litre?

6 Measure one litre of water (People have different sizes of cups and glasses; guidelines are 4 large Elasses or 8 small Elasses or 8 teacups ).

7 Pour the packet of ORS into the water and mix until the ORS is dissolved.

8 Make sure it does not taste ton salty. 
Main variants mentioned by the responondents for preparing SaltSugar Solution (SSS):

VARIANT I: For one litre of SSS

Mix well in:

Step 1 - One litre (clean/boiled) drinking water.

Step 2 - 1 (level) teaspoon of salt

Step $3-8$ (level) teaspoons of sugar

VARIANT II: For one glass of special drink/pinch and scoop method Mix well in:

Step 1 - a glass with (clear/boiled) drinking water

Step 2 - a pinch of salt (two fingers and thumb method), and

Step 3 - a scoop of sugar (in palm of hand)

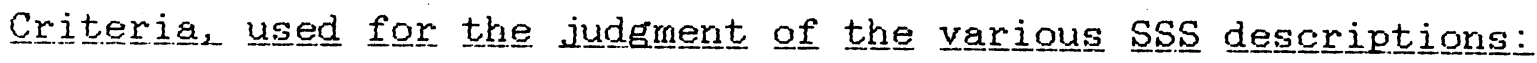

The method described by the respondent wass considered correct when all steps were mentioned, so including the text between brackets.

The method described was considered tolerable when all the three above mentioned steps were named, without the text between brackets.

The method described was considered confused, when only one of the three above mentioned steps was missing or fault.

- The method described was considered incorrect, when two or more of the above mentioned steps were missing or fault.

Brief summary of the method taught to the CHWs for preparing (SSS):

1 Ore jug

2 Ore glass or teacup

3 Sugar ("Gur") and salt

4 Clean Pakha well water or cooled boiled water

5 One teaspoon

6 Measure one litre of water (People have different sizes of cups and glasses; guidelines are 4 large glasses or 8 small gilasses or 8 teacupsi .

7 Pour the water into the jug. With the teaspoon measure:

8 leveled teaspoons of sugar and 1 leveled teaspoon of salt,

8 Mix until all the sugar and salt has dissolved

9 Taste the solution if it is too salty add more water and sugar 


\section{APPENDIX 9}

\section{An anthology of incorrect Salt-Sugar-Solution descriptions}

"Boil 4 teacups clean water, pour 1 teacup of sugar and a pinch of salt with three fingers in it, and then give it little by little to the child". (Man, 3 years programme, taught by cHW)

"Boil six cups of water, then put 4 teaspoons salt ard 5 teaspoons sugar in it, when it is cold give it to the child". (Man, 3 years programme, taught by CHW)

"Boil 8 teacups of water, then let it become cold, put 4 teaspoons salt and 2 teaspoors sugar in it, and give the child little, little". (Man, 3 years programe, taught by BHU-doctor)

"Boil one teapot of water, then put 2 teaspoons of salt and one teaspoon of sugar in it, dissolve it, and give it to the patient". (Man, 3 years programme, taught by CHW)

"Boil one liter of water, then let it become cold, then put 3 teaspoons sugar and ? level teaspoons of salt in it". (Man, 3 years programme, taught by CHW)

"Boil 4 glasses of water, then let it become cold, then put one glass sugar and 3 teaspoons salt in it". (Man, 3 years programme, taught by BHU-doctor)

"Boil 9 teacups water, let it become cold and pour 3 teaspoons salt and 3 teaspoons sugar in it and give it to the patient" (Man, 3 years programme, taught by BHU-doctor)

"Boil 8 teacups of water, then let it become cold, put 2 teaspoons sugar and a half teaspoon salt in it and dissolve it " (Man, 3 years programme, taught by CHW)

"Boil 4 teacups of water, put 8 teaspoons of salt and 1 teaspoon of sugar in it." (Woman, 3 years programme, taught by BHUdoctor)

"Boil 7 teacups of water, put 1 teaspoon of sugar and 2 teaspoons of salt in it". (Woman, 3 years programme, taught by CHW)

"I mix 2 teaspoons of sugar and 2 teaspoons of salt in 4 teacups of boiled water." (Woman, 3 years programme, taught by CHW)

"Boil 8 glasses of water: Then put 250 gram sugar and 125 gram salt and give this to the patient". (Man, 1.5 years programme, taught by CHW)

"One teacup of salt and 1.5 teacups of sugar are put in 7 teacups of water, which is boiled first". (Man, 1.5 years programme, taught by CHW) 
"In one litre of boiled water, I mix 2 teaspoons of sugar and 3 teaspoons of salt". (Woman, 1.5 years programme, taught by CHW)

"Boil 6 teacups of water, mix this with 3 teaspoons of sugar and 2 teaspoons of salt". (Woman, 1.5 years programme, taught by CHW)

"I take one teacup of boiled water, and I mix well in it one teaspoon of salt and 2 teaspoons of sugar". (Woman, 1.5 years programme, taught by her husband)

"I take half a litre boiled water, in this I mix well 2 teaspoons of salt and 3 teaspoons of sugar". (Woman, 1.5 years programme, taught by CHW)

"Boil 4 glasses of water up to $100 \mathrm{C}$, then we put 4 teaspoons salt and 1.5 teaspoons sugar in it, and give it to the patient". (Man, without programme, taught by the radio)

"In a half glass of boiled water 2 teaspoons of salt and 2 teaspoons of sugar have to be mixed". (Man, without programme, taught by a doctor)

"We mix one teaspoon salt and 2 teaspoons of sugar in one cup of boiled water. (Man, without programme, taught by a doctor)

"Boil a glass of water, then put 3 teaspoons sugar and one teaspoon salt in it and give it to the patient". (Man, without programme, taught by a doctor)

"Mix in half a cup of boiled water one teaspoonful of salt and one of sugar". (Woman, without programme, taught by BHU-doctor)

"Boil one teacup of water, put one teaspoon of sugar and 2 teaspoons of salt in it". (Woman, without programme, taught by a relative)

"I Boil 1 litre of water, then I mix a pinch of sugar and a pinch of salt in it". (Woman, without programme, taught by BHU-doctor) 
APPENDIX 10

\section{Mortality rates and possible causes of death}

\section{Mortaiity rates}

A reliable computation of the infant mortality and under-five mortality rates required a bigger sample of children than the one used in this study (see Appendix 1). For most of the evaluation issues a sample of 400 children per village was sufficient. However, the computation of workable confidence limits for the mortality rates were. likely to require a sample of at least 1,500 children per village, which would be rather problematic given the resources available. Furthermore, we believed that the additional costs involved were not justifiable, given the fact that no research in this field known to us has produced sufficient evidence that a primary health care service by itself has affected mortality rates significantly (see e.g. Vaughan, 1984, and Bourne, 1987). The chance that such evidence would be found by this study was therefore considered rather small. Thus, although a sample size of 400 children per village was not optimal to compute exact mortality rates in each village, these rates were still used as indicators of the children"s health status.

Interviews were conducted with all the mothers available in 541 compourds to obtain information about 1282 children less than 5 years of age who lived whole or part of the last year. The age distribution of the 1251 living children in the samples was as follows: In the village without CHW programme 29 per cent of the children were below one year of age and 71 per cent was between 1 and 4 years old. In both villages with CHWs 26 per cent of the children was less than one year of age and 74 per cent one to four years old. Of all 31 children who died in the last year 29 per cent was less than one month old, 58 per cent was at least one month old but below the age of one, 10 per cent was one year old and 3 per cent was three years old.

Table A-4: Mortality rates, by village

\begin{tabular}{|c|c|c|c|}
\hline & $\begin{array}{l}\text { without } \\
\text { CHW }\end{array}$ & $\begin{array}{l}5 \text { yrs } \\
\text { CHW }\end{array}$ & $\begin{array}{l}3 \text { yrs } \\
\text { CHW }\end{array}$ \\
\hline No: of children $<5$ yrs old & 466 & 408 & 408 \\
\hline Alive at the time of interview & 448 & 403 & 400 \\
\hline Died last year & 18 & 5 & 8 \\
\hline No. of live birth in last year & 130 & 104 & 102 \\
\hline Children < 1 yrs., died last year & 15 & 5 & 7 \\
\hline $\begin{array}{c}\text { Infant mortality rate (per 1000) } \\
\text { confidence limits } 95 \% .\end{array}$ & $\begin{array}{r}115 \\
60-170\end{array}$ & $\begin{array}{r}48 \\
7-89\end{array}$ & $\begin{array}{c}69 \\
20-118\end{array}$ \\
\hline $\begin{array}{l}\text { Under-5 mortality rate (per 1000) } \\
\text { confidence limits } 95 \%\end{array}$ & $\begin{array}{r}138 \\
75-201\end{array}$ & $\begin{array}{r}48 \\
7-89\end{array}$ & $\begin{aligned} & 78 \\
& 26-130\end{aligned}$ \\
\hline
\end{tabular}


Table A. 4 presents the data with regard to the resulting infant mortality rates and the under-five mortality rates. These rates are computated as follows (UNICEF, 1987). The infant mortality rate is calculated by dividing the number of children who died in the prior 12 months and who were less than 12 months old at the time of death by the number of live births in the previous 12 months. The under-five mortality rate is calculated by dividing the number of children who died in the previous 12 months and who were under 5 years of age at the time of death by the number of live births in the previous 12 months. Both mortality rates are independent of seasonal variation in occurense of disease and death as they cover all deaths taking place in one whole year.

From table A-4 it appears that in the villages where the CHW programme is running the infant mortality as well as the underfive mortality rates are lower than in the village without CHWs. A possible positive effect of the CHW programe seems to be stronger in the village, where the programme has been operating for a relatively short period than in the other one.

However, these differences are not statistically significant at the 95 per cent probability level, as the confidence limits of the villages overlap. Therefore, we can not speak of a trend, statistically speaking, since there is a considerable chance that the differences are mere coincidences. Consequently, a replication of this survey with the same sample size is likely to lead to another conclusion for the same population.

Still this does not imply that the CHW programme would not have a positive, let alone a negative, impact on mortality rates. It only means that we can not conclude that the mortality rates improve significantly. And even if a survey would show that mortality rates would deteriorate significantly, one could not conclude that the CHW programme would not have a positive effect, since there are many other factors which influence these rates, such as nutrition, income, water supply etc.

\section{Possible causes of death}

To get an indication about the possible cause of death of the children, it was systematically checked whether a child had a history:

- of diarrhoea in the week prior to its death;

- of malaria in two weeks prior to its death;

- of measles in the month prior to its death; and

- of tuberculosis in the year preceding its death.

Especially diarrhoea is considered as one of the main killers of children. Another' common disease among infants, which is more difficult to recognize by mothers, is neonatal tetanus. Even by checking whether the main symptoms of this disease were present before the child's death, it still remains difficult to ascertain a death due to neonatal tetanus. Therefore, no special effort was 
made to gather information about this disease. The diseases possibly contributing to the children's death are presented in
table A-5.

Table A-5: Diseases possibly contributing to the children's death in percentages, by village

\begin{tabular}{lccc} 
& $\begin{array}{c}\text { Without } \\
\text { CHW }\end{array}$ & $\begin{array}{c}1.5 \text { yrs } \\
\text { CHW }\end{array}$ & 3 CHW \\
\hline Diarrhoea & 50 & - & $\bar{y}$ \\
Malaria & 17 & - & - \\
Measles & - & - & - \\
Tuberculosis & 33 & 80 & 87 \\
Other & 100 & 100 & 100 \\
\hline Total no of death & 100 & -
\end{tabular}

It is remarkable that in the village without $\mathrm{CHW}$ programme 50 per cent of the children had a history of diarrhoea. All of these children, except one, were younger than one year. In the two other villages none of the children suffered from diarrhoea.

The mother themselves were asked as well what, they believed, was the cause of their child"s death. Table A-6 shows the answers given to this question. The case of suffocation of a child of three month old was according to the mother due to the fact that she herself rolled over the baby while she was asleep.

Table A-6: Number of children who died, by possible cause of death, according to their mother, by village

$\begin{array}{lccc} & \begin{array}{c}\text { Without } \\ \text { CHW }\end{array} & \begin{array}{c}1.5 \\ \text { CHW }\end{array} & 3 \text { yrs } \\ \text { CHW }\end{array}$




\section{GLOSSARY}

$\begin{array}{ll}\text { BHU } & \text { Basic Health Unit } \\ \text { CAR } & \text { Commissioner for Afghan Refugees } \\ \text { CCAR } & \text { Chief Commissioner for Afghan Refugees } \\ \text { CDC } & \text { Centre for Disease Control (USA) } \\ \text { CHS } & \text { Community Health Supervisor } \\ \text { CHSs } & \text { Commuity Health Supervisors } \\ \text { CHW } & \text { Community Health Worker } \\ \text { CHWs } & \text { Community Health Workers } \\ \text { DACAAR } & \text { Danish Comittee for Aid to Afghan Refugees } \\ \text { DPD (PHC) } & \text { Deputy Project Director (Primary Health Care) } \\ \text { EPI } & \text { Expanded Programme for Immunizations } \\ \text { GOP } & \text { Government of Pakistan } \\ \text { ICD } & \text { Italian Corporation for Development } \\ \text { IRC } & \text { International Rescue Committtee } \\ \text { NWFP } & \text { North West Frontier Province } \\ \text { ORS } & \text { Oral-Rekydration-Salts } \\ \text { ORT } & \text { Oral-Rehydration-Therapy } \\ \text { PHC } & \text { Primary Health Care } \\ \text { PDH } & \text { Project Director of Health for Afghan Refugees } \\ \text { PRCS } & \text { Pakistan Red Crescent Society } \\ \text { SCF } & \text { Save the Children Fund (U.K.) } \\ \text { SSS } & \text { Salt-Sugar-Solution } \\ \text { TB } & \text { Tuberculosis } \\ \text { UNHCR } & \text { United Nations High Commisioner for Refugees } \\ \text { UNICEF } & \text { United Nations Children's Fund } \\ \text { WHO } & \text { World Health Organization }\end{array}$




\section{REFERENCES}

Ajzen I., M. Fishbein, Understanding attitudes and predictiing social behavior, Prentice-Hall, New Yersey, 1980

Bourne, F.G., Beyond the barefoot doctor, the unfillied promise of primary health care, Developrent International, pp. 3235, May/Jure 1987

CCAR/UNHCR, Annual Report 1986 - Afghan Refugee Health Programme Pakistan, 1987

CDC/UNHCR, Evaluation of infant mortality and childhood nutritional status among Afghan Refugees in Pakistan, 1986, by L.P. Boss and J. Lewis

Feachem, R.G., Preventing Diarrhoea: what are the policy op.tions?, Health Policy and Planning, Vol 2, p. 109-117, 1986

IRC, Health Status of Afghan women and children: an assessment of trends in 10 refugee camps between Hangu and Thal, NWFP, Pakistan, 1987, by E. Krijgh

Mendenhal1 W., L. Ott, and R.F. Larson, Statistics: a tool for the social sciences, Duxbury Press, Massachusetts, 1974

Mushtaque A., R. Chowdhury, Evaluating community ORT programmes: indicators for use and safety, Health Policy and Planning, Vol 3. pp. 214-221, 1986

Nosseir N.K., J.Mccarthy, et al, Using mini-surveys to evaluate community health programmes, Health Policy and Planning, Vol.1, pp. $67-74,1986$

Rifkin S.B., Lessons from community participation in health programmes, Health Polioy and Planning, Vol. 3, pp. 240-249, 1986

SCF (U.K.), Afghan refugees projects -- 1987 Annual Report, Peshawar, 1988

SCF (U.K.), Results of a health belief survey (unpublished)

Simmonds, S., P. Vaughan and S.W. Gunn, Refugee Community Health Care, Oxford University Press, New York, 1986

Swanborn, P.G., Methoden van sociaal-wetenschappelijk onderzoek, (Research methods for the social sciences) Boom, Meppel, The Netherlands, 1987

UNHCR/CCAR, Operation Manual for Afghan refugee health programme in Pakistan, Islamabad, 1986

UNICEF, The state of the world"s children, Oxford University Press, New York, 1987, by J.F. Grant

UNICEF/SCF(U.K.), Report of the conference: Primary health care for NWFP, lessons from the Afghan refugees, Peshawar, Pakistan 7 th and 8 th January, 1987

Vaughan, J.F., G. Walt and D. Ross, Evaluation of primary health care: approaches, comments and criticisms, Tropical Doctor, Vol. 14, pp. 56-60, 1984

WHO, Treatment and prevention of acute diarrhoea; guidelines for the trainers of health workers, Geneva, 1985 